$$
\begin{gathered}
\text { UNIVERSIDADE DE BRASÍLIA } \\
\text { FACULDADE DE TECNOLOGIA } \\
\text { DEPARTAMENTO DE ENGENHARIA ELÉTRICA }
\end{gathered}
$$

\title{
ANÁLISE DOS ENSAIOS DE COMISSIONAMENTO DE UM GERADOR SÍNCRONO
}

VITOR SILVA MACHADO

Brasília - DF 


\title{
VITOR SILVA MACHADO
}

\section{ANÁLISE DOS ENSAIOS DE COMISSIONAMENTO DE UM GERADOR SÍNCRONO}

\begin{abstract}
Projeto de Conclusão de Curso submetido à Universidade de Brasília, como requisito parcial para obtenção do título de Engenheiro Eletricista.
\end{abstract}

Orientador: Professor Ivan Marques de Toledo Camargo 


\section{VITOR SILVA MACHADO}

\section{ANÁLISE DOS ENSAIOS DE COMISSIONAMENTO DE UM GERADOR SÍNCRONO}

Projeto de Conclusão de Curso submetido à Universidade de Brasília, como requisito parcial para obtenção do título de Engenheiro Eletricista.

\section{Banca Examinadora}

Prof. Ivan Marques de Toledo Camargo - Orientador

Prof. Anésio de Leles Ferreira Filho

Prof. Rafael Amaral Shayani

Brasília - DF

2008 


\section{DEDICATÓRIA}

Dedico esse trabalho ao meu amigo/irmão Philippe (in memorian), por me fazer acreditar que o sentido da vida está além de uma simples conquista, concretiza-se na busca da sua felicidade, dos seus sonhos e de suas realizações. 


\section{AGRADECIMENTOS}

Primeiramente eu gostaria de agradecer à minha família; ao meu pai Túlio, que antes de tudo me inspirou a fazer este projeto e me deu força, apoio e incentivo sempre; à minha mãe Lize, pelos ensinamentos e por sempre dizer que a minha maior herança é o estudo, me incentivando para tal; aos meus irmãos Anna e Túlio pela compreensão e apoio nas horas que eu mais precisei.

Agradeço também à galera da Babilônia, pela prestatividade e força em todos os momentos, além de sempre terem me ajudado, me motivando e me apoiando na elaboração deste projeto.

Ao meu orientador Ivan, pelo incentivo, confiança e auxílio.

A todos aqueles que direta ou indiretamente contribuíram pra este projeto, principalmente a Deus que me capacitou para vencer todos os obstáculos encontrados no decorrer desta etapa, permitindo a concretização dos meus objetivos. 


\section{RESUMO}

O presente trabalho tem por objetivo a descrição e análise dos principais ensaios realizados em um gerador síncrono durante a fase de comissionamento.

Este é um projeto de caráter exploratório, com a finalidade de analisar e identificar os principais testes realizados em um gerador síncrono antes de sua operação comercial, através de visita ao local de comissionamento, para acompanhamento e coleta dos resultados obtidos em campo.

Apresentam-se inicialmente, a título de fundamentação, referências que contextualizam conceitos dos principais parâmetros que descrevem o modelo do circuito equivalente de uma máquina síncrona operando em regime permanente e transitório, dando embasamento para a análise dos resultados obtidos. $\mathrm{Na}$ seqüência, são abordados os procedimentos metodológicos, por meio de definições, descrições e esquemáticos, a apresentação e justificativa dos principais critérios de avaliação descritos em norma e o procedimento adotado em um conceituado livro de máquinas elétricas para a determinação das características da máquina em estudo para uma situação real de carga.

Por fim é apresentada a conclusão do projeto, expondo as principais idéias levantadas sobre a obtenção dos dados coletados em campo durante a fase de comissionamento, por parte da equipe responsável pelo fornecimento da unidade geradora.

Palavras-chave: Gerador síncrono. Ensaios de comissionamento. Determinação de características e parâmetros. 


\begin{abstract}
The aim of this paper is the description and analysis of the recommended site tests and the special performance tests of a synchronous generator during the commissioning phase.
\end{abstract}

This is an exploratory project, aimed to analyze and identify the main tests conducted in a synchronous generator before its commercial operation, through visits to the place of commissioning, to follow up and collect the results obtained in the field.

Initially, references will be presented for the concepts of the main parameters that describe the model of the equivalent circuit of a synchronous machine operating in steady and transitory state, giving basis for the analysis of the obtained results. In the sequence, the methodological procedures are approached, through definitions, descriptions and schematic. A presentation and justification of the principles described in the standards will be made. It will also be made a description of the procedure adopted in a considered book of electric machines for the determination of the characteristics of the machine in study for a real situation of load.

Finally the conclusion of the project is presented, exposing the ideas about the obtaining of the data collected in field during the commissioning, on the part of the responsible team for the supplied generating unit.

Keywords: acceptance and performance testing, parameter determination, synchronous generator. 


\section{LISTA DE FIGURAS}

Figura 2.1: Modelo do Circuito Equivalente

Figura 3.1: Esquema de ligação para medição da resistência de isolamento e índice de polarização do estator. 25

Figura 3.2: Medições da resistência de isolamento no enrolamento do estator para $27^{\circ} \mathrm{C}$. 29

Figura 3.3: Medições da resistência de isolamento no enrolamento do estator convertido para $40^{\circ} \mathrm{C}$

Figura 3.4: Esquema de ligação para ensaio com tensão alternada no enrolamento estatórico.

Figura 3.5: Esquema de ligação do ensaio com tensão contínua no enrolamento estatórico. 35

Figura 3.6: Esquemático do método voltímetro-amperímetro. 38

Figura 3.7: Esquemático para o método da Ponte. 40

Figura 3.8: Esquema de ligação para medição da resistência de isolamento do rotor.

Figura 3.9: Esquema de ligação para ensaio com tensão alternada no enrolamento de campo. 49

Figura 3.10: Esquema de ligação do ensaio com tensão contínua no enrolamento de campo.

Figura 3.11: Esquemático do método corrente e tensão para o enrolamento de campo.

Figura 3.12: Esquemático do método da ponte de Thomson para o enrolamento de campo.

Figura 3.13: Característica teórica do Gerador Síncrono W42 …..........................57

Figura 3.14: Esquemático para o levantamento da característica à vazio. ...............59

Figura 3.15: Característica de saturação a vazio. ................................................61

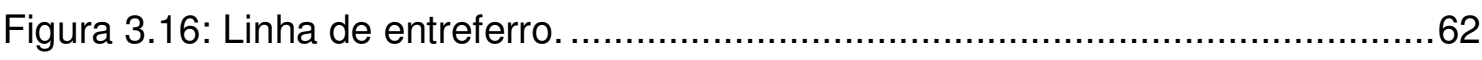

Figura 3.17: Esquemático para o levantamento da característica em curto-circuito. 64

Figura 3.18: Curva característica de curto-circuito. ................................................6

Figura 3.19: Caracterização do gerador W42

Figura 3.20: Esquemático para verificação da seqüência de fase. .............................71 
Figura 3.21: Esquemático de ligação do ensaio de rejeição de carga. ……..............74

Figura 3.22: Determinação do Triângulo de Potier................................................78

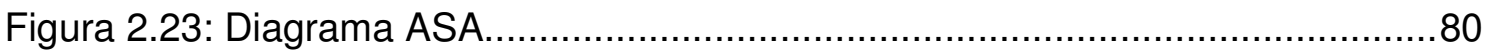

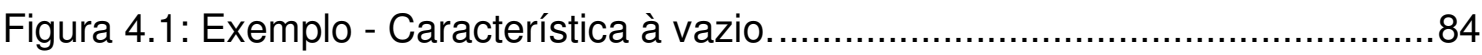

Figura A1: Vista do Vertedouro e da Casa de Força da UHE Capim Branco II, durante a fase de comissionamento da Unidade Geradora 1.................................92

Figura A2: Estrutura do núcleo magnético do estator. ..........................................93

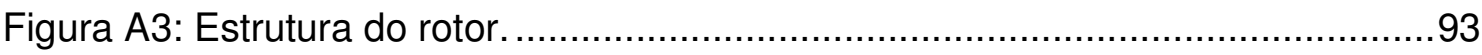

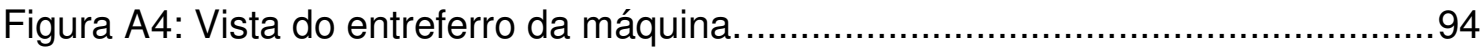

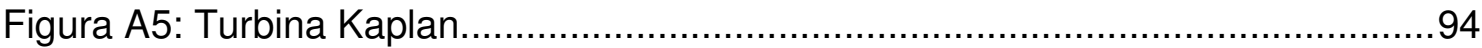

Figura A6: Vista panorâmica da máquina em fase final de comissionamento. ..........95 


\section{LISTA DE TABELAS}

Tabela 2.1: Temperatura de referência no cálculo das perdas. ..............................12

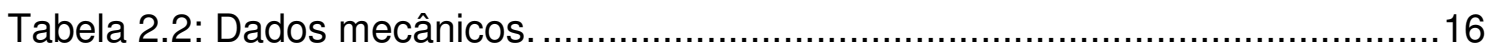

Tabela 3.1: Ajuste da tensão no aparelho de medição. ....................................24

Tabela 3.2: Valores mínimos recomendados para IP......................................27

Tabela 3.3: Valores da resistência de isolamento e IP do estator em $27^{\circ} \mathrm{C} \ldots \ldots \ldots \ldots . . .28$

Tabela 3.4: Valores da resistência de isolamento e I.P. do estator corrigidos para

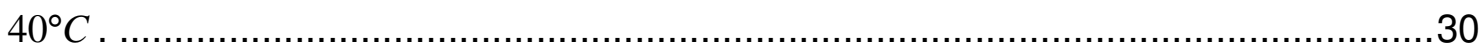

Tabela 3.5: Valores medidos da resistência ôhmica do enrolamento estatórico para cada fase.

Tabela 3.6: Resultado do ensaio da resistência de isolamento do rotor, para $27^{\circ} \mathrm{C} .46$

Tabela 3.7: Resultado do ensaio da resistência de isolamento do rotor, para $40^{\circ} \mathrm{C} .46$

Tabela 3.8: Valores medidos da resistência ôhmica do enrolamento de campo.......55

Tabela 3.9: Dados do ensaio à vazio coletados em campo. .................................60

Tabela 3.10: Dados do ensaio em curto-circuito coletados em campo. ...................65

Tabela 3.11: Dados do ensaio de rejeição de carga. ..........................................75

Tabela 3.12: Dados do ensaio de Fator de Potência Zero ......................................81 


\section{LISTA DE SÍMBOLOS E ABREVIATURAS}

CA: Corrente Alternada.

CC: Corrente Contínua.

IEC: International Electrotechnical Commission.

IEEE: Institute of Electrical and Electronics Engineers.

ITC: Instrução de Teste de Campo.

kV: Quilovolt.

kVA: Quilovolt-ampère.

kvar: Potência Reativa.

kW: Potência Ativa.

RT: Regulador de Tensão.

RV: Regulador de Velocidade.

TC: Transformador de Corrente.

TP: Transformador de Potêncial.

UHE: Usina Hidrelétrica. 


\section{SUMÁRIO}

1 INTRODUÇÃO

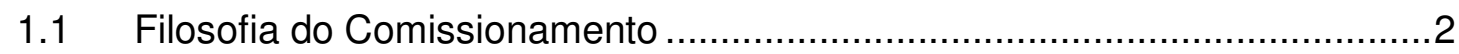

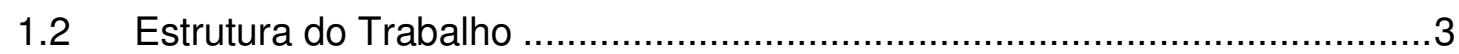

2 CARACTERÍSTICAS E ASPECTOS CONSTRUTIVOS …..................................

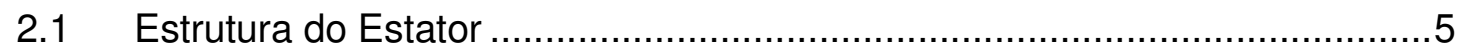

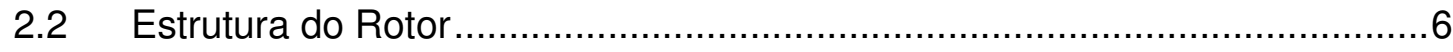

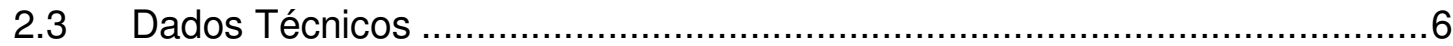

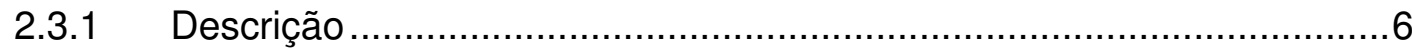

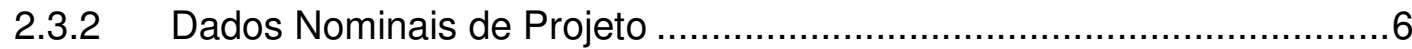

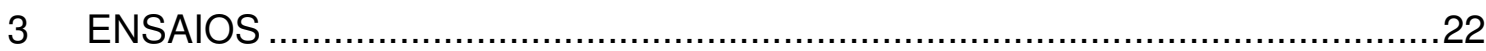

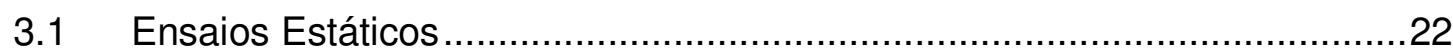

3.1.1 Ensaio de medição da resistência de isolamento e verificação do Índice

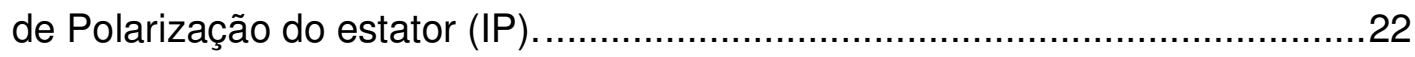

3.1.2 Ensaio de tensão aplicada no enrolamento do Estator........................32

3.1.3 Medição da resistência ôhmica do enrolamento do Estator...................37

3.1.4 Medição da resistência de isolamento do Rotor. .................................43

3.1.5 Ensaio de tensão aplicada no enrolamento do Rotor. ..........................47

3.1.6 Medição da resistência ôhmica do enrolamento de campo. .................51

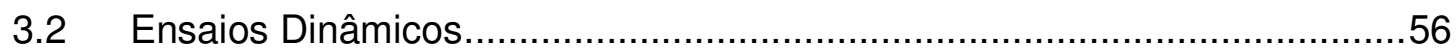

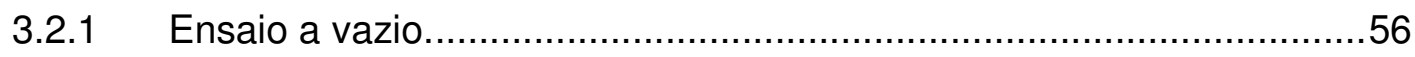

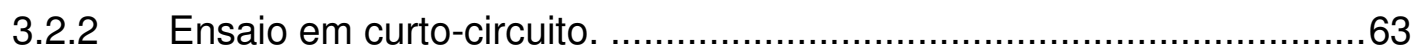

3.2.3 Verificação da seqüência de fase. ................................................

3.2.4 Ensaio de rejeição de carga ativa..................................................

3.2.5 Curva de Fator de Potência Zero e determinação da corrente de

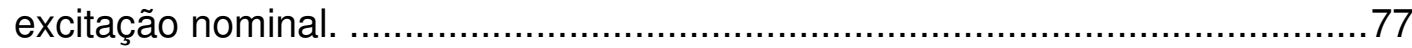

4 EXEMPLO DE CÁLCULO DAS CARACTERÍSTICAS DO GERADOR ...............83

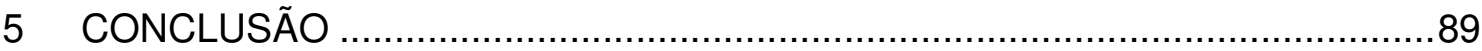

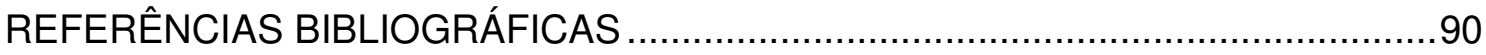

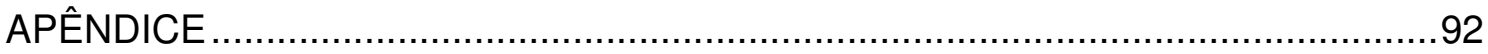




\section{INTRODUÇÃO}

As máquinas síncronas estão entre os três tipos mais comuns de máquinas elétricas. Além da síncrona existem as máquinas de indução e as máquinas de corrente contínua. Denominam-se síncronas pois operam à velocidade e freqüência constante em regime permanente. A sua operação pode ser como um motor ou como um gerador. Devido às razões construtivas e ao seu custo maior em relação às outras máquinas elétricas, como as máquinas de indução, elas são, entretanto mais utilizadas como geradores.

Uma utilização típica da máquina síncrona funcionando como gerador é em centrais elétricas independente do seu tipo (hídrica, a carvão, a diesel, etc.). No Brasil praticamente toda energia elétrica disponível é produzida por geradores síncronos operando em Hidroelétricas; eles convertem energia mecânica em energia elétrica a partir da movimentação de turbinas pela força da água.

Para um gerador síncrono entrar em operação comercial, é necessário a realização de testes que comprovam a sua integridade quanto ao desenvolvimento e montagem dos principais componentes que formam a estrutura da máquina. Estes testes são chamados de Ensaios de Comissionamento e são realizados seguindo normas e diretrizes específicas.

Neste trabalho, são abordados os principais ensaios realizados em um gerador síncrono específico, quanto aos seus conceitos, objetivos e metodologia. Uma análise qualitativa é feita a partir dos resultados coletados em campo.

O gerador síncrono em estudo é uma máquina produzida e montada pela VA TECH HYDRO do Grupo ANDRITZ. Os resultados dos ensaios foram coletados durante a fase de comissionamento realizada na Usina de Capim Branco II, localizada no rio Araguari entre os municípios de Uberlândia e Araguari, no período de Janeiro à Março do ano de 2007. 


\subsection{Filosofia do Comissionamento}

A fase de comissionamento de um gerador síncrono é realizada após a conclusão da montagem das estruturas do gerador pela empresa responsável, que deverá fornecer o Certificado de Conclusão de Montagem (CCM), contendo, além do visto do responsável técnico, as eventuais pendências de montagem e ou fornecimento. De posse deste certificado o supervisor de comissionamento deverá avaliar as reais condições para o início dos ensaios, caso o mesmo considere que o equipamento não esteja em condição de operação, o documento deverá ser devolvido à equipe de montagem para as devidas correções.

O comissionamento do gerador síncrono é dividido em duas fases. Primeiramente, tem-se a fase de pré-comissionamento que consiste na realização da calibração e verificação do correto funcionamento de todos os equipamentos e instrumentos utilizados para medição e monitoramento dos principais parâmetros da unidade geradora. Os sensores de temperatura, responsáveis pelo monitoramento da temperatura das estruturas que compõem o conjunto gerador-turbina, são verificados e calibrados para garantir uma leitura adequada das temperaturas durante os ensaios. Os sensores de vibração, responsáveis por monitorar o equilíbrio e a correta montagem das estruturas da máquina, são verificados e calibrados para assegurar que nenhum dano ocorra nos elementos que compõem a estrutura da máquina durante os ensaios que requerem o giro mecânico da unidade.

Concluída a fase de pré-comissionamento, o Supervisor, em conjunto com os demais componentes do grupo de comissionamento, deverão efetuar uma reunião para definir a seqüência da segunda fase de testes no gerador.

A segunda fase do comissionamento consiste na realização dos testes responsáveis pela determinação das principais características de uma máquina síncrona. São divididos em ensaios estáticos e ensaios dinâmicos.

Compreendem-se por ensaios estáticos todos aqueles os testes que não implicam na rotação da unidade geradora, ou seja, preparatório para o giro mecânico. Alguns ensaios estáticos não possuem interfaces com os demais 
equipamentos da central geradora, como turbina, mancais e eixos, e poderão ocorrer, se devidamente acordado com a montadora, em paralelo com as atividades de montagem.

Entende-se por ensaios dinâmicos todos os testes realizados quando a máquina se encontra em movimento, giro mecânico. No momento da sua realização, recomenda-se que seja efetuada a distribuição de pessoas por toda a unidade, para observação de eventuais anomalias e/ou ruídos estranhos, bem como definição da ordem de contato com o gerente líder do grupo de comissionamento para, caso houver necessidade, abortar o ensaio em curso.

Todos os ensaios executados devem ser registrados nas respectivas planilhas de resultados, para obtenção de parâmetros de comparação com o projeto e análise dos dados operacionais iniciais dos equipamentos e sistemas auxiliares que servirão como valores de referência para composição do histórico e utilização na futura operação e manutenção do equipamento.

\subsection{Estrutura do Trabalho}

Este trabalho apresenta-se desenvolvido da seguinte forma:

O Capítulo 2 destina-se à conceituação dos principais parâmetros de uma máquina síncrona operando como um gerador. São definidas as características e os dados nominais de projeto, tanto de estado permanente quanto de estado transitório da máquina em estudo.

No Capítulo 3 são apresentados os principais ensaios realizados na fase de comissionamento. São definidos os conceitos, os objetivos e a metodologia de cada ensaio. Os resultados obtidos para a máquina em estudo são descritos, e uma análise, quanto ao critério de avaliação, é feita comparando-se com os valores nominais de projeto definidos no capítulo 2 .

Um exemplo de cálculo das principais características da máquina é realizado 
no capítulo 4, mostrando os conceitos e metodologia desenvolvidos em um conceituado livro de máquinas elétricas. No final, é feita uma análise dos valores obtidos para uma situação real de carga.

As conclusões finais alcançadas com este trabalho são abordadas no Capítulo 5. 


\section{CARACTERÍSTICAS E ASPECTOS CONSTRUTIVOS}

O princípio de funcionamento de um gerador síncrono é baseado na lei da indução eletromagnética de Faraday. A geração da força eletromotriz (fem) é devido ao movimento relativo entre os condutores e o fluxo magnético gerado pela circulação das correntes nas duas principais partes elétricas da máquina, o estator e o rotor.

No rotor, a circulação de corrente é devido ao sistema de excitação, pela aplicação de uma fonte de corrente contínua. E a circulação de corrente no estator é devido à ligação do mesmo a uma carga.

As características do estator e do rotor serão descritas a seguir, juntamente com seus aspectos construtivos que melhor representam o modelo físico adotado para descrever seu desempenho e funcionalidade. Essas características são baseadas nos valores nominais de projeto.

\subsection{Estrutura do Estator}

A estrutura do estator de uma máquina síncrona é cilíndrica e é composta de um material ferromagnético laminado posicionado de forma a deixar espaços iguais entre as laminações subseqüentes. Preenchendo esses espaços, são colocadas estruturas feitas de material isolante, as bobinas. Essas bobinas são interconectadas formando o enrolamento do estator também denominado armadura. (vide figura A2 em anexo).

O seu sistema de isolamento é definido como Vacuband, constituído por mica, com uma camada de fibra de vidro, impregnado com uma resina especial (epoxy). 


\subsection{Estrutura do Rotor}

A estrutura do rotor de uma máquina síncrona é de formato cilíndrico constituído por material ferromagnético laminado com propriedades semelhantes ao material do estator. O rotor pode ser de dois tipos, rotor de pólos lisos e de pólos salientes. Como o gerador em estudo, a maioria dos geradores hidráulicos possuem pólos salientes. O termo saliente pode significar projetado; os pólos são projetados para fora da estrutura do rotor caracterizando um entreferro não uniforme. Para uma melhor visualização vide figura A3 em anexo.

\subsection{Dados Técnicos}

\subsubsection{Descrição}

A máquina em estudo é um Gerador Síncrono Trifásico de eixo vertical, com dimensões 6,80 metros de altura e 1,42 metros de largura, acoplado rígido a uma turbina tipo Kaplan. (vide figura A5 em anexo).

As principais partes do gerador são: o enrolamento e o núcleo do estator, o enrolamento do rotor, o corpo dos pólos e o isolamento dos pólos.

O rotor possui 44 pólos simétricos, sendo montados de forma a obter uma alternância na polaridade dos pólos consecutivos.

A alimentação da máquina é feita através de anéis e escovas, conectados ao enrolamento do rotor. O seu sistema de isolamento pertence a classe térmica $F$ definida de acordo com [1]. O sistema de resfriamento é formado por duas vias, ar/água, sendo que a temperatura projetada para este sistema é de $30^{\circ} \mathrm{C}$.

\subsubsection{Dados Nominais de Projeto}


Os principais valores nominais da máquina em estudo são descritos a seguir. Sabendo que a máquina é um gerador síncrono de pólos salientes conforme descrito anteriormente, temos:

\section{- Tensão Nominal}

Tensão nominal é definida como sendo a tensão de trabalho do enrolamento do estator. Para o gerador em estudo tem-se:

$$
V_{\text {nomi nal }}=13,8 \mathrm{kV}
$$

Para manter a tensão nominal em uma margem próxima ao valor de projeto, a máquina deve ser conectada um regulador de tensão (RT), o qual atua em paralelo com o sistema de excitação.

\section{- Freqüência}

Em uma máquina síncrona o processo de conversão de energia ocorre quando o campo do estator e do rotor estão sincronizados, isto é, eles rodam na mesma velocidade. Essa velocidade de operação é denominada velocidade síncrona, e pode ser obtida da seguinte forma:

$$
\omega_{s}=\frac{120 f}{N_{p}}
$$

Sabendo que $f=60 \mathrm{~Hz}$ (freqüência de operação) e que a máquina possui 44 pólos no seu enrolamento de campo, tem-se:

$$
\omega_{s}=\frac{(120)(60)}{44}=163,64 \mathrm{rpm}
$$

- Potência Nominal 
Um dos principais dados de projeto de uma máquina síncrona é a sua potência instalada, ou seja, a sua potência aparente. O seu valor pode ser calculado como:

$$
\bar{S}_{3 \phi}=\sqrt{3} \bar{V}_{\text {nominal }} \bar{I}_{a} *
$$

Na forma retangular, tem-se:

$$
\bar{S}_{3 \phi}=\sqrt{3} V_{\text {nominal }} I_{a} \cos \phi+\sqrt{3} V_{\text {nominal }} I_{a} \operatorname{sen} \phi
$$

onde:

$$
P=\sqrt{3} V_{\text {nominal }} I_{a} \cos \phi \quad Q=\sqrt{3} V_{\text {nominal }} I_{a} \operatorname{sen} \phi
$$

As expressões acima descritas referem-se às potências ativa e reativa, respectivamente. A potência ativa $(P)$ representa a taxa de variação média de energia que flui da máquina para a rede em que ela se encontra conectada. Já a potência reativa $(Q)$ está relacionada ao armazenamento de energia por parte dos elementos reativos do sistema da máquina e não contribui para o trabalho efetivamente realizado.

Sendo o valor nominal de projeto da potência aparente do gerador síncrono em estudo $S_{3 \phi}=74200 \mathrm{kVA}$ e sabendo que a máquina opera com tensão nominal igual a $V_{\text {nominal }}=13800 \mathrm{~V}$ na freqüência $60 \mathrm{~Hz}$, encontra-se a corrente nominal de armadura da seguinte forma:

$$
I_{a}=\frac{S_{3 \phi}}{V_{\text {nominal }} \sqrt{3}}=\frac{74200}{13,8 \sqrt{3}} \Rightarrow I_{a}=3104,3 \mathrm{~A}
$$

Sabendo que em condições nominais de operação o fator de potência $(f p)$ é de 0,95 e que a corrente está atrasada em relação a tensão, pode-se escrever os 
fasores da tensão e corrente nominal da seguinte forma (tomando como referência a tensão):

$$
\bar{V}_{\text {nominal }}=13800 \angle 0^{\circ} \mathrm{V} \text { e } \quad \bar{I}_{a}=3104,3 \angle-18,2^{\circ} \mathrm{A}
$$

Logo,

$$
\begin{gathered}
\bar{S}_{3 \phi}=\sqrt{3} \bar{V}_{\text {nominal }} \bar{I}_{a}^{*}=74200 \angle 18,2^{\circ}=70487,92+j 23175,25 \\
P_{\text {out }}=70487,92 \mathrm{~kW} \quad Q_{\text {out }}=23175,25 \mathrm{kvar}
\end{gathered}
$$

\section{- Circuito equivalente em regime permanente}

Para uma melhor compreensão a respeito do comportamento dos principais parâmetros de uma máquina síncrona de pólos salientes, desenvolveu-se um modelo de seu circuito equivalente. A figura 2.1 descreve esse modelo.

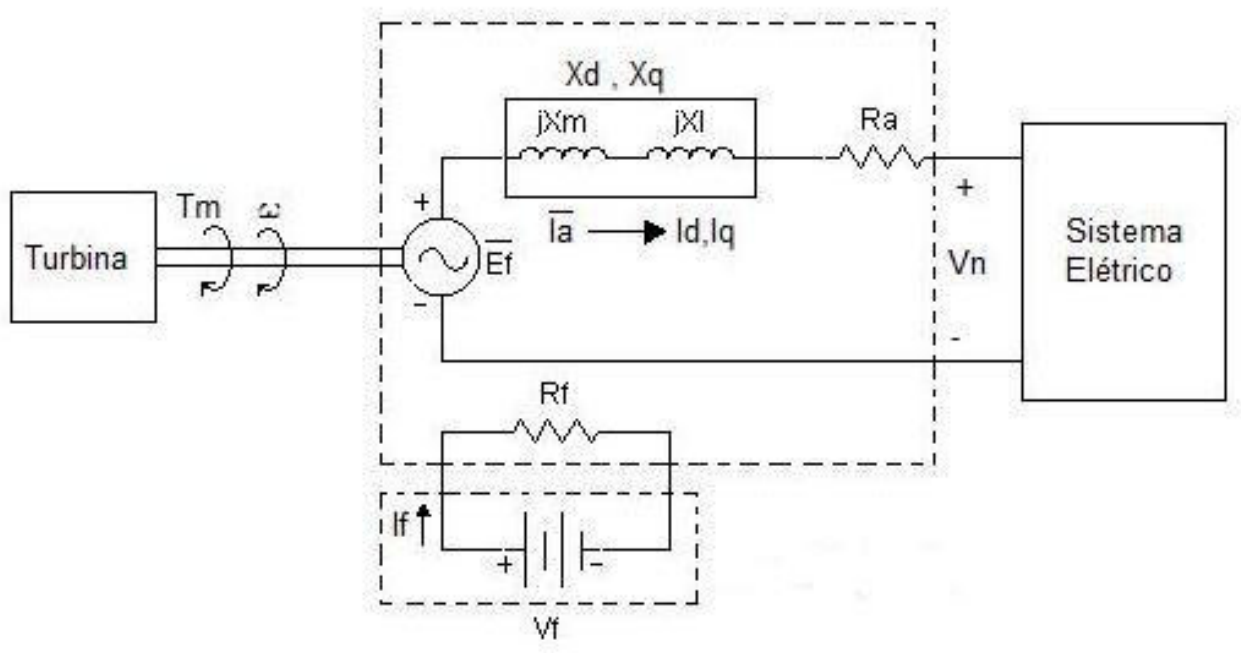

Figura 2.1: Modelo do Circuito Equivalente. 
Neste modelo, são consideradas somente as características do estado permanente e a descrição é feita para cada fase do enrolamento de armadura.

A tensão $E_{f}$ é definida como sendo a tensão induzida no enrolamento de armadura. Do circuito tem-se:

$$
\overline{E_{f}}=R_{a} \overline{I_{a}}+j X_{d} \overline{I_{d}}+j X_{q} \overline{I_{q}}+\overline{V_{n}}
$$

Sendo $I_{a}$ a corrente que circula no enrolamento de armadura e pode ser dividida em duas componentes - uma atuando no eixo d (direto) e a outra no eixo $q$ (quadratura). Logo,

$$
\overline{I_{a}}=\overline{I_{d}}+\overline{I_{q}}
$$

As componentes $I_{d}$ e $I_{q}$ produzem quedas de tensão caracterizadas pela presença das reatâncias $X_{d}$ e $X_{q}$.

Para melhor elucidar o modelo do circuito equivalente do gerador síncrono em estudo, serão dados as definições e os valores nominais de projeto de cada parâmetro baseados em [2] e [3].

$\rightarrow$ Reatância síncrona de eixo direto $X_{d}$.

Define-se como sendo a razão entre a componente $A C$ da tensão de armadura $\left(E_{f}\right)$ que é produzida pelo fluxo total no eixo direto gerado pela componente $I_{d}$ da corrente de armadura, pela componente AC dessa corrente, considerando que a máquina opera na velocidade nominal. Existem dois diferentes valores para este parâmetro, a componente saturada $\left(X_{d s}\right)$ e não-saturada $\left(X_{d n}\right)$.

A reatância síncrona de eixo direto não-saturada $X_{d n}$ pode ser determinada pela relação entre a tensão nominal e a corrente de armadura obtida com a mesma corrente de campo no ensaio de curto-circuito. O valor de projeto é dado por:

$$
X_{d n}=0,947 p u
$$


A reatância síncrona de eixo direto saturada $X_{d s}$ depende das condições de operação da máquina e está relacionada à saturação do circuito magnético. $O$ valor nominal de projeto é dado por:

$$
X_{d s}=0,757 p u
$$

$\rightarrow$ Reatância síncrona de eixo em quadratura $X_{q}$.

Define-se como sendo a razão entre a componente $A C$ da tensão de armadura que é produzida pelo fluxo de armadura total no eixo em quadratura gerado pela componente $I_{q}$ da corrente de armadura, pela componente fundamental dessa corrente no estado permanente e em condições nominais de freqüência. $O$ valor nominal de projeto é dado por:

$$
X_{q}=0,60 p u
$$

$\rightarrow$ Reatância de dispersão $X_{l}$

A reatância de dispersão do enrolamento está ligada ao fluxo de dispersão gerado pela reação de armadura no circuito magnético do enrolamento de armadura. Seu valor pode ser encontrado a partir da Curva de Fator de Potência Zero e a construção do Triângulo de Potier. Para a máquina em estudo tem-se:

$$
X_{l}=0,104 p u
$$

$\rightarrow$ Resistência de campo $R_{f}$.

A resistência ôhmica de campo define-se como sendo a relação entre a tensão nominal e a corrente nominal do enrolamento do rotor, e é responsável pela queda de tensão interna em carga. $O$ valor desse parâmetro depende diretamente da temperatura em que se encontra a estrutura.

Sabendo que os valores nominais de projeto da tensão e corrente de excitação para uma temperatura de $115^{\circ} \mathrm{C}$ são $V_{C C}=173 \mathrm{~V}$ e $I_{f}=1140 \mathrm{~A}$, respectivamente tem-se: 


$$
R_{f}=\frac{V_{C C}}{I_{f}}=\frac{173}{1140}=151 \mathrm{~m} \Omega
$$

$\rightarrow$ Resistência de armadura $R_{a}$.

A resistência ôhmica de armadura é definida com os mesmos critérios da resistência do enrolamento de campo. Na maioria dos modelos de circuito equivalente para máquinas de grande porte, a resistência $R_{a}$ possui um valor muito pequeno e quase sempre é desconsiderada para facilitar os cálculos.

Para a máquina em estudo o valor nominal de projeto da resistência ôhmica do enrolamento do estator para cada fase na temperatura de $25^{\circ} \mathrm{C}$ é dado por:

$$
R_{a}=7,31 \mathrm{~m} \Omega
$$

Concluída a descrição dos valores nominais dos principais parâmetros do modelo de circuito equivalente para a máquina operando em estado permanente, a próxima etapa é encontrar as perdas relacionadas às diferentes estruturas.

\section{- Perdas - condições nominais}

De acordo com a norma [4], para o cálculo das perdas nos enrolamentos estatórico e rotórico, a resistência do enrolamento deve ser corrigida para a temperatura de referência para cada tipo de classe de isolamento. A tabela 2.1 mostra essa temperatura para as duas principais classes de isolamento para uma máquina síncrona de pólos salientes.

Tabela 2.1: Temperatura de referência no cálculo das perdas.

\begin{tabular}{|c|c|}
\hline $\begin{array}{l}\text { Classe do sistema } \\
\text { de Isolamento }\end{array}$ & $\begin{array}{l}\text { Temperatura de } \\
\text { referência }\left({ }^{\circ} \mathrm{C}\right)\end{array}$ \\
\hline Classe B & 95 \\
\hline Classe F & 115 \\
\hline
\end{tabular}

A correção da resistência ôhmica é dada pela equação (2.6) a seguir. 


$$
R_{2}=\frac{\left(K+T_{2}\right)}{\left(K+T_{1}\right)} x R_{1}
$$

onde:

- $R_{1}$ é a resistência medida na temperatura $T_{1}$;

- $R_{2}$ é a resistência calculada na temperatura desejada $T_{2}$;

- $K=234,5$ para o cobre ou $K=228$ para o alumínio.

$\rightarrow$ Perdas no enrolamento do estator.

A perda no enrolamento do estator é a soma das perdas em todos os caminhos por onde circula a corrente de armadura. Em cada fase do enrolamento, ela é calculada como o produto da resistência ôhmica, corrigida para a temperatura de referência, e o quadrado da corrente de armadura.

A máquina em estudo, pertencente à classe $\mathrm{F}$ de isolamento, possui uma corrente nominal de armadura igual a $I_{a}=3104,3 A$ e uma resistência ôhmica de $R_{a}=9,84 m \Omega$, corrigida para a temperatura de referência descrita pela tabela 2.1. Calcula-se o valor da perda no enrolamento estatórico da seguinte forma:

$$
P_{\text {estator }}=3 I_{a}^{2} R_{a}=3(3104,3)^{2}(0,00984)=284,47 \mathrm{~kW}
$$

$\rightarrow$ Perdas no enrolamento do rotor.

A perda no enrolamento do rotor é calculada como o produto da resistência ôhmica, corrigida para a temperatura de referência, e o quadrado da corrente nominal de campo.

A máquina em estudo, pertencente à classe $\mathrm{F}$ de isolamento, possui uma corrente nominal de campo igual a $I_{f}=1140 \mathrm{~A}$ e uma resistência ôhmica de 
$R_{f}=151 \mathrm{~m} \Omega$, corrigida para a temperatura de $115^{\circ} \mathrm{C}$. Calcula-se o valor da perda no enrolamento rotórico da seguinte forma:

$$
P_{\text {rotor }}=I_{f}^{2} R_{f}=(1140)^{2}(0,151)=197 k W
$$

$\rightarrow$ Perdas no núcleo.

A perda no núcleo se deve à variação dos mecanismos, como o fenômeno de histerese e a correntes parasitas, relativos ao campo magnético flutuante, produzido nos enrolamentos da máquina. O seu valor pode ser obtido pela diferença na potência necessária para conduzir a máquina na velocidade nominal quando esta é excitada produzindo uma tensão nos seus terminais (tensão nominal à vazio), e a potência necessária para conduzir a máquina com a mesma velocidade mas sem excitação. Para a máquina em estudo tem-se:

$$
P_{\text {núcleo }}=275 \mathrm{~kW}
$$

$\rightarrow$ Perdas externas - Sistema de Excitação.

Essas perdas externas estão relacionadas às perdas elétricas e mecânicas dos equipamentos que formam o sistema de excitação, diretamente ligados à estrutura do gerador. Devem ser inclusos a fonte CC, o Regulador de Tensão e os outros dispositivos associados ao sistema de excitação. Para a máquina em estudo tem-se:

$$
P_{\text {externa }}=25,00 \mathrm{~kW}
$$

$\rightarrow$ Perdas por atrito e ventilação.

As perdas por atrito e ventilação, incluindo o atrito mecânico das escovas, é a potência dissipada pelo sistema de ventilação e pelo atrito das estruturas quando a 
máquina é conduzida à sua velocidade nominal sem que esta esteja excitada, mantendo as escova em contato. Para a máquina em estudo tem-se:

$$
P_{\text {atrito }}=90,00 \mathrm{~kW}
$$

$\rightarrow$ Perdas rotacionais.

Essas perdas estão relacionadas às perdas nas estruturas mecânicas que fazem o suporte da máquina. Entre elas estão:

- Perdas no mancal combinado inferior - parcela do gerador: $P_{G}=65 \mathrm{~kW}$

- Perdas no mancal combinado inferior - parcela da turbina: $P_{T}=238 \mathrm{~kW}$

- Perdas no mancal guia superior: $P_{M G S}=9 \mathrm{~kW}$

- Rendimento $\eta$

O rendimento de um gerador elétrico é definido como a razão entre a potência de entrada e a potência de saída. Para a máquina em estudo tem-se:

○ Potência de saída: $\quad P_{\text {out }}=70487,92 \mathrm{~kW}$

○ Potência de entrada: $\quad P_{\text {in }}=P_{\text {out }}+$ Perdas $=71671,39 \mathrm{~kW}$

Portanto, o rendimento da máquina é dado por:

$$
\eta=\frac{P_{\text {out }}}{P_{\text {ind }}}=\frac{70487,92}{71671,39}=0,9834
$$

Logo,

$$
\eta=98,34 \%
$$




\section{- Dados Mecânicos}

Nesta seção serão apresentados alguns dados mecânicos de projeto da máquina em estudo.

$\rightarrow$ Torque.

A geração de energia feita pelas máquinas rotativas é baseada no princípio de conversão eletromecânica de energia. Pela ação das três partes essenciais de um sistema eletromecânico de conversão de energia, (1) o sistema elétrico, (2) o sistema mecânico e (3) acoplamento de campo, a máquina como um todo desenvolve uma força ou torque. Este parâmetro é definido como a relação entre a potência ativa e a velocidade de rotação angular da máquina.

$$
T_{n}=\frac{P}{\omega_{s}}[N m]
$$

Para a máquina em estudo tem-se:

$$
T_{n}=\frac{P}{\omega_{s}}=\frac{70487,92}{17,13}=4114,8 \mathrm{kNm}
$$

A tabela 2.2 a seguir, descreve os dados mecânicos quantitativos das estruturas do gerador.

Tabela 2.2: Dados mecânicos.

\begin{tabular}{|c|l|l|}
\hline \multirow{3}{*}{ Rotor } & Diâmetro externo & $6278 \mathrm{~mm}$ \\
\cline { 2 - 3 } & Diâmetro interno & $5350 \mathrm{~mm}$ \\
\cline { 2 - 3 } & Massa & $218 \mathrm{t}$ \\
\hline Estator & Massa (sem mancais e acessórios) & $100 \mathrm{t}$ \\
\hline
\end{tabular}

- Dados de Estado Transitório

Nos tópicos anteriores foram descritos as principais características da máquina operando em estado permanente. Entretanto, quando um distúrbio ocorre, 
o comportamento da máquina é um pouco diferente. Esse período entre o estado permanente inicial e final é denominado de Estado Transitório.

De acordo com [5], em uma máquina síncrona, um distúrbio pode ocorrer de várias maneiras. Um curto-circuito acidental pode ocorrer entre a fase e o neutro, entre uma fase e outra e entre as três fases. Um distúrbio também pode ser evidenciado pela aplicação de carga na máquina. Todo tipo de distúrbio caracteriza um estado transitório.

Nesta seção, serão descritos os principais parâmetros de estado transitório de uma máquina síncrona, definidos em [3] e [6], e serão dados os valores dos parâmetros da máquina em estudo.

$\rightarrow$ Reatância Transitória - eixo direto $X^{\prime}{ }_{d}$

A Reatância Transitória de eixo direto é definida como o quociente entre a componente $\mathrm{AC}$ da tensão de armadura, gerada pelo fluxo total de armadura no eixo direto, e o valor da componente $A C$ da corrente de armadura após a ocorrência de um curto-circuito e eliminando os efeitos sub-transitório, ou seja, desconsiderando as correntes nos enrolamentos amortecedores. Para a máquina em estudo tem-se:

$$
X_{d}^{\prime}=0,278 p u
$$

$\rightarrow$ Reatância Transitória - eixo em quadratura $X_{q}^{\prime}$

A reatância Transitória de eixo em quadratura é definida como o quociente entre a tensão de armadura, gerada pelo fluxo total de armadura no eixo em quadratura, e o valor da componente $A C$ da corrente de armadura após a aplicação da carga e eliminando os efeitos sub-transitórios. Geralmente, a reatância transitória e a reatância síncrona em quadratura possuem o mesmo valor. Assim, para a máquina em estudo tem-se:

$$
X_{q}^{\prime}=0,600 p u
$$


$\rightarrow$ Reatância Sub-transitória - eixo direto $X^{\prime \prime}{ }_{d}$

A reatância Sub-transitória de eixo direto define-se como o quociente entre a tensão de armadura, gerada pelo fluxo total de armadura no eixo direto, e o valor da componente AC da corrente de armadura após a ocorrência de um curto-circuito, contando os primeiros ciclos onde existe passagem de corrente no enrolamento amortecedor. Para a máquina em estudo tem-se:

$$
X_{d}{ }_{d}=0,24 p u
$$

$\rightarrow$ Reatância Sub-transitória - eixo em quadratura $X^{\prime \prime}{ }_{q}$

A reatância Sub-transitória de eixo em quadratura define-se como o quociente entre a tensão de armadura, gerada pelo fluxo total de armadura no eixo em quadratura, e o valor da componente $\mathrm{AC}$ da corrente de armadura após a ocorrência de um curto-circuito, contando os primeiros ciclos. Para a máquina em estudo temse:

$$
X_{q}^{\prime \prime}=0,24 p u
$$

Sabendo que o valor de $X^{\prime \prime}{ }_{d}$ e $X^{\prime \prime}{ }_{q}$ são iguais, tem-se que a máquina em estudo não possui saliência sub-transitória.

$\rightarrow$ Constante de tempo transitória em circuito aberto - eixo direto $T^{\prime}{ }_{d o}$

Define-se como sendo o tempo necessário para a tensão de armadura em circuito aberto, devido ao fluxo no eixo direto seguido de uma mudança repentina nas condições de operação, decrescer 0,368 do seu valor inicial (decaimento exponencial $1 / \varepsilon$ ), com a máquina operando na velocidade nominal. Para a máquina em estudo, o valor de projeto é dado por:

$$
T^{\prime}{ }_{d o}=6,25 s
$$


$\rightarrow$ Constante de tempo transitória em curto-circuito - eixo direto $T^{\prime}{ }_{d}$

Define-se como sendo o tempo necessário para a componente $I_{d}$ da corrente de armadura acompanhando uma abrupta mudança nas condições de operação, passado os primeiros ciclos, decrescer 0,368 de seu valor inicial (decaimento exponencial $1 / \varepsilon)$, com a máquina operando na velocidade nominal. $O$ seu valor pode ser obtido da seguinte relação:

$$
X_{d} . T_{d}^{\prime}=X_{d}^{\prime} T_{d o}^{\prime}
$$

Onde os valores da relação são as constantes e reatâncias descritas anteriormente. Logo, para a máquina em estudo tem-se:

$$
T_{d}^{\prime}=\frac{X_{d}^{\prime} T^{\prime}{ }_{d o}}{X_{d}}=\frac{0,278 x 6,25}{0,947}=1,83 \mathrm{~s}
$$

$\rightarrow$ Constante de tempo sub-transitória em circuito aberto - eixo direto $T^{\prime \prime}{ }_{d o}$

Define-se como sendo o tempo necessário para a tensão de armadura em circuito aberto, devido ao fluxo no eixo direto seguido de uma mudança repentina nas condições de operação, contando os primeiros ciclos, decrescer 0,368 do seu valor inicial (decaimento exponencial $1 / \varepsilon$ ), com a máquina operando na velocidade nominal. Para a máquina em estudo, o valor de projeto é dado por:

$$
T^{\prime \prime}{ }_{d o}=0,043 s
$$

$\rightarrow$ Constante de tempo sub-transitória em curto-circuito - eixo direto $T^{\prime \prime}{ }_{d}$

Define-se como sendo o tempo necessário para a componente $I_{d}$ da corrente de armadura acompanhando uma abrupta mudança nas condições de operação, contando os primeiros ciclos, decrescer 0,368 de seu valor inicial (decaimento exponencial $1 / \varepsilon$ ), com a máquina operando na velocidade nominal. Para a máquina em estudo tem-se:

$$
T^{\prime \prime}{ }_{d}=0,037 \mathrm{~s}
$$


$\rightarrow$ Constante de Tempo sub-transitória em curto-circuito - eixo em quadratura $T^{\prime \prime}{ }_{q}$

Define-se como sendo o tempo necessário para a componente $I_{q}$ da corrente de armadura acompanhando uma abrupta mudança nas condições de operação, contando os primeiros ciclos, decrescer 0,368 de seu valor inicial (decaimento exponencial $1 / \varepsilon$ ), com a máquina operando na velocidade nominal. Para a máquina em estudo tem-se:

$$
T^{\prime \prime}{ }_{q}=0,064 \mathrm{~s}
$$

\section{- Outros Dados Elétricos.}

$\rightarrow$ Relação de curto-circuito $R_{c}$

Define-se como a razão entre a corrente de excitação obtida da característica à vazio para a corrente de armadura nominal, e a corrente de excitação obtida da característica de curto-circuito para a mesma corrente de armadura. Para a máquina em estudo tem-se:

$$
R_{c}=1,32 p u
$$

$\rightarrow$ Momento de Inércia $J$

O Momento de Inércia mede a distribuição da massa de um corpo entorno do seu eixo de rotação. Para o cálculo tem-se:

$$
\left.J=m r^{2} \text { [tonelada } m^{2}\right]
$$

onde:

$m$ : massa do corpo

$r$ : distância do corpo ao eixo de rotação. 
Para a máquina em estudo tem-se:

$$
J=m r^{2}=1610 \mathrm{tm}^{2}
$$

$\rightarrow$ Constante da energia armazenada do Gerador $H$

Define-se como o quociente entre a energia cinética armazenada no rotor quando a máquina opera na velocidade constante e a potência aparente nominal do gerador. Para a máquina em estudo tem-se:

$$
H=3,1857 \mathrm{~s}
$$




\section{ENSAIOS}

Neste capítulo serão descritos os diferentes ensaios de comissionamento realizados em um gerador síncrono antes de sua operação comercial. Os ensaios são divididos em duas categorias: ensaios estáticos e ensaios dinâmicos.

\subsection{Ensaios Estáticos}

Os ensaios estáticos são todos aqueles testes que não implicam no giro da unidade geradora. Dentre esses ensaios, alguns não possuem interfaces com os demais equipamentos da central geradora podendo ser efetuados em paralelo com as atividades de montagem.

Os principais ensaios estáticos que fazem parte do rol de testes realizados no gerador antes da sua entrada em operação serão descritos nas seções seguintes.

\subsubsection{Ensaio de medição da resistência de isolamento e verificação do Índice de Polarização do estator (IP).}

Das definições citadas em [3] e [7], tem-se que a resistência de isolamento é definida como sendo a capacidade do isolamento elétrico de um enrolamento resistir à circulação de uma corrente contínua.

O Índice de Polarização define-se como sendo a medida que descreve a variação da resistência de isolamento com o tempo.

Nos enrolamentos das máquinas rotativas, a resistência de isolamento é função do tipo e da condição em que se encontra o material isolante utilizado, bem como da técnica utilizada na aplicação deste material para construção dos 
enrolamentos. Geralmente, a resistência de isolamento varia proporcionalmente com a camada de isolamento e inversamente com a área da superfície do condutor.

Da definição, a resistência de isolamento é o quociente da tensão continua aplicada no elemento isolante pela corrente total em um determinado tempo. Essa corrente total $\left(I_{T}\right)$, que aparece no instrumento de medição (amperímetro) é a soma de quatro diferentes correntes, sendo elas: corrente de fuga $\left(I_{L}\right)$; corrente geométrica capacitiva $\left(I_{C}\right)$; corrente de condução $\left(I_{G}\right)$ e corrente de absorção $\left(I_{A}\right)$. As definições das correntes geradas no enrolamento em teste, com a aplicação da tensão contínua, podem ser encontradas em [7].

$\rightarrow$ Objetivo do ensaio.

O ensaio de medição da resistência de isolamento do enrolamento do estator visa obter informações sobre o estado em que o material isolante se encontra, podendo indicar se a máquina está em condições de ser submetida aos ensaios dielétricos, como por exemplo, o ensaio de tensão aplicada.

$\rightarrow$ Método do ensaio.

No ensaio, utilizou-se um aparelho chamado megôhmetro para fazer a medição da resistência de isolamento. Este aparelho utiliza uma fonte de corrente contínua e possui um amperímetro e um multímetro integrados, indicando diretamente o valor do quociente entre a tensão aplicada e a corrente que passa através do enrolamento em teste.

A medição da resistência de isolamento constitui um teste de aplicação de uma tensão contínua, sendo essa, restrita a um valor apropriado para cada tipo de enrolamento em teste.

Deve-se ajustar a tensão de ensaio no megôhmetro conforme descrito na tabela 3.1. 
Tabela 3.1: Ajuste da tensão no aparelho de medição.

\begin{tabular}{|l|l|}
\hline $\begin{array}{c}\text { Tensão Nominal no } \\
\text { Enrolamento (V). }\end{array}$ & $V_{\text {aparelho }}(V c c)$ \\
\hline$<1000$ & 500 \\
\hline $1000-2500$ & $500-1000$ \\
\hline $2501-5000$ & $1000-2500$ \\
\hline $5001-12000$ & $2500-5000$ \\
\hline$>12000$ & $5000-10000$ \\
\hline
\end{tabular}

Para a máquina em estudo, utilizou-se a tensão de $5 k V c c$ no aparelho, pois o enrolamento em teste possui uma tensão nominal de $13,8 \mathrm{kV}$. De acordo com [7], a medição da resistência de isolamento é feita nas fases individualmente, contra as demais fases e carcaça ligadas à terra. Normalmente mede-se também com as três fases conectadas. A leitura deve ser feita após um minuto da aplicação da tensão, a fim de evitar o efeito de polarização.

O índice de polarização é um parâmetro que analisa a característica do isolamento com a aplicação da tensão durante dez minutos. Para o cálculo deste parâmetro, as leituras são tomadas após um minuto e dez minutos da aplicação da tensão. Recomenda-se também, que além das leituras de um e dez minutos, sejam tomadas as leituras intermediárias, em intervalos de um minuto, para monitorar se não houve saturação e também para uma melhor acurária dos resultados.

Para o cálculo do índice de polarização utiliza-se a seguinte fórmula:

$$
I P=\frac{R_{\text {isol }}(10 \mathrm{~min})}{R_{\text {isol }}(1 \mathrm{~min})}
$$

onde:

IP : Índice de Polarização.

$R_{\text {isol }}(10 \mathrm{~min})$ : Valor da resistência de isolamento medida após dez minutos. 
$R_{i s o l}(1 \mathrm{~min})$ : Valor da resistência de isolamento medida após um minuto.

Concluídas as leituras e desligado o megôhmetro, conecta-se à terra o enrolamento sob ensaio para descarga. O tempo de descarga aconselhável é quatro vezes o tempo de duração do ensaio [7].

Para a realização do ensaio deve-se utilizar o circuito esquematizado a seguir:

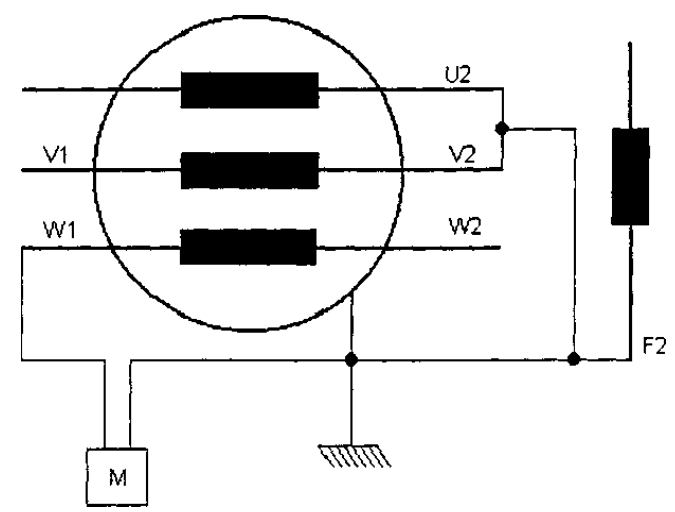

Figura 3.1: Esquema de ligação para medição da resistência de isolamento e índice de polarização do estator.

Legenda:

W1 Enrolamento da fase submetida ao ensaio.

F2 Enrolamento do rotor.

M Megôhmetro.

Após a obtenção dos resultados, deve-se efetuar uma avaliação dos valores obtidos seguindo os critérios descritos a seguir. 
- Resistência de isolamento:

O valor da resistência de isolamento de um enrolamento depende da temperatura do enrolamento e do tempo de duração da aplicação da tensão. A massa térmica da máquina em teste geralmente é tão grande que a diferença de temperatura entre os pontos de medição (um e dez minutos) pode ser desconsiderada. Assim, para evitar o efeito da temperatura é recomendado que todas as medidas da resistência de isolamento sejam corrigidas para uma base comum de temperatura, em $40^{\circ} \mathrm{C}$.

Tomando como base as considerações feitas em [8], tem-se que a correção do valor da resistência de isolamento medido é feita a partir da equação (3.2) abaixo.

$$
R_{C}=K_{\text {isol }} R_{\text {isol }}
$$

onde

$R_{C}$ : valor da resistência de isolamento em $(M \Omega)$ corrigida $40^{\circ} \mathrm{C}$.

$K_{i s o l}:$ coeficiente de temperatura na temperatura de medição.

$R_{\text {isol }}$ : valor da resistência de isolamento em ( $M \Omega$ ) na temp. de medição.

O método para obtenção do coeficiente de temperatura para uma temperatura específica de medição é dado em [7]. Para a base de temperatura utilizada nesta análise, $40^{\circ} \mathrm{C}$, o valor de $K_{\text {isol }}$ é dado pela equação (3.3) abaixo.

$$
K_{\text {isol }}=(0,5)^{\frac{(40-T)}{10}}
$$

onde

$T$ : valor da temperatura de medição em ${ }^{\circ} \mathrm{C}$.

Conforme os requisitos mínimos indicado em [7], considera-se satisfatório o ensaio, quando a resistência do isolamento medida, corrigida para a temperatura de 
$40^{\circ} \mathrm{C}$, for maior ou igual ao nível do isolamento (em $\mathrm{kV}$ ) somando-se a unidade, ou seja:

$$
R_{C}(M \Omega) \geq\left[V_{\text {aparelho }}(k V)+1\right]
$$

onde

$V_{\text {aparelho }}(k V)$ : Tensão CC aplica nos terminais do enrolamento sob teste.

Conforme descrito no método do ensaio, recomenda-se, para máquinas trifásicas, que a medição da resistência de isolamento do estator deve ser feita nas três fases separadamente com as outras fases conectadas ao terra e com as três fases conectadas. De acordo com [7], o valor mínimo obtido para cada fase separadamente deve ser aproximadamente o dobro do valor obtido com as três fases conectadas.

- $\quad$ Índice de Polarização:

O índice de polarização é um indicativo do declive da curva característica da resistência do material isolante. O seu cálculo é feito para avaliar a condição em que se encontra o material isolante.

De acordo com [7], o valor mínimo recomendado para o IP de máquinas rotativas é descrito pela tabela 3.2. Os valores da tabela são baseados nas classes térmicas dos materiais isolantes, descritas em [1] e são aplicados para todos os tipos de materiais.

Tabela 3.2: Valores mínimos recomendados para IP.

\begin{tabular}{|c|c|}
\hline Classe Térmica & IP (valor mínimo) \\
\hline Classe A & 1,5 \\
\hline Classe B & 2,0 \\
\hline Classe F & 2,0 \\
\hline Classe H & 2,0 \\
\hline
\end{tabular}


$\rightarrow$ Análise dos resultados.

Os resultados obtidos para a resistência de isolamento e índice de polarização do estator, para uma temperatura de ensaio de $27^{\circ} \mathrm{C}$, são descritos na tabela 3.3.

Tabela 3.3: Valores da resistência de isolamento e IP do estator em $27^{\circ} \mathrm{C}$.

\begin{tabular}{|c|c|c|c|c|}
\cline { 2 - 5 } \multicolumn{1}{c|}{} & \multicolumn{5}{|c|}{ Conexões } \\
\hline & & & \\
&
\end{tabular}

A medida da resistência de isolamento cresce rapidamente quando a tensão é inicialmente aplicada, e no decorrer da aplicação, essa medida gradualmente se aproxima de um valor constante. Isso pode ser explicado pela dinâmica das moléculas presentes no material isolante empregado na construção do enrolamento. Desde que essas moléculas tendem a se opor às forças atrativas de outras moléculas, isso leva geralmente alguns minutos, após a aplicação do campo elétrico, 
para que essas moléculas se reorientem, e, conseqüentemente, para que a energia de polarização da corrente gerada se reduz a zero.

Para uma melhor visualização da variação do valor da resistência de isolamento durante a aplicação da tensão, os valores medidos são plotados no gráfico da figura 3.2.

Tipos modernos de materiais isolantes, como o material utilizado na construção do isolamento do enrolamento estatórico da máquina em estudo ("epoxymica"), o valor da resistência de isolamento irá aproximar-se de um valor constante em 4 minutos ou menos.

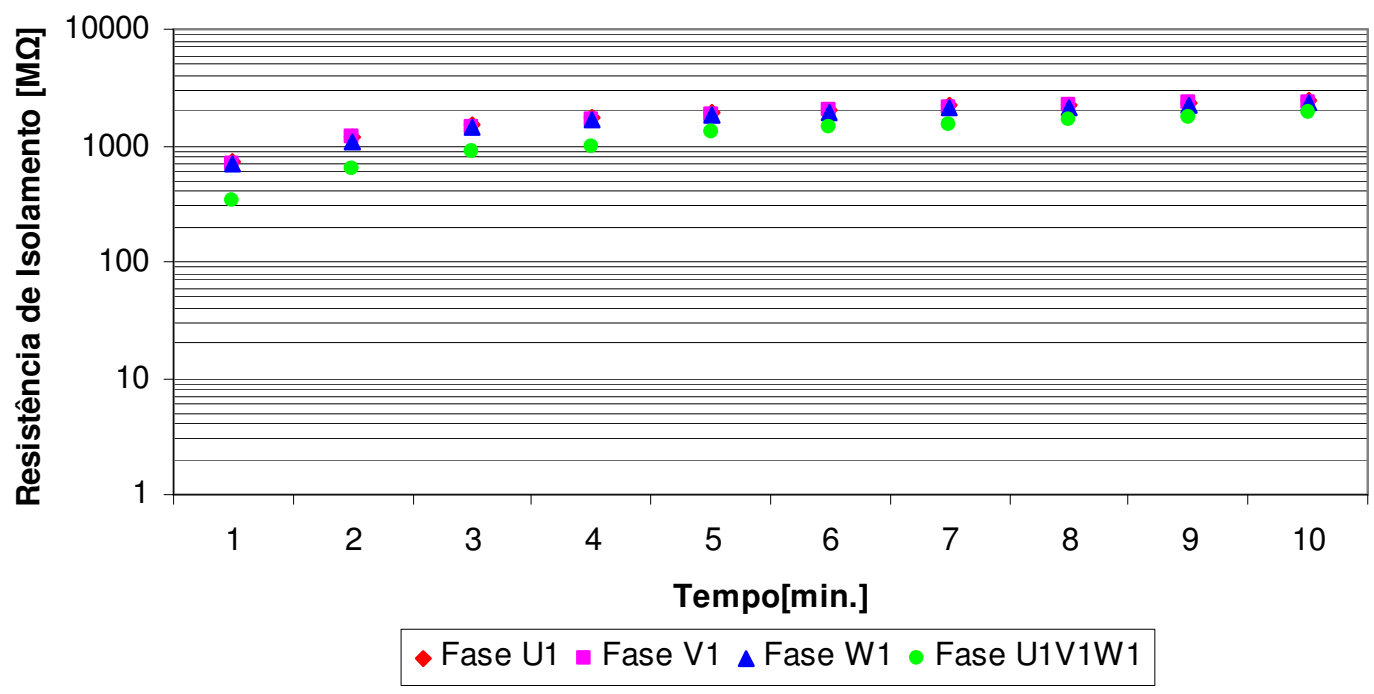

Figura 3.2: Medições da resistência de isolamento no enrolamento do estator para $27^{\circ} \mathrm{C}$.

Como mencionado anteriormente, para evitar o efeito da temperatura é recomendado que todas as medidas da resistência de isolamento sejam corrigidas para uma base comum de temperatura, em $40^{\circ} \mathrm{C}$.

A conversão é feita com base na equação (3.2). Os valores corrigidos para a temperatura de base são descritos na tabela 3.4 . 
Tabela 3.4: Valores da resistência de isolamento e I.P. do estator corrigidos para $40^{\circ} \mathrm{C}$.

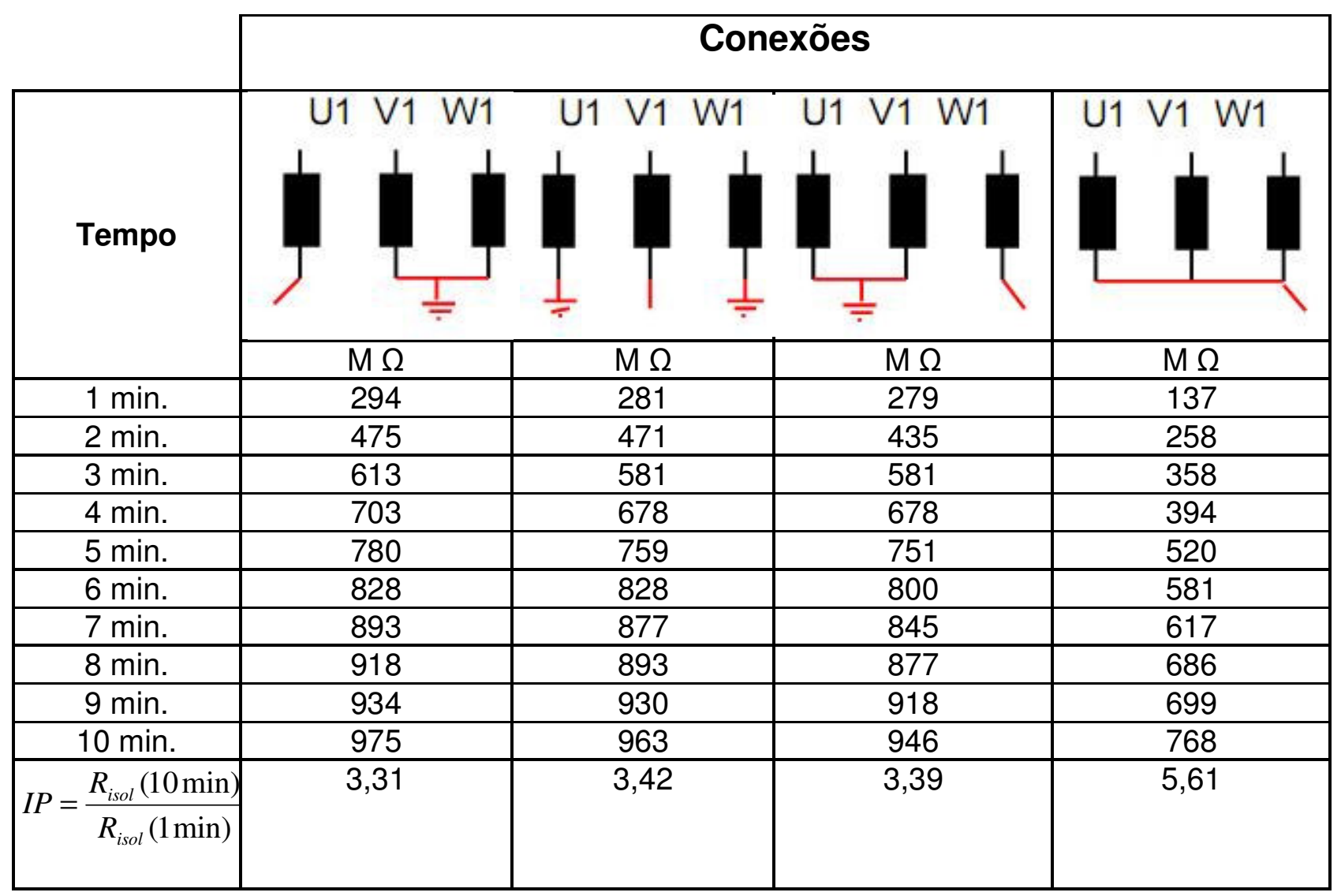

Plotando os resultados, obtemos o gráfico da variação do valor corrigido da resistência de isolamento mostrado na figura 3.3. 


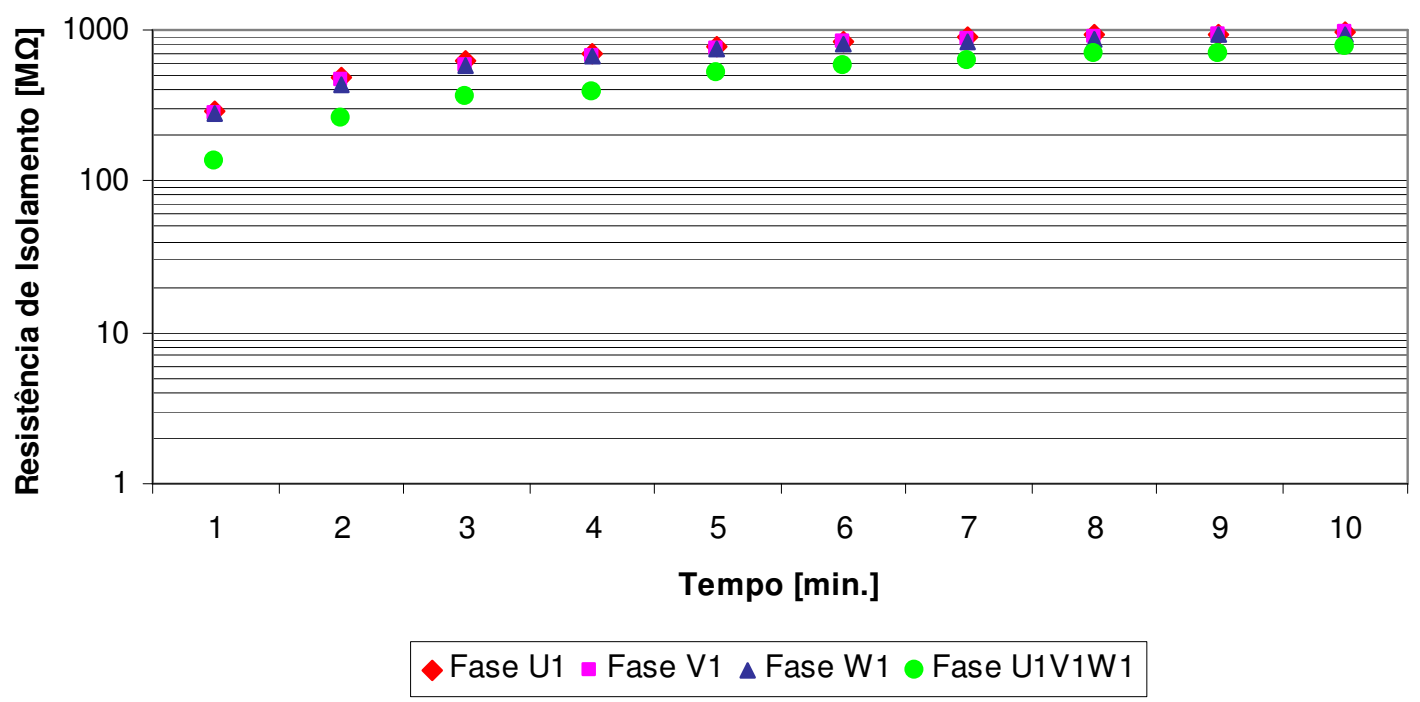

Figura 3.3: Medições da resistência de isolamento no enrolamento do estator convertido para $40^{\circ} \mathrm{C}$.

Avaliando os resultados obtidos, após um minuto da aplicação da tensão, de acordo com o critério de avaliação descrito anteriormente, tem-se:

- $\quad$ Fase U1V1W1: $R_{U V W}=137 M \Omega$

- Fase U1: $R_{U}=294 M \Omega>2 R_{U V W}$

- $\quad$ Fase $\mathrm{V} 1: R_{V}=281 M \Omega>2 R_{U V W}$

- Fase $\mathrm{W} 1: R_{W}=279 M \Omega>2 R_{U V W}$

O ensaio de medição da resistência de isolamento do enrolamento estatório foi considerado satisfatório, pois os resultados estão dentro do especificado em norma e pode-se dizer que o material isolante utilizado na construção do isolamento está em ótimas condições. 
Conforme descrito no capítulo 2 deste trabalho, a classe térmica do isolamento do enrolamento estatórico é F. Assim, analisando os resultados obtidos tem-se:

- Fase U1V1W1: $I P_{U V W}=5,61>2$

- Fase U1: $I P_{U}=3,31>2$

- Fase $\mathrm{V} 1: I P_{V}=3,42>2$

- Fase $\mathrm{W} 1: I P_{W}=3,39>2$

Portanto, pode-se afirmar que o valor para o IP de cada fase do enrolamento está dentro do especificado em norma, garantindo assim a operacionalidade da máquina.

\subsubsection{Ensaio de tensão aplicada no enrolamento do Estator.}

O ensaio de tensão aplicada deve ser realizado obrigatoriamente após a conclusão do ensaio de medição da resistência de isolamento, sendo o resultado do isolamento um pré-requisito para o início do ensaio. O local de realização é a área de montagem da usina, durante a instalação das estruturas da unidade geradora. De acordo com a norma [9], para o enrolamento do estator deve-se aplicar a tensão em cada fase separadamente, com as demais fases conectadas a terra.

$\rightarrow$ Objetivo do ensaio.

Este ensaio visa avaliar a suportabilidade do dielétrico de máquinas rotativas, quando submetido a tensões acima da nominal, garantindo desta forma, seu bom desempenho durante a vida útil da máquina. 
$\rightarrow$ Método do ensaio.

O valor da tensão de ensaio, aplicada no enrolamento do estator, em corrente alternada, é de $1000 \mathrm{~V}$ mais duas vezes a tensão nominal, em volts, na freqüência industrial $(60 \mathrm{~Hz})$, de acordo com [9], tendo como base as características nominais do enrolamento em teste.

Para a máquina em estudo, utilizou-se um HIPOT, aparelho utilizado na maioria dos testes que necessitam de uma fonte de corrente alternada com um nível adequado de equilíbrio no valor da tensão aplicada. Este aparelho fornece uma tensão estável suficiente para assegurar que a sua forma não seja afetada pela variação da corrente de fuga. Produzida nas estruturas de isolamento submetidas a uma aplicação de alta tensão.

Caso não exista fonte $C A$ disponível, pode-se utilizar tensão contínua. Entretanto, de acordo com a norma [10] o valor aplicado deve ser 1,7 vezes maior que o valor especificado em corrente alternada. Esse valor é determinado pela realização de testes em tensão contínua e alternada (descritos em [11]), comparando a durabilidade de um material isolante contendo falhas em sua estrutura, e de testes em tensão contínua e alternada, comparando a durabilidade do isolamento em estruturas novas e intactas.

O ensaio em CA deve ser iniciado com uma tensão que não exceda a metade do valor da tensão total aplicada, ou seja, menor que $\frac{2 x V_{\text {nominal }}+1000 \mathrm{~V}}{2}$. Então, deve-se elevar o valor da tensão a uma velocidade de $0,5 \mathrm{kV} / \mathrm{s}$, que corresponde a aproximadamente $2 \%$ da tensão total aplicada, até atingir o valor especificado, permanecendo neste nível por um minuto, sendo então reduzida a zero volt, também com a mesma velocidade. Essa velocidade de elevação da tensão aplicada permite obter grande acurácia nos valores medidos pelo equipamento de medição utilizado. [8]

Em caso de repetição do ensaio ou quando os enrolamentos não são novos, o valor da tensão a ser utilizado é $85 \%$ do valor acima indicado. [4] 
Após o final do teste, conforme descrito em [10], a máquina deve permanecer aterrada por um tempo quatro vezes maior que o de ensaio. Isso garante que nenhum resquício de energia seja encontrado no enrolamento após a execução do ensaio. Deve-se evitar desligar a fonte com tensões superiores a $40 \%$ em relação à tensão nominal do enrolamento em teste.

As seguintes observações devem ser consideradas para um melhor monitoramento do ensaio realizado.

- Os parâmetros de ensaio como tensão, tempo de aplicação e temperatura do enrolamento (normalmente o ensaio é realizado na temperatura ambiente) podem ser alterados conforme solicitação da empresa responsável pela compra da máquina. Entretanto, isto deve ser feito por ocasião da oferta, através de especificação técnica e/ou norma específica, sofrendo análise e aprovação dos setores competentes, quanto à suportabilidade.

- Para que os resultados obtidos sejam considerados satisfatórios, não deve ocorrer descarga entre o enrolamento energizado e os demais itens aterrados.

Para a realização do ensaio utilizou-se o circuito esquematizado a seguir:

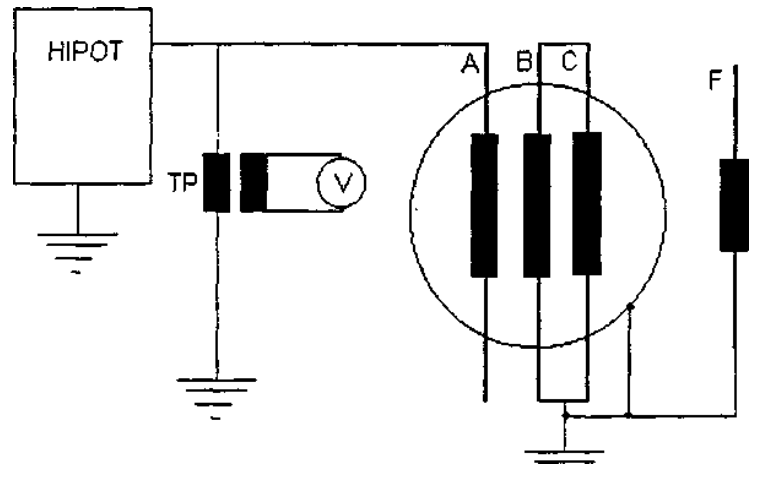

Figura 3.4: Esquema de ligação para ensaio com tensão alternada no enrolamento estatórico.

Legenda:

HIPOT HIPOT para ensaio em tensão alternada. 
V Voltímetro CA.
A, B e C
Fases do estator.
F
Enrolamento do rotor.

Para o ensaio realizado em corrente contínua, deve-se utilizar o seguinte esquemático.

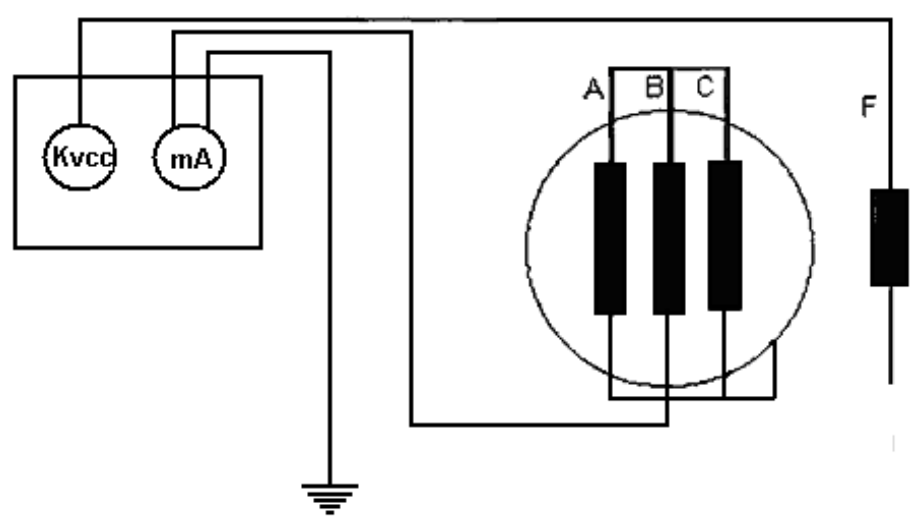

Figura 3.5: Esquema de ligação do ensaio com tensão contínua no enrolamento estatórico.

Legenda:

kV Voltímetro.
A, B e C
Fases do estator.
$\mathrm{F}$
Enrolamento do rotor.
$\mathrm{mA}$
Miliamperimetro.

$\rightarrow$ Análise dos resultados.

Neste ensaio utilizou-se um transformador de potencial (TP), conforme descrito no esquemático da figura 3.4 , para realizar o monitoramento da tensão 
aplicada. Para garantir que a tensão de teste não seja afetada pela corrente de fuga, o TP deve fornecer uma corrente de curto-circuito suficiente para manter um nível de tensão em 3\% durante uma eventual descarga elétrica.

De acordo com [4], considera-se satisfatório a realização do ensaio de tensão aplicada no enrolamento estatórico se no decorrer da aplicação da tensão, nenhuma evidência de distúrbio ou falha no isolamento for observada. Essa falha no isolamento elétrico ou quebra do isolamento é caracterizada por uma acentuada descarga capacitiva, chamada de disparo, no local onde se localiza a falha. Em alguns casos, entretanto, essa falha é observada por uma mudança brusca na corrente de medição.

Para a máquina em estudo, sabendo que a tensão nominal do enrolamento do estator é $13800 \mathrm{~V}$, tem-se que a tensão de teste em CA é dada por:

$$
V_{c a}=2 x(13800)+1000=28600 \mathrm{~V}
$$

O resultado do ensaio foi considerado satisfatório, pois durante o tempo de aplicação da tensão (aproximadamente um minuto), nenhuma descarga elétrica foi evidenciada. Assim, pode-se considerar que o enrolamento do estator passou pelo teste de tensão aplicada e que o material utilizado o isolamento está em ótimas condições. 


\subsubsection{Medição da resistência ôhmica do enrolamento do Estator.}

A medição da resistência ôhmica é considerada como ensaio de rotina e deve ser realizado sempre antes dos ensaios dinâmicos com a finalidade de se obter as características da máquina elétrica.

Diferente dos outros ensaios estáticos descritos anteriormente, a medição da resistência ôhmica dos enrolamentos da máquina deve ser realizada quando todas as estruturas da máquina já tiverem sido devidamente montadas. $\mathrm{E}$ de acordo com a norma [9], a resistência ôhmica do enrolamento do estator deve ser medida em cada fase separadamente. Se, por alguma razão, a resistência por fase não puder ser feita diretamente, a medição é feita entre cada par do terminal de linha do enrolamento.

$\rightarrow$ Objetivo do ensaio.

Este ensaio visa obter a resistência ôhmica do enrolamento de armadura, a qual poderá ser usada para calcular as perdas $\left(I_{a}^{2} R_{a}\right)$, e determinar a componente ativa da queda de tensão interna em carga, ou para determinar a temperatura dos enrolamentos. Além disso, é importante sua comparação com os valores de projeto para se detectar possíveis erros de ligação durante a bobinagem.

$\rightarrow$ Método do ensaio.

Existem diferentes métodos de medição da resistência ôhmica do enrolamento de uma máquina elétrica. A escolha do melhor método depende da natureza do circuito formado pelo enrolamento da máquina em teste e do grau de acurácia que se deseja obter com a medição.

De acordo com [12], e tendo como base as características da máquina síncrona, descritas no capítulo 2 deste trabalho, como valor de projeto da resistência do enrolamento estatórico menor que aproximadamente $5 \Omega$, tem-se que os dois métodos mais utilizados são o método voltímetro-amperímetro, mais conhecido como método da corrente e tensão, e o método da ponte de Thomson. 
Para os dois métodos, deve-se monitorar a temperatura do enrolamento, pois de acordo com [6], o aumento da temperatura do enrolamento não deve ultrapassar $1 K$ durante a realização do ensaio. Se o monitoramento da temperatura não for feito, o valor da corrente, que passa pelo enrolamento em teste, não deve ultrapassar $10 \%$ do valor da corrente nominal do enrolamento e o tempo de aplicação não deve ser maior que 1 minuto.

Os dois métodos são descritos a seguir.

- Método da corrente e tensão.

Esse método consiste em fazer circular uma corrente contínua, que pode ser ajustada através de um reostato ligado em série com a fonte $\mathrm{CC}$ e o enrolamento, medindo-se a queda de tensão nos terminais do enrolamento. Com alterações no valor do reostato obtêm-se diferentes valores de corrente e tensão.

Devem-se efetuar no mínimo três medições de resistência ôhmica com valores de correntes diferentes. O valor a ser considerado é a média das medições. No caso de valor discrepante, ou seja, que diferem de $\pm 0,01$ do valor da média em pu, recomenda-se não considerá-lo e repetir a medição.

O esquemático do método é descrito na figura 3.6 a seguir.

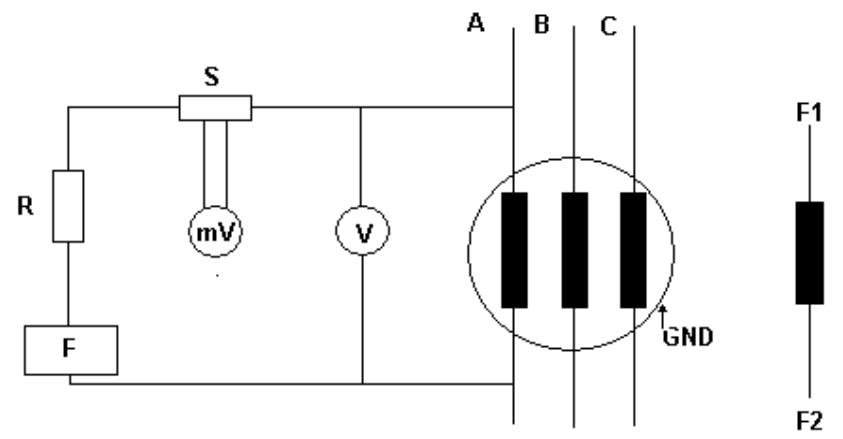

Figura 3.6: Esquemático do método voltímetro-amperímetro. 
Legenda:

F Fonte CC.

V Voltímetro.

$\mathrm{mV} \quad$ Milivoltímetro.

S Shunt.

R Reostato variável.

A Fase A do enrolamento sob teste.

- Método da Ponte:

Neste método utiliza-se um aparelho que realiza a medição da resistência ôhmica de um enrolamento utilizando o método da ponte de Thomson, também conhecida como Ponte dupla de Kelvin. O valor da resistência é obtido diretamente no aparelho.

De acordo com [6], ao utilizar o método da ponte, é necessário realizar no mínimo três medições da resistência ôhmica. Para isso, deve-se modificar o balanço da ponte, isto é, o valor da corrente de medição deve ser modificado diretamente no aparelho. $O$ valor a ser considerado é a média das três diferentes medições. Ao determinar o valor médio, o valor da resistência em cada medição que diferir de $\pm 0,01$ desse valor médio calculado, deve ser desconsiderado e uma nova medição é realizada.

Para a realização do ensaio de medição da resistência ôhmica do enrolamento do estator, o seguinte circuito deve ser montado com as devidas conexões. 


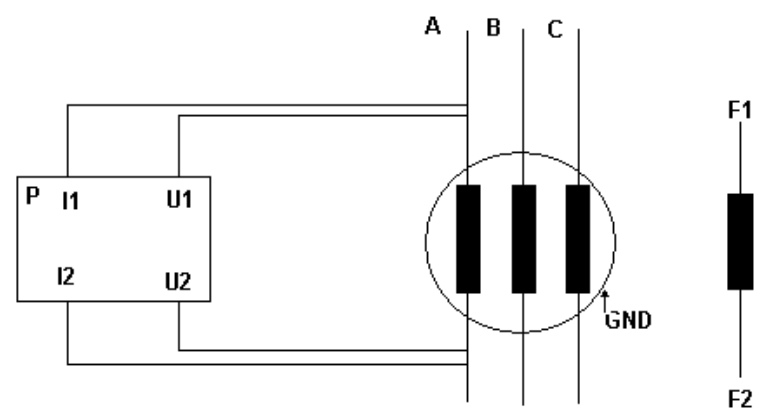

Figura 3.7: Esquemático para o método da Ponte.

Legenda:

P Ponte de Thomson.

A Fase A do enrolamento sob teste.

Para todos os ensaios de medição da resistência de um determinado material ou estrutura isolante, um fator que influencia bastante o resultado é a temperatura em que se encontra a estrutura. Um aumento na temperatura do enrolamento ocasiona a liberação de cargas ionizantes reduzindo assim a resistividade.

Portanto, para se ter um padrão na análise de uma determinada característica, para cada valor de resistência ôhmica medido deve-se sempre associar o valor da temperatura do enrolamento no instante da leitura. Entretanto, através da fórmula abaixo, pode-se referir este valor para qualquer outra temperatura:

$$
R_{2}=\frac{\left(K+T_{2}\right)}{\left(K+T_{1}\right)} x R_{1}
$$

onde:

- $R_{1}$ é a resistência medida na temperatura $T_{1}$;

- $R_{2}$ é a resistência calculada na temperatura desejada $T_{2}$; 
- $K=234,5$ para o cobre ou $K=228$ para o alumínio.

De acordo com as características da máquina em estudo, o valor de $\mathrm{K}$ usado deve ser de 234,5 .

O valor da resistência ôhmica medido é considerado satisfatório, se não diferir mais que $10 \%$ em relação ao valor de projeto. Em adicional, no estator aplica-se a tolerância de 3\% entre fases.

$\rightarrow$ Análise dos resultados.

Para a máquina em estudo, utilizou-se para a medição da resistência ôhmica do enrolamento do estator o método da ponte de Thomson. Conforme descrição do método, foram realizadas três medições com os seguintes valores de corrente, $10,0 A, 7,5 A$ e $5,0 A$.

Os resultados obtidos para os três diferentes valores da corrente aplicada, juntamente com a média, são descritos na tabela 3.5 abaixo.

Tabela 3.5: Valores medidos da resistência ôhmica do enrolamento estatórico para cada fase.

\begin{tabular}{|c|c|c|}
\hline \multirow{2}{*}{ Corrente (A) } & Fase & $\begin{array}{c}\text { Resistência Ôhmica ( } \Omega \\
\text { ) }\end{array}$ \\
\hline \multirow{3}{*}{10,00} & A & 0,007300 \\
\cline { 2 - 3 } & B & 0,007292 \\
\cline { 2 - 3 } & C & 0,007303 \\
\hline \multirow{3}{*}{7,50} & A & 0,007300 \\
\cline { 2 - 3 } & B & 0,007293 \\
\cline { 2 - 3 } & C & 0,007305 \\
\hline \multirow{3}{*}{5,00} & A & 0,007303 \\
\cline { 2 - 3 } & B & 0,007292 \\
\cline { 2 - 3 } & C & 0,007306 \\
\hline
\end{tabular}




\begin{tabular}{|c|c|c|}
\hline \multirow{3}{*}{ Média } & $\mathrm{A}$ & 0,007301 \\
\cline { 2 - 3 } & $\mathrm{B}$ & 0,007292 \\
\cline { 2 - 3 } & $\mathrm{C}$ & 0,007305 \\
\hline \multicolumn{2}{|c|}{ Temperatura de medição } & $28,96^{\circ} \mathrm{C}$ \\
\hline
\end{tabular}

Sabendo que o valor de projeto da resistência ôhmica do enrolamento do estator é de $0,00731 \Omega$, pode-se calcular a diferença entre esse valor e o valor coletado em campo, para cada fase.

- Fase A: $\Delta R_{a}=R_{\text {aprojeto }}-R_{\text {amédio }}=0,00731-0,007301=9 \times 10^{-6} \Rightarrow \Delta R_{a}=0,1 \%$.

- Fase B: $\Delta R_{a}=R_{\text {aprojeto }}-R_{\text {amédio }}=0,00731-0,007292=1,8 \times 10^{-5} \Rightarrow \Delta R_{a}=0,25 \%$.

- Fase C: $\Delta R_{a}=R_{\text {a projeto }}-R_{\text {amédio }}=0,00731-0,007305=5 \times 10^{-6} \Rightarrow \Delta R_{a}=0,07 \%$.

Baseando no critério de avaliação conforme descrito anteriormente, dos resultados encontrados acima, pode-se concluir que o ensaio de medição da resistência ôhmica do enrolamento de armadura foi considerado satisfatório. Nenhum valor da resistência coletado em campo ultrapassou a tolerância de $3 \%$ em relação ao valor de projeto para cada fase. 


\subsubsection{Medição da resistência de isolamento do Rotor.}

A resistência de isolamento é definida como sendo a capacidade do isolamento elétrico de um enrolamento resistir à circulação de uma corrente contínua. [7]

O rotor é a estrutura rotativa de uma máquina elétrica. $O$ ensaio de medição de sua resistência de isolamento avalia o tipo e a condição em que se encontra o material isolante, bem como da técnica utilizada na aplicação deste material para construção das estruturas que compõe o enrolamento.

O sistema de isolamento elétrico do enrolamento do rotor de uma máquina síncrona, conforme descrito em [4], é dividido em três subsistemas. São eles: o isolamento da bobina e de seus acessórios, o isolamento das conexões e suportes do enrolamento, e as demais partes associadas à estrutura do rotor.

$\mathrm{O}$ isolamento da bobina compreende todos os materiais isolantes que envolvem os condutores e seus componentes como fios e dobras, formando o isolamento entre esses materiais e a estrutura da máquina. Esse isolamento inclui a fita de blindagem, os cordões elétricos, as faixas de ranhura e o isolamento caracterizado pelo corpo dos pólos.

$\mathrm{O}$ isolamento das conexões e suportes do enrolamento inclui todos os materiais isolantes que envolvem as conexões entre as bobinas, e entre as bobinas e o circuito externo, como também o isolamento dos suportes metálicos do enrolamento.

As demais partes associadas a estrutura do rotor completam o sistema de isolamento. São elas: os anéis coletores, os suportes não metálicos do enrolamento e as bordas terminais. 
$\rightarrow$ Objetivo do ensaio.

Este ensaio visa obter informações sobre o estado em que o material isolante se encontra, podendo indicar se a estrutura rotativa da máquina está em condições de ser submetida aos ensaios dielétricos.

$\rightarrow$ Método do ensaio.

Como descrito para o enrolamento do estator, neste ensaio também utiliza-se um megôhmetro para fazer a medição da resistência de isolamento. Este aparelho utiliza uma fonte de corrente contínua e possui um amperímetro e um multímetro integrados, indicando diretamente o valor do quociente entre a tensão aplicada e a corrente que passa através do enrolamento.

A medição da resistência de isolamento constitui um teste de aplicação de uma tensão contínua, sendo essa, restrita a um valor apropriado para cada tipo de enrolamento. Ao contrário do enrolamento estatórico, no rotor este ensaio é realizado quando todas as estruturas da máquina já estejam devidamente montada e conectadas.

A tensão de aplicação deve sempre ser ajustada para cada tipo de enrolamento em teste. A tabela 3.1 mostra os valores adequados da tensão de aplicação de acordo com o valor nominal da tensão do enrolamento.

Para a máquina em estudo, utilizou-se a tensão de $1000 \mathrm{~V}$ em corrente contínua. A aplicação da tensão deve ser feita entre o enrolamento e metal do eixo do rotor, com todos os outros equipamentos externos conectados a mesma malha de aterramento. Para evitar o efeito da polarização, a leitura deve ser tomada após um minuto da aplicação da tensão.

Concluídas as leituras e desligado o megôhmetro, conectar à terra o enrolamento sob ensaio para descarga e deixar no mínimo quatro vezes o tempo de duração do ensaio.[7]

Para a realização do ensaio deve-se utilizar o circuito esquematizado a seguir: 


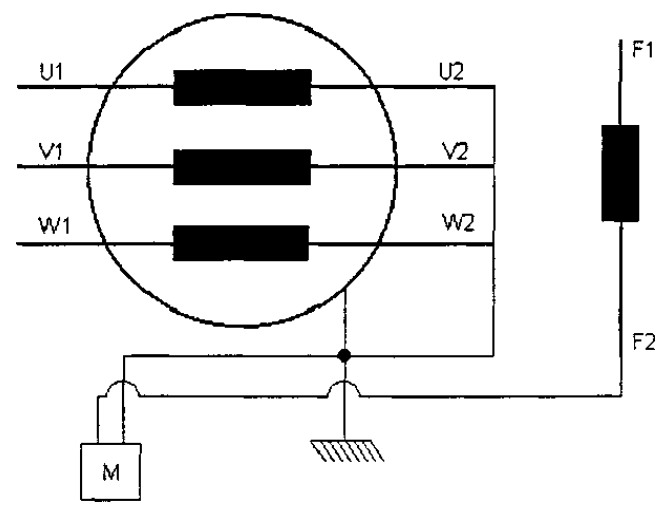

Figura 3.8: Esquema de ligação para medição da resistência de isolamento do rotor.

Legenda:

F1/F2 Enrolamento do rotor submetido ao ensaio.

U, V, W Fases do estator.

M Megôhmetro.

Após a obtenção dos resultados, deve-se efetuar uma avaliação dos valores obtidos seguindo os mesmos critérios descritos para o enrolamento do estator, ou seja, o ensaio é considerado satisfatório quando a resistência do isolamento medida, corrigida para a temperatura de $40^{\circ} \mathrm{C}$, for maior ou igual ao nível do isolamento (em kV) somando-se a unidade, dado pela equação (3.4).

Se o enrolamento apresentar baixo valor, recomenda-se abrir uma conexão entre pólos no meio do enrolamento, e medir a resistência de isolamento de cada metade. Caso as duas metades apresentem valores de resistência de isolamento próximos, existe grande probabilidade de ser umidade excessiva. Deve-se girar a máquina e secá-la através da circulação de ar. Opção final seria girar a máquina em curto circuito permanente, tomando-se o cuidado de não elevar demais a tensão de campo. Caso contrário, ou seja, se os valores forem discrepantes, devem-se efetuar 
novas divisões e medições no lado com problema, até se identificar o(s) pólo(s) com problema. Remover o pólo problemático e secá-lo em estufa.

$\rightarrow$ Análise dos resultados.

Os resultados obtidos para a resistência de isolamento do rotor, para uma temperatura de ensaio de $27^{\circ} \mathrm{C}$, são descritos na tabela 3.6 abaixo.

Tabela 3.6: Resultado do ensaio da resistência de isolamento do rotor, para $27^{\circ} \mathrm{C}$.

\begin{tabular}{|c|c|}
\hline Tempo & $\begin{array}{c}\text { Resistência isolamento } \\
(\mathrm{M} \Omega)\end{array}$ \\
\hline 1 min. & 1650 \\
\hline Temp. de medição $\left({ }^{\circ} \mathrm{C}\right)$ & 27 \\
\hline
\end{tabular}

Para evitar o efeito da temperatura é recomendado que todas as medidas da resistência de isolamento sejam corrigidas para uma base comum de temperatura, em $40^{\circ} \mathrm{C}$.

A conversão é feita com base na equação (3.2). Os valores da resistência de isolamento do rotor, corrigidos para a temperatura de base, são descritos na tabela 3.7.

Tabela 3.7: Resultado do ensaio da resistência de isolamento do rotor, para $40^{\circ} \mathrm{C}$.

\begin{tabular}{|c|c|}
\hline Tempo & $\begin{array}{c}\text { Resistência isolamento } \\
(\mathrm{M} \Omega)\end{array}$ \\
\hline $1 \mathrm{~min}$. & 670 \\
\hline Temperatura Base $\left({ }^{\circ} \mathrm{C}\right)$ & 40 \\
\hline
\end{tabular}

Avaliando os resultados obtidos, aplicando o mesmo critério de avaliação descrito para o ensaio no enrolamento do estator pela equação 3.4, tem-se: 


$$
R_{U V W}=670 M \Omega>\left(V_{\text {aparelho }}(k V)+1\right)
$$

Portanto o ensaio de medição da resistência de isolamento do enrolamento de campo foi considerado satisfatório, pois o resultado está dentro do especificado em norma e pode-se dizer que o material isolante utilizado na construção do isolamento está em ótimas condições.

\subsubsection{Ensaio de tensão aplicada no enrolamento do Rotor.}

O ensaio de tensão aplicada deve ser realizado obrigatoriamente após a conclusão do ensaio de medição da resistência de isolamento. Sendo o resultado do isolamento um pré-requisito para o início do ensaio.

O local de realização pode ser a área de montagem da usina, durante a instalação das estruturas da unidade geradora, ou no poço do gerador, quando toda estrutura da máquina já esteja montada e conectada. Isso depende do contrato feito entre o fabricante e o comprador. No caso da máquina em estudo, este ensaio foi realizado no poço do gerador com todas as estruturas da máquina conectadas.

$\rightarrow$ Objetivo do ensaio.

Este ensaio visa avaliar a integridade e desempenho do dielétrico da estrutura do rotor, quando submetido a tensões acima da nominal.

$\rightarrow$ Método do ensaio.

O valor da tensão de ensaio, aplicada no enrolamento do rotor, em corrente alternada, é de dez vezes a tensão nominal do enrolamento com um valor mínimo de $1500 \mathrm{~V}$, na freqüência industrial $(60 \mathrm{~Hz})$, de acordo com [9], tendo como base as suas características nominais. 
Para a máquina em estudo, utilizou-se o mesmo aparelho descrito anteriormente no ensaio no enrolamento do estator, o HIPOT.

Caso não exista fonte CA disponível, pode-se utilizar tensão contínua. Entretanto, de acordo com a norma [10] o valor aplicado deve ser 1,7 vez maior que o valor especificado em corrente alternada, ou seja,

$$
V_{C C}=1,7 x\left(10 x V_{f}\right)
$$

onde

$V_{C C}$ : Tensão de aplicação em corrente contínua.

$V_{f}$ : Tensão nominal do enrolamento do rotor.

O ensaio em CA deve ser iniciado com uma tensão que não exceda a metade do valor da tensão total aplicada, ou seja, menor que $\frac{10 x V_{f}}{2}$. Então, deve-se elevar o valor da tensão a uma velocidade suficientemente pequena para garantir grande acurácia nos valores medidos, mais não muito pequena para não causar stress na máquina durante o ensaio. Quando o valor da tensão atingir o especificado, deve-se permanecer neste nível por um minuto, sendo então reduzida a zero volt. Essa redução não pode ser imediata, para não causar uma mudança brusca no transitório da máquina, podendo causar danos na estrutura do enrolamento. [8]

Em caso de repetição do ensaio ou quando os enrolamentos não são novos, o valor da tensão a ser utilizado é $85 \%$ do valor acima indicado. [4]

No ensaio em tensão contínua deve-se elevar o valor da tensão em degraus monitorando-se a corrente de fuga, que deve permanecer em valores baixos, evitando assim o acúmulo de cargas no dielétrico.

Após o final do teste, conforme descrito em [10], a máquina deve permanecer aterrada por um tempo quatro vezes maior que o de ensaio

Para a realização do ensaio utilizou-se o circuitos esquematizado a seguir: 


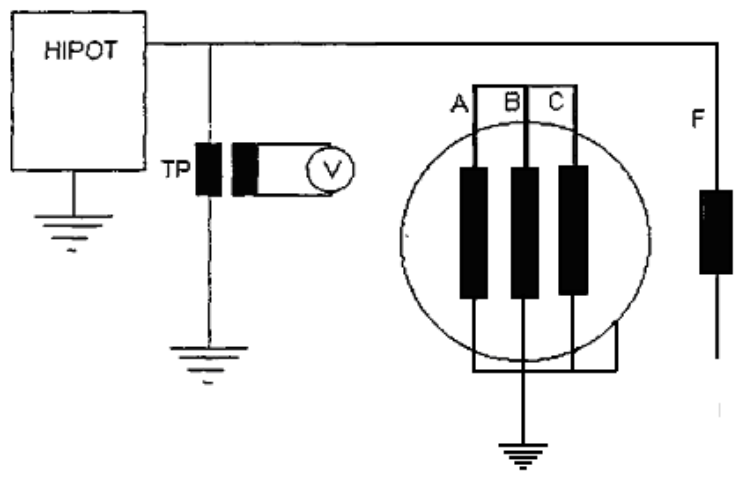

Figura 3.9: Esquema de ligação para ensaio com tensão alternada no enrolamento de campo.

Legenda:

$\begin{array}{ll}\text { HIPOT } & \text { HIPOT para ensaio em tensão alternada; } \\ \text { TP } & \text { Transformador de potencial; } \\ \text { V } & \text { Voltímetro CA; } \\ \text { A, B e C } & \text { Fases do estator; } \\ \text { F } & \text { Enrolamento do rotor. }\end{array}$

Para o ensaio em corrente contínua, deve-se utilizar o esquemático descrito da figura 3.10.

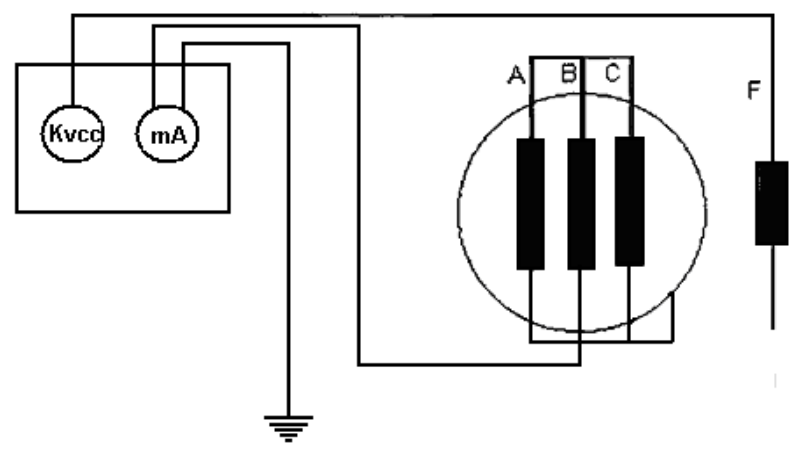

Figura 3.10: Esquema de ligação do ensaio com tensão contínua no enrolamento de campo. 
Legenda:
A, B e C
Fases do estator.
$\mathrm{F}$
Enrolamento do rotor.
$\mathrm{mA}$
Miliamperimetro.

Para que os resultados obtidos sejam considerados satisfatórios, não deve ocorrer descarga entre o enrolamento energizado e os demais itens aterrados.

$\rightarrow$ Análise dos resultados.

Neste ensaio utilizou-se um transformador de potencial (TP), com as mesmas características do TP utilizado no ensaio do estator, para realizar o monitoramento da tensão aplicada.

De acordo com [4], considera-se satisfatório a realização do ensaio de tensão aplicada no enrolamento de campo se no decorrer da aplicação da tensão, nenhuma evidência de distúrbio ou falha no isolamento for observada.

Para a máquina em estudo, sabendo que a tensão nominal do enrolamento do rotor é $173 \mathrm{~V}$, tem-se que a tensão de teste em CA é dada por:

$$
V_{C A}=10 x(173)=1730 \mathrm{~V}
$$

O resultado do ensaio foi considerado satisfatório, pois durante o tempo de aplicação da tensão, nenhuma descarga elétrica foi evidenciada. Assim, pode-se considerar que o enrolamento de campo está em ótimas condições de operação. 


\subsubsection{Medição da resistência ôhmica do enrolamento de campo.}

A medição da resistência ôhmica é considerada como ensaio de rotina e deve ser realizado sempre antes dos ensaios dinâmicos.

Analogamente aos ensaios realizados no rotor, a medição da resistência ôhmica do enrolamento de campo deve ser realizada no poço do gerador, quando todas as estruturas da máquina já tiverem devidamente montadas.

$\rightarrow$ Objetivo do ensaio.

Este ensaio visa obter a resistência ôhmica dos enrolamentos, a qual poderá ser usada para calcular as perdas no enrolamento de campo $\left(I_{f}{ }^{2} R_{f}\right)$, e determinar a componente ativa da queda de tensão interna em carga. Além disso, é importante sua comparação com o valor especificado em projeto.

$\rightarrow$ Método do ensaio.

Analogamente ao ensaio no enrolamento de armadura, para a medição da resistência ôhmica do enrolamento de campo existem diferentes métodos de medição. A escolha do melhor método depende da natureza do circuito formado pelo enrolamento da máquina em teste e do grau de acurácia que se deseja obter com a medição.

De acordo com [12], e tendo como base as características do enrolamento de campo, como o valor de projeto ser inferior a $5 \Omega$, tem-se que os dois métodos utilizados são o método da corrente e tensão, e o método da ponte de Thomson.

Para os dois métodos, deve-se monitorar a temperatura do enrolamento, pois de acordo com [6], o aumento da temperatura do enrolamento não deve ultrapassar $1 K$ durante a realização do ensaio. Se o monitoramento da temperatura não for feito, o valor da corrente, que passa pelo enrolamento em teste, não deve ultrapassar $10 \%$ do valor da corrente nominal do enrolamento e o tempo de aplicação não deve ser maior que 1 minuto. 
De acordo com [13], pode-se determinar o valor da resistência em carga para determinação da temperatura do rotor estabilizada. Neste caso é aplicável o método da corrente e tensão, onde se mede a resistência com os anéis coletores. E o rotor é exposto em um ambiente, com temperatura constante, por um tempo suficientemente longo para que toda sua estrutura permaneça na mesma temperatura.

Para um melhor entendimento dos dois métodos utilizados para a medição da resistência ôhmica dos enrolamentos da máquina síncrona em estudo, uma breve descrição será feita.

- Método da corrente e tensão.

Esse método consiste em fazer circular uma corrente contínua, que pode ser ajustada através de um reostato ligado em série com a fonte CC e o enrolamento, medindo-se a queda de tensão nos terminais do enrolamento. Com alterações no valor do reostato obtêm-se diferentes valores de corrente e tensão. O valor da corrente não deve ultrapassar a $10 \%$ da corrente nominal do enrolamento, sendo suficiente para garantir uma perda pequena que não irá causar uma significativa mudança na temperatura do enrolamento durante o tempo de aplicação.

De acordo com [6], devem-se efetuar no mínimo três medições de resistência ôhmica com valores de correntes diferentes. $O$ valor a ser considerado é a média das medições. No caso de valor discrepante, ou seja, que diferem de $\pm 0,01$ do valor da média em pu, recomenda-se não considerá-lo e repetir a medição.

O esquema de ligação do método é descrito na figura 3.11 a seguir. 


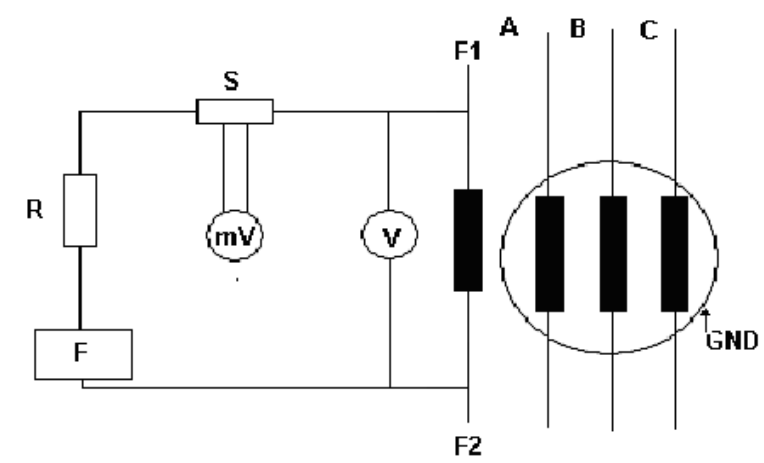

Figura 3.11: Esquemático do método corrente e tensão para o enrolamento de campo.

Legenda:

$\begin{array}{ll}\mathrm{F} & \text { Fonte de corrente continua. } \\ \mathrm{V} & \text { Voltímetro. } \\ \mathrm{mV} & \text { Milivoltimetro. } \\ \mathrm{S} & \text { Shunt. } \\ \mathrm{R} & \text { Reostato variável. }\end{array}$

F1 / F2 Enrolamento sob teste.

- Método da Ponte de Thomson.

Neste método utilizou-se o mesmo aparelho descrito no ensaio realizado no estator, ou seja, a Ponte dupla de Kelvin. O valor da resistência é obtido diretamente no aparelho.

Analogamente ao método da corrente e tensão, ao utilizar o método da ponte, é necessário realizar no mínimo três medições da resistência ôhmica. Para isso, deve-se modificar o balanço da ponte, isto é, o valor da corrente de medição deve ser modificado diretamente no aparelho. $O$ valor a ser considerado é a média das três diferentes medidas. 
Ao determinar o valor médio, o valor da resistência em cada medição que diferir de $\pm 0,01$ desse valor médio calculado, deve ser desconsiderado e uma nova medição é realizada.

Para a realização do ensaio de medição da resistência ôhmica do enrolamento de campo, o seguinte circuito deve ser montado com as devidas conexões.

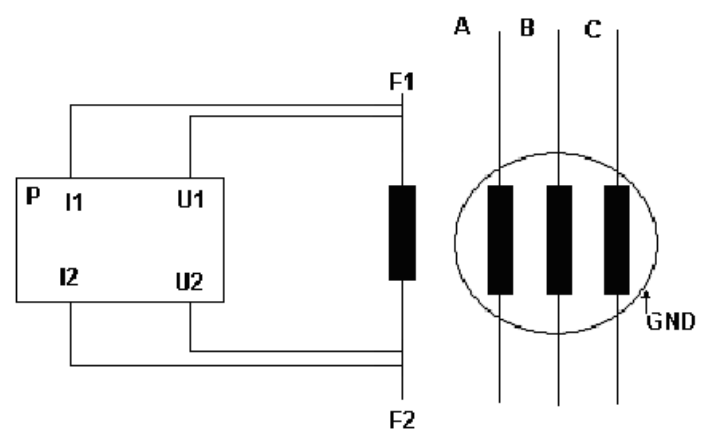

Figura 3.12: Esquemático do método da ponte de Thomson para o enrolamento de campo.

Legenda:
P Ponte de Thomson.
F1/F2 Enrolamento sob teste.

O valor da resistência ôhmica medido é considerado satisfatório, se não diferir mais que $10 \%$ em relação ao valor de projeto.

$\rightarrow$ Análise dos resultados.

Para a máquina em estudo, utilizou-se para a medição da resistência ôhmica do enrolamento de campo o método da ponte de Thomson. Conforme descrição do método, foram realizadas três medições com os seguintes valores de corrente, $10,0 \mathrm{~A}, 7,5 \mathrm{~A}$ e $5,0 \mathrm{~A}$. 
Os resultados obtidos para os diferentes valores de corrente, juntamente com a média, são descritos na tabela 3.8.

Tabela 3.8: Valores medidos da resistência ôhmica do enrolamento de campo.

\begin{tabular}{|c|c|}
\hline Corrente (A) & Resistência Ôhmica $(\Omega)$ \\
\hline 10,00 & 0,112880 \\
\hline 7,50 & 0,112880 \\
\hline 5,00 & 0,112920 \\
\hline Média & 0,112890 \\
\hline Temp. de Medição & $28,96{ }^{\circ} \mathrm{C}$ \\
\hline
\end{tabular}

Sabendo que o valor de projeto da resistência ôhmica do enrolamento de campo é $0,11400 \Omega$, pode-se calcular a diferença entre esse valor e o valor coletado em campo.

$$
\Delta R_{f}=R_{f_{\text {projeto }}}-R_{f_{\text {médio }}}=0,11400-0,112890=1,1 \times 10^{-3} \Rightarrow \Delta R_{f}=1 \% .
$$

Baseando no critério de avaliação, do resultado encontrado acima, pode-se concluir que o ensaio de medição da resistência ôhmica do enrolamento de campo foi considerado satisfatório. O valor da resistência coletado em campo não ultrapassou a tolerância de $10 \%$ em relação ao valor de projeto, ficando bem abaixo. 


\subsection{Ensaios Dinâmicos}

Depois de concluída a fase de ensaios estáticos, com a correta verificação dos valores obtidos para os parâmetros da máquina, deve-se efetuar a segunda parte de testes na unidade geradora. Entende-se por ensaios dinâmicos, todos os testes realizados quando a máquina se encontra em movimento (giro mecânico).

Antes de iniciar esta etapa, devem-se efetuar algumas preparações para garantir o correto funcionamento do gerador nessa fase de comissionamento. Por exemplo, verificar se as escovas estão instaladas corretamente, ajustar as proteções de corrente para não atuarem durante o ensaio e verificar se o regulador de velocidade está operando satisfatoriamente, garantindo assim uma rotação constante.

\subsubsection{Ensaio a vazio.}

Em uma máquina síncrona, conforme descrito no capítulo 2, a tensão induzida no enrolamento de armadura é proporcional a velocidade de rotação da máquina e ao fluxo de excitação, sendo esse último dependente da corrente de campo que circula no enrolamento do rotor. Variando-se a corrente de campo, temse uma variação na tensão induzida.

Inicialmente a tensão aumenta linearmente com o aumento da corrente de campo. Quando o valor da corrente cresce consideravelmente, percebe-se o efeito da saturação do circuito magnético, pois o fluxo produzido não cresce mais linearmente com o aumento da corrente.

Para efeito de comparação, a figura 3.13 mostra a característica teórica da máquina síncrona em estudo [2]. 


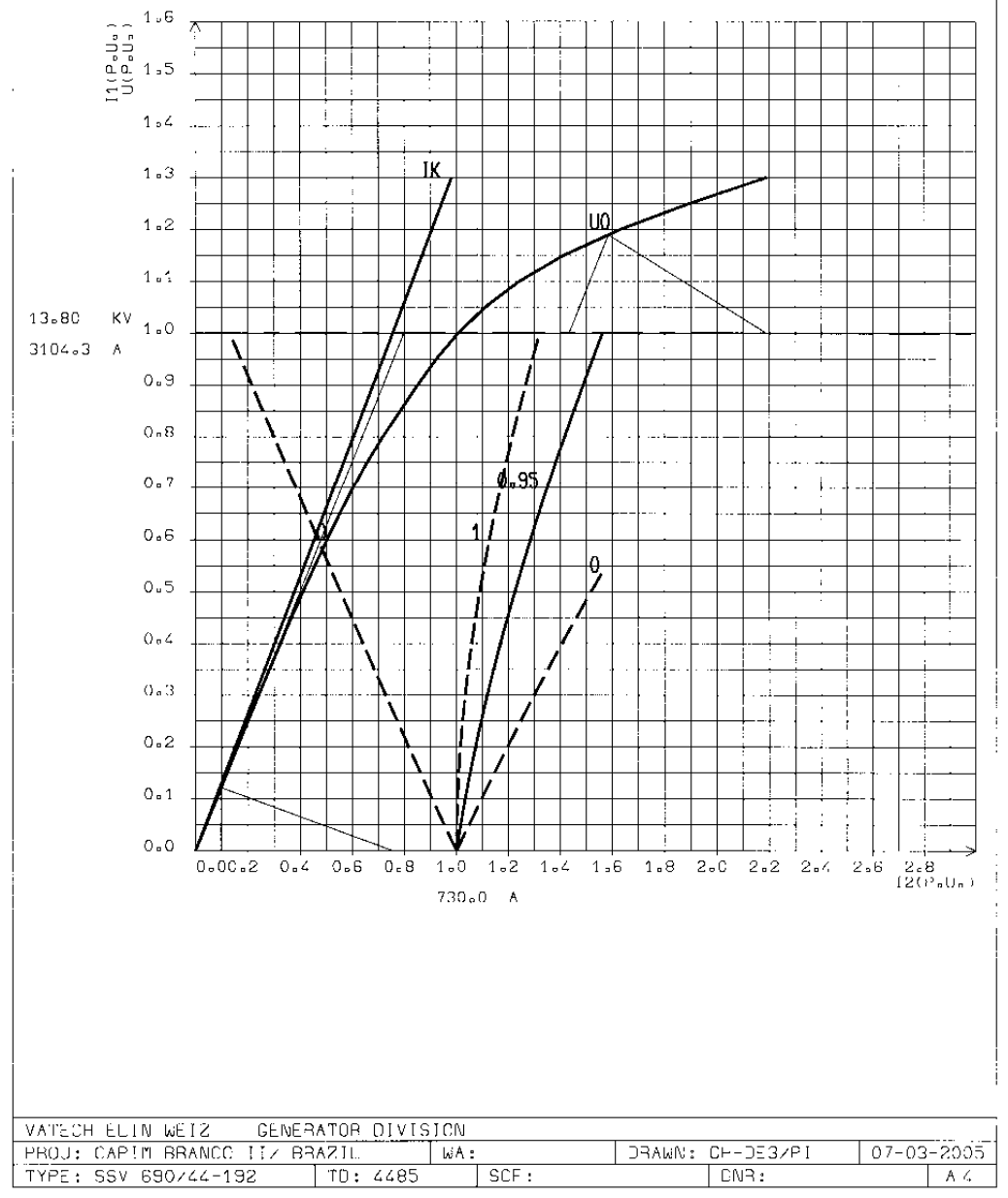

Figura 3.13: Característica teórica do Gerador Síncrono W42.

A determinação de uma das características do gerador síncrono, a característica a vazio, é um dos principais ensaios realizados em uma máquina elétrica. $\mathrm{O}$ objetivo, a metodologia e a análise dos resultados coletados em campo serão descritos a seguir.

$\rightarrow$ Objetivo do ensaio.

Este ensaio visa determinar a característica de saturação da máquina síncrona, além de permitir a determinação da reatância síncrona de eixo direto não 
saturada. Além disso, permite-se comparar as características encontradas em campo com os valores específicos de projeto.

$\rightarrow$ Método do ensaio.

Com os terminais da máquina abertos, eleva-se a rotação da mesma até seu valor nominal (velocidade síncrona), mantendo-se esta constante, durante todo o ensaio.

Alterna-se gradualmente a excitação (independente), em degraus, variando os valores da tensão induzida na armadura desde $0,2 * E_{f}$ até $1,2 * E_{f}$, mede-se a tensão e corrente de excitação, utilizando-se para tanto um multímetro digital. Durante o levantamento da curva, em que a corrente de excitação é sempre acrescida, pode ocorrer de ultrapassar o ponto de medição desejada, neste caso deve-se efetuar a leitura no valor em que estiver ajustado. No caso de dúvida de algum ponto medido anteriormente, recomenda-se iniciar novamente o ensaio. [13]

Quando a corrente de excitação é reduzida a zero, a tensão residual que permanece no circuito magnético do gerador é então medida.

É possível, então, traçar a característica de saturação à vazio da máquina, onde a abscissa é a corrente de excitação $\left(I_{f}\right)$ e a ordenada a tensão induzida no enrolamento de armadura $\left(E_{f}\right)$. Se a tensão residual medida apresentar um valor elevado, faz-se necessário uma correção. Deve-se prolongar a parte reta da curva, chamada de linha de entreferro, até a sua intersecção com o eixo das abscissas, o que ocorre do lado direito do eixo das ordenadas. O comprimento do segmento de eixo das abscissas, limitado pela intersecção do eixo com o prolongamento da curva até o ponto zero, representa o valor da correção a ser somado a todos os valores medidos da corrente de excitação.

Para a realização do ensaio deve-se utilizar o circuito esquematizado a seguir. 


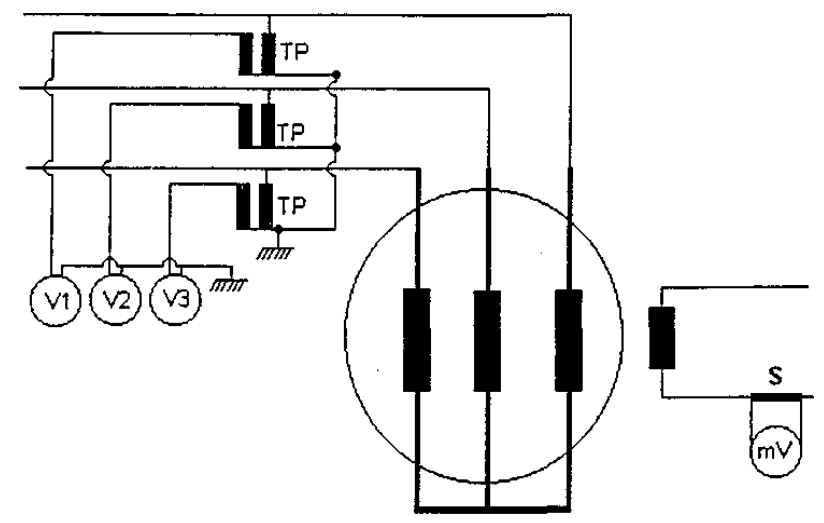

Figura 3.14: Esquemático para o levantamento da característica à vazio.

Legenda:

$\begin{array}{ll}\text { TP } & \text { Transformador de potencial. } \\ \text { V1,V2 e V3 } & \text { Voltímetro de CA. } \\ \mathrm{S} & \text { Shunt. } \\ \mathrm{mV} & \text { Milivoltímetro CC. }\end{array}$

Conforme descrito no esquemático, utiliza-se TPs para realizar as medições da tensão induzida em cada fase do enrolamento de armadura. A corrente de excitação é monitorada pelo circuito de excitação independente caracterizado pelo Shunt.

$\rightarrow$ Análise dos resultados.

Para a máquina em estudo, a tabela 3.9 mostra os resultados obtidos em campo para o ensaio a vazio. 
Tabela 3.9: Dados do ensaio à vazio coletados em campo.

\begin{tabular}{|c|c|c|c|c|c|c|}
\hline \multirow{2}{*}{$\begin{array}{l}E_{f}(\%) \\
\text { Teórico }\end{array}$} & \multicolumn{4}{|c|}{ Tensão nos terminais $\left(E_{f}\right)$} & \multirow{2}{*}{$\begin{array}{c}\begin{array}{c}\text { Corrente } \\
\text { Excitação }\end{array} \\
I_{f} \\
\text { (A) }\end{array}$} & \multirow{2}{*}{$\begin{array}{c}\begin{array}{c}\text { Tensão } \\
\text { de }\end{array} \\
\text { excitação }\end{array}$} \\
\hline & $\begin{array}{c}\text { Fase } \\
\text { A } \\
\text { (medido) }\end{array}$ & $\begin{array}{c}\text { Fase } \\
\text { B } \\
\text { (medido) }\end{array}$ & $\begin{array}{c}\text { Fase } \\
\text { C } \\
\text { (medido) }\end{array}$ & $\begin{array}{c}E_{f} \text { média } \\
\text { (calculada) }\end{array}$ & & \\
\hline 119,80 & 16535,1 & 16534,7 & 16528,7 & 16532,8 & 1074,53 & 132,18 \\
\hline 109,56 & 15121,6 & 15121,9 & 15113,9 & 15119,1 & 818,47 & 101,16 \\
\hline 99,43 & 13723,5 & 13723,4 & 13716,3 & 13721,1 & 667,49 & 83,02 \\
\hline 89,35 & 12333,2 & 12333,1 & 12326,5 & 12330,9 & 564,05 & 70,46 \\
\hline 79,66 & 10994,7 & 10995,9 & 10988,3 & 10993,0 & 484,85 & 60,80 \\
\hline 68,91 & 9511,5 & 9512,6 & 9505,1 & 9509,7 & 407,55 & 51,38 \\
\hline 58,75 & 8109,6 & 8110,6 & 8102,9 & 8107,7 & 339,88 & 43,09 \\
\hline 49,05 & 6767,8 & 6769,5 & 6770,6 & 6769,3 & 278,03 & 35,33 \\
\hline 39,19 & 5406,2 & 5409,2 & 5409,6 & 5408,3 & 217,85 & 27,93 \\
\hline 29,11 & 4015,6 & 4018,9 & 4018,1 & 4017,5 & 159,15 & 20,61 \\
\hline 19,82 & 2736,1 & 2736,2 & 2733,7 & 2735,3 & 105,81 & 13,68 \\
\hline 9,83 & 1356,1 & 1356,8 & 1356,0 & 1356,3 & 49,38 & 6,54 \\
\hline 1,78 & 246,0 & 246,3 & 246,0 & 246,1 & 0 & 0 \\
\hline
\end{tabular}

A partir dos dados coletados no ensaio à vazio, descritos na tabela 3.9, consegue-se construir a característica a vazio da máquina síncrona em estudo. As curvas da figura 3.15 mostram claramente a parte linear e o efeito da saturação do circuito magnético da máquina.

Conforme mencionado anteriormente, devido a um valor alto de tensão residual, isto é, $V_{\text {residual }}=246,1 \mathrm{~V}$, faz-se necessário uma correção. Essa correção é feita a partir da intersecção da parte linear da curva, linha de entreferro, com o eixo das abscissas na sua parte negativa. O comprimento do segmento do eixo das abscissas até a intersecção com o eixo das ordenadas representa o valor da correção. 


\section{Característica à vazio}

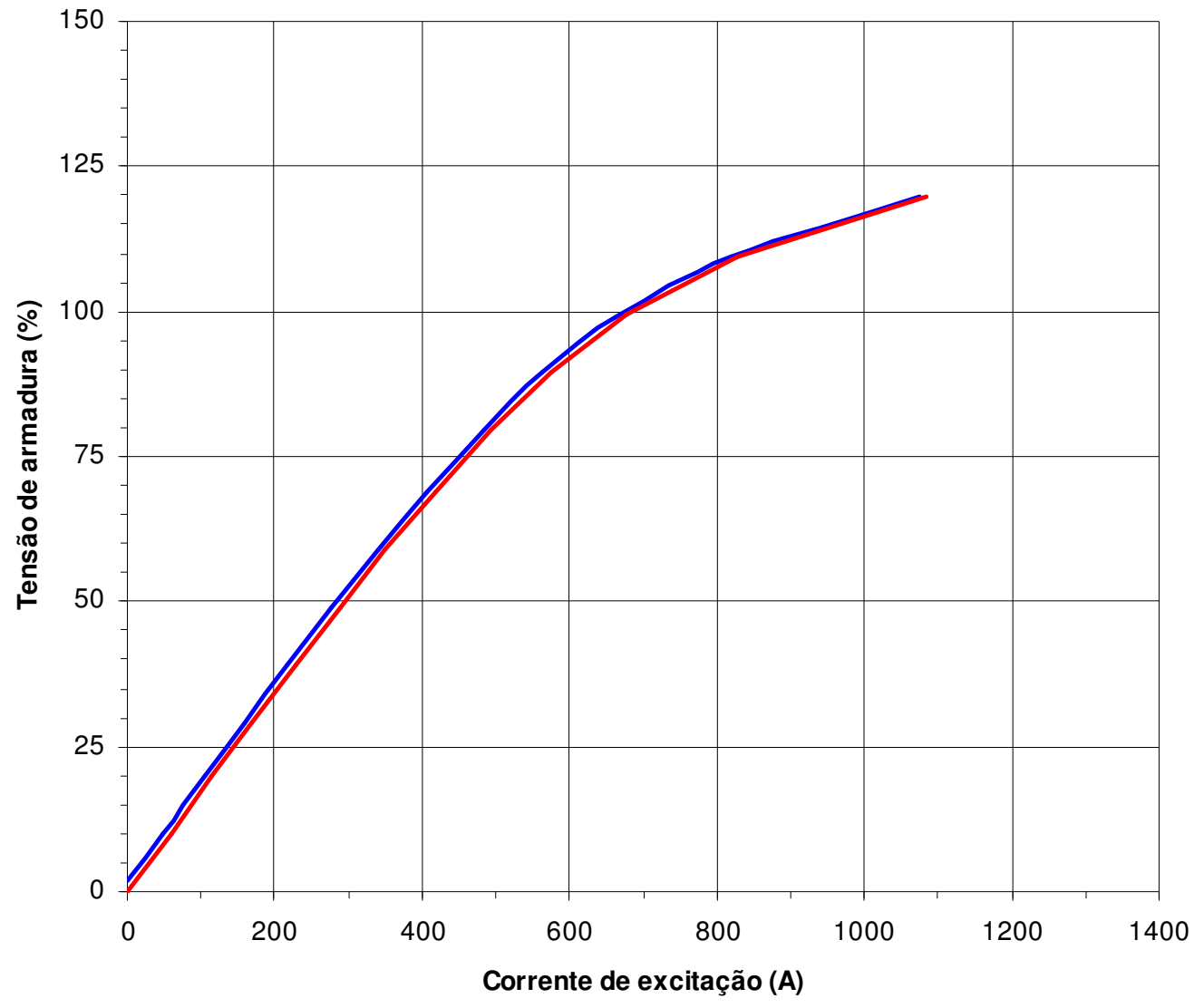

—Característica à vazio —C Característica à vazio corrigida

Figura 3.15: Característica de saturação a vazio.

Primeiramente, define-se a linha de entreferro, pegando os pontos da parte linear da curva em azul. Fazendo uma regressão linear, obtêm-se o gráfico da figura 3.16 . 
Linha de entreferro

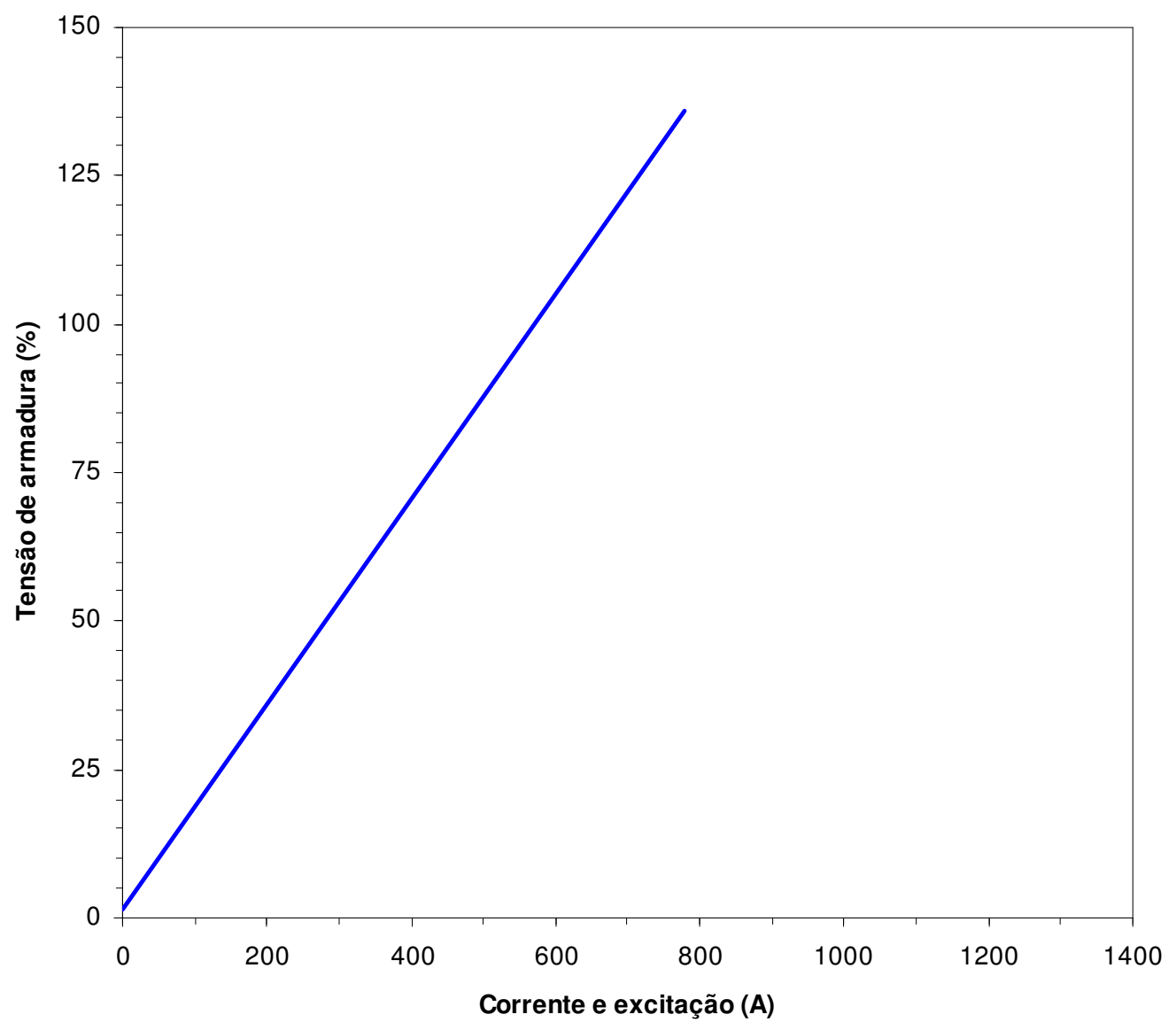

Figura 3.16: Linha de entreferro.

A equação da linha de entreferro é dada por:

$$
E_{f}=23,62 I_{f}+231,2[V]
$$

Da equação (3.7) acima, encontra-se o valor da corrente de excitação referente à tensão residual da seguinte forma:

$$
E_{f}=23,62 I_{f}+231,2 \quad \text { sendo } \quad E_{f}=0 \Rightarrow \Delta I_{f}=\frac{-231,2}{23,62}=-9,78 \mathrm{~A}
$$


A correção feita em todos os valores da corrente de excitação para se obter a curva característica a vazio corrigida é $\Delta I_{f}=-9,78 \mathrm{~A}$.

Da curva característica à vazio corrigida, obtêm-se a seguinte relação entre a tensão nominal a vazio e a corrente de excitação.

$$
E_{f}=13800 \mathrm{~V} \Rightarrow I_{f}=682,1 \mathrm{~A}
$$

\subsubsection{Ensaio em curto-circuito.}

O ensaio de curto-circuito é caracterizado pela relação entre a corrente de excitação e a corrente que circula nos enrolamentos de armadura, quando os terminais da máquina são curto-circuitados. Essa variação é obtida movendo a máquina pela ação da turbina, com a abertura do distribuidor, isto é, as paletas que separam a caixa espiral e as pás da turbina.

$\rightarrow$ Objetivo do ensaio.

Este ensaio visa determinar a característica de curto-circuito da máquina síncrona, além de permitir a determinação da reatância síncrona de eixo direto não saturada $\left(X_{d n}\right)$ e a relação de curto-circuito $\left(K_{c}\right)$.

$\rightarrow$ Método do ensaio.

Após o fechamento do curto-circuito, eleva-se a rotação da máquina até seu valor nominal, mantendo-se esta constante durante todo o ensaio. Se por alguma perturbação a velocidade de rotação da máquina durante o decorrer do ensaio diferir da velocidade nominal, recomenda-se que a diferença não ultrapasse os 20\%. [6] 
De acordo com [13], as leituras das correntes devem ser feitas decrescendo o valor da excitação, começando com um valor que produzirá uma máxima corrente de armadura permitida, isto é, $120 \%$ da corrente nominal do enrolamento.

Alternando gradualmente a excitação (independente), em degraus, alternamse os valores de corrente de armadura. Inicia-se subindo o valor de corrente de armadura para a $1,2 x I_{a}$ e posteriormente reduz-se em degraus de $0,1 x I_{a}$ até a corrente remanescente, medindo-se e anotando-se, ponto a ponto, a corrente de excitação, a tensão nos terminais do gerador e a corrente de armadura. Assim é possível traçar a característica de curto-circuito da máquina, onde a abscissa é a corrente de excitação $\left(I_{f}\right)$ e a ordenada a corrente de armadura $\left(I_{a}\right)$.

Para realização do ensaio deve-se utilizar o circuito esquematizado na figura 3.17. Para a medição das correntes de armadura, utiliza-se um transformador de corrente (TC) conectado em cada fase. E para o monitoramento da tensão, utiliza-se TPs.

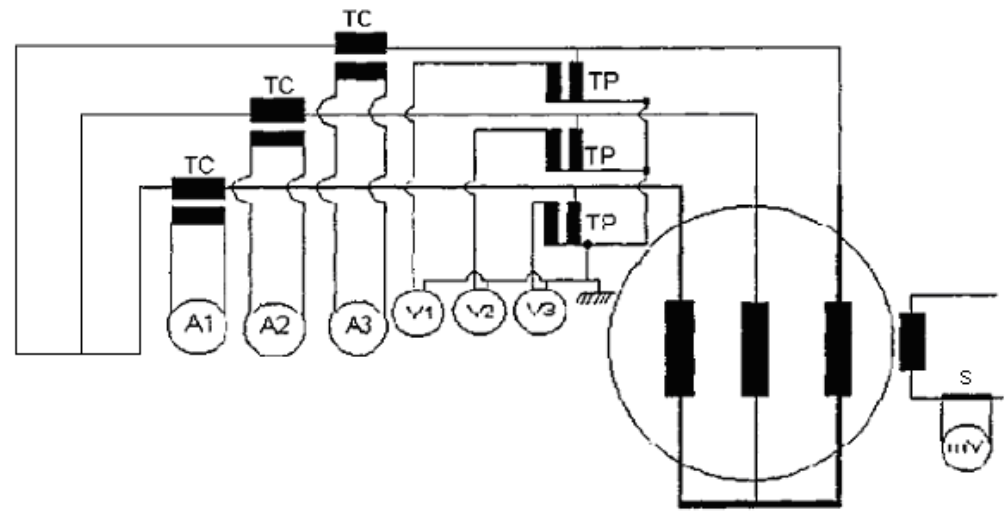

Figura 3.17: Esquemático para o levantamento da característica em curto-circuito.

Legenda:
A1, A2 e A3 Amperímetro de CA.
TC
Transformador de corrente.
TP
Transformador de potencial. 
V1, V2 e V3 Voltímetro de CA.

S Shunt.

$\mathrm{mV} \quad$ Milivoltimetro CC.

$\rightarrow$ Análise dos resultados.

Os dados coletados do ensaio em curto-circuito são descritos na tabela 3.10.

Tabela 3.10: Dados do ensaio em curto-circuito coletados em campo.

\begin{tabular}{|c|c|c|c|c|c|c|}
\hline \multirow{2}{*}{$\begin{array}{l}I_{a}(\%) \\
\text { Teórico }\end{array}$} & \multicolumn{4}{|c|}{ Corrente de Armadura } & \multirow{2}{*}{$\begin{array}{c}\begin{array}{c}\text { Corrente } \\
\text { Excitação }\end{array} \\
I_{f}(\mathrm{~A})\end{array}$} & \multirow{2}{*}{$\begin{array}{c}\begin{array}{c}\text { Tensão } \\
\text { Excitação }\end{array} \\
V_{f}(\mathrm{~V})\end{array}$} \\
\hline & $\begin{array}{l}\text { Fase A } \\
\text { (medido) }\end{array}$ & $\begin{array}{l}\text { Fase B } \\
\text { (medido) }\end{array}$ & $\begin{array}{l}\text { Fase C } \\
\text { (medido) }\end{array}$ & $\begin{array}{c}I_{a} \text { media } \\
\text { calculada }\end{array}$ & & \\
\hline 120,25 & 3732,21 & 3735,84 & 3731,05 & 3733,03 & 678,70 & 83,44 \\
\hline 111,49 & 3460,15 & 3463,70 & 3459,28 & 3461,04 & 623,60 & 77,04 \\
\hline 100,21 & 3110,17 & 3113,29 & 3109,29 & 3110,92 & 557,95 & 69,12 \\
\hline 90,26 & 2801,41 & 2804,10 & 2800,60 & 2802,04 & 501,11 & 62,32 \\
\hline 80,39 & 2495,09 & 2497,46 & 2494,19 & 2495,58 & 445,04 & 55,69 \\
\hline 69,11 & 2144,89 & 2147,08 & 2144,28 & 2145,42 & 381,53 & 48,01 \\
\hline 60,67 & 1882,85 & 1884,78 & 1882,29 & 1883,31 & 334,14 & 42,33 \\
\hline 50,63 & 1571,35 & 1573,00 & 1570,90 & 1571,75 & 278,21 & 2441 \\
\hline 31,15 & 966,78 & 967,84 & 966,47 & 967,03 & 170,91 & 22,24 \\
\hline 26,23 & 814,07 & 814,96 & 813,87 & 814,30 & 142,80 & 18,72 \\
\hline 18,05 & 560,15 & 560,82 & 560,09 & 560,35 & 97,92 & 12,86 \\
\hline 9,72 & 301,81 & 302,12 & 301,72 & 301,88 & 51,57 & 6,91 \\
\hline 1,33 & 41,24 & 41,30 & 41,24 & 41,26 & 0,00 & 0,00 \\
\hline
\end{tabular}

A partir dos dados descritos na tabela acima, consegue-se construir a característica de curto-circuito do gerador síncrono em estudo. A figura 3.18 contempla essa característica. 


\section{Característica de curto-circuito}

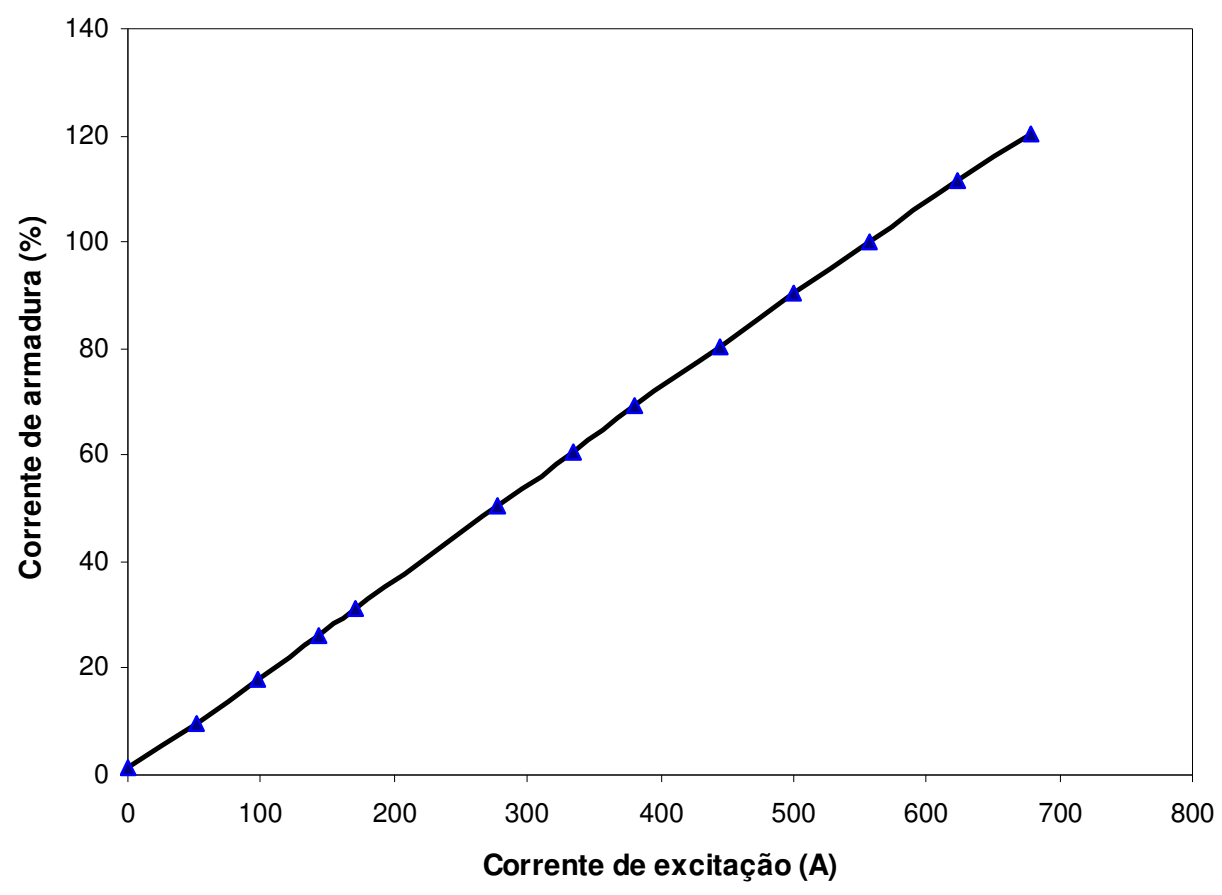

Figura 3.18: Curva característica de curto-circuito.

Pela construção da característica de curto-circuito nota-se uma linearidade. Isso se explica pelo fato de que nas condições de curto-circuito, o circuito magnético não sofre saturação, pois o fluxo no entreferro permanece em nível baixo.

A reatância do eixo direto nâo saturada $\left(X_{d n}\right)$ da máquina síncrona é definida como a relação entre a tensão (nominal) e a corrente de armadura obtida com a mesma corrente de campo no ensaio em curto-circuito.

A partir da curva característica de curto-circuito obtêm-se a seguinte equação linear, em pu:

$$
I_{a}=0,001772 I_{f}+0,010846[p u]
$$


Logo,

$$
I_{a}=3104,3 \mathrm{~A} \quad \Rightarrow \quad I_{f_{c c}}=558,2 \mathrm{~A}
$$

A partir da equação linear da linha de entreferro obtida no ensaio a vazio, tem-se:

$$
E_{f}=23,62 I_{f}+231,2[V]
$$

Para $E_{f}=13800 \mathrm{~V}$ :

$$
13800=23,62 I_{f}+231,2 \quad \Rightarrow \quad I_{f}=\frac{13.568,8}{23,62}=574,46 \mathrm{~A}
$$

Portanto, a reatância de eixo direto não-saturada é dada por:

$$
X_{d n}=\frac{558,2}{574,46}=0,97 p u
$$

A relação de curto-circuito é determinada a partir da característica a vazio e da característica em curto-circuito como o quociente entre a corrente de excitação correspondendo a valor nominal de tensão da curva à vazio e a corrente de excitação correspondendo a um valor nominal de corrente de armadura da curva em curto-circuito. Portanto,

$$
K_{c}=\frac{I_{f o}}{I_{f c}}
$$

Para a curva em curto-circuito: $I_{a}=0,001772 I_{f}+0,010846$, para $I_{a}=1 \mathrm{pu}$ temse: 


$$
1=0,001772 I_{f}+0,010846 \Rightarrow I_{f c}=558,2 \mathrm{~A}
$$

Para uma tensão nominal de $13800 \mathrm{~V}$, da curva de saturação à vazio tem-se um valor de corrente de excitação igual a $I_{f o}=684,1 \mathrm{~A}$.

Logo,

$$
K_{c}=\frac{684,1}{558,2}=1,22 p u
$$

Comparando com os valores de projeto descritos no capítulo 2, o resultado do ensaio em curto-circuito pode ser considerado satisfatório, pois os valores obtidos para a reatância de eixo direto e para a relação de curto circuito possuem uma diferença de menos de $10 \%$ dos valores específicos de projeto, como se pode ver pelos cálculos abaixo.

- Reatância eixo direto:

$$
\Delta X_{d}=X_{\text {d projeto }}-X_{d}=0,947-0,97=0,023 \Rightarrow \Delta X_{d}=2,4 \%
$$

- Relação de curto-circuito:

$$
\Delta R_{c}=R_{\text {c projeto }}-R_{c}=1,32-1,22=0,10 \Rightarrow \Delta R_{c}=7,5 \%
$$

Concluído os ensaios a vazio e em curto-circuito, a caracterização da máquina em estudo é descrita pela figura 3.19. 


\section{Características Gerador W42}

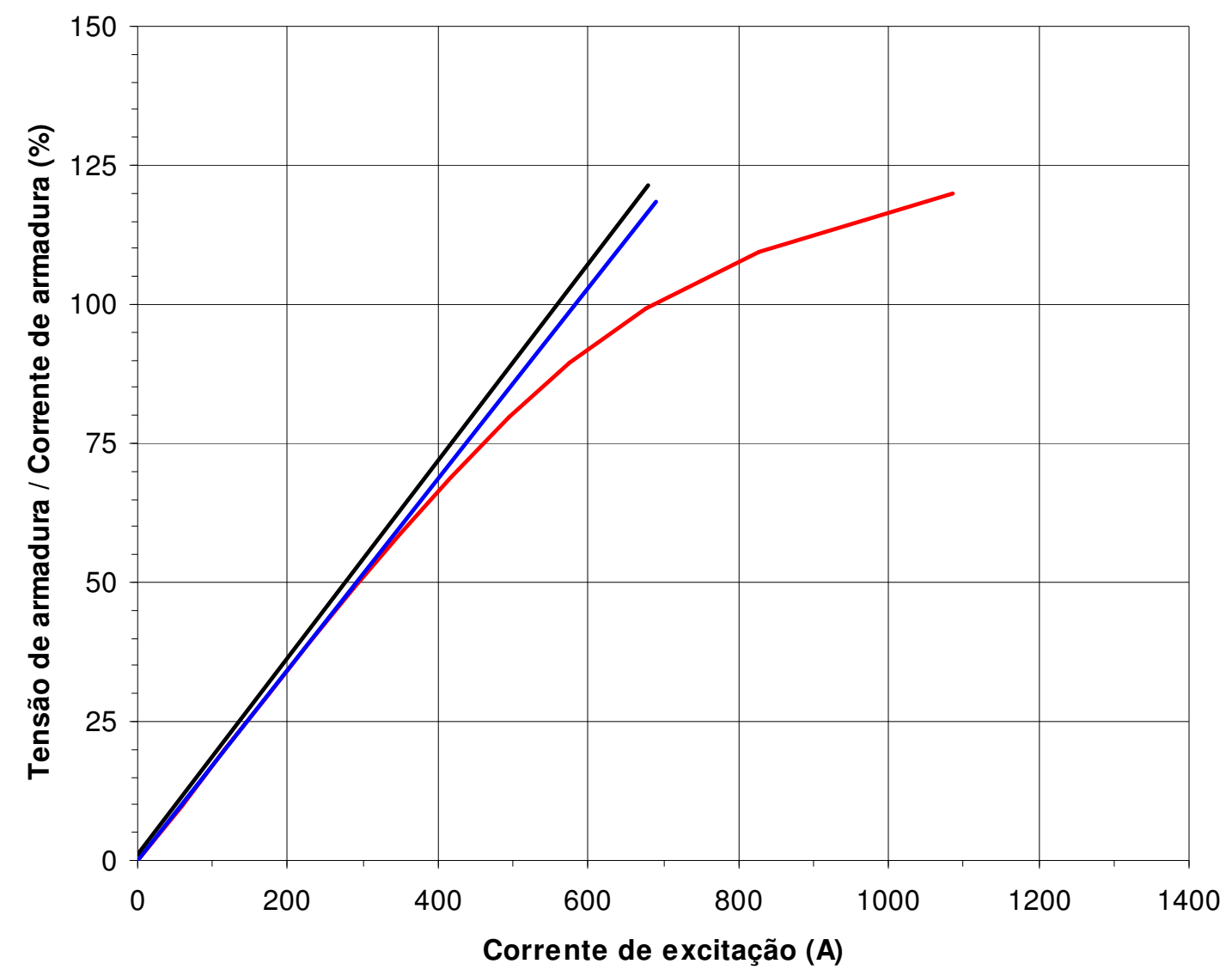

Figura 3.19: Caracterização do gerador W42.

Do gráfico, interpreta-se que a curva em vermelho é a característica a vazio, a curva em azul é a característica em curto-circuito e a curva em preto é a linha de entreferro. 


\subsubsection{Verificação da seqüência de fase.}

A seqüência de fase define a ordem em que a tensão de fase alcança o seu máximo valor positivo nos terminais de uma máquina trifásica, e deve estar de acordo com o especificado entre o fornecedor da máquina e o comprador.

Geralmente, a seqüência de fase especificada em projeto é dada em uma seqüência de três letras, como DCE (direita, centro, esquerda) ou ECD (esquerda, centro, direita), definida por um observador olhando para os terminais do lado de fora da máquina. Em casos em que os terminais estejam localizados na parte superior ou inferior da máquina, a seqüência de fases é definida olhando para o extremo da máquina, perto dos terminais, em direção ao eixo da mesma.

$\rightarrow$ Objetivo do ensaio.

Este ensaio visa determinar se a seqüência de fases marcada nos terminais do gerador está de acordo com o especificado no projeto.

$\rightarrow$ Método do ensaio.

Antes de começar o ensaio deve-se certificar se os valores das resistências de isolamento dos enrolamentos, anel coletor e porta escovas e se a polaridade dos transformadores de potencial, assim como suas ligações nos barramentos, está dentro do especificado, pois qualquer erro pode implicar em seqüência inversa.

De acordo com [13], existem dois métodos para realizar a verificação da seqüência de fases. São eles, o método do seqüencímetro e o método da indicação de diferença de potencial.

Os dois métodos são descritos a seguir.

- Método 1: Seqüencímetro.

No ensaio em vazio, após obtenção do ponto máximo da curva, na curva de descida, ajusta-se a tensão nominal para verificação da seqüência de fases por meio da conexão de um seqüencímetro nos terminais secundários dos TPs. 
A conexão do aparelho ao TP deve ser feita com bastante cuidado, pois devese observar a convenção adotada para as marcas de polaridade feita nos TPs. [14]

Para a realização do ensaio com o seqüencímetro deve-se utilizar o circuito esquematizado a seguir:

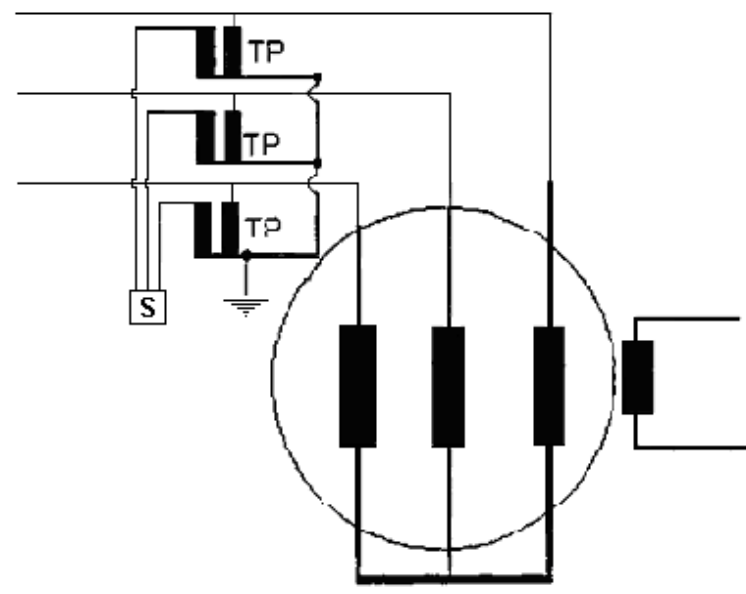

Figura 3.20: Esquemático para verificação da seqüência de fase.

Legenda:

S Seqüencímetro;

TP Transformador de potencial.

- Método 2: Indicação de diferença de potencial.

Este método verifica se a máquina está na mesma seqüência de fases do sistema elétrico em que está conectada com a utilização de lâmpadas indicativas conectadas ao secundário dos TPs.

A máquina deve ser acelerada e a excitação deve ser aplicada correspondendo à tensão nominal de operação. Quando a velocidade de rotação da máquina estiver próxima a velocidade síncrona, as lâmpadas conectadas aos TPs irão acender ou permanecer apagadas simultaneamente se a máquina estiver em 
fase com a rede. Se as lâmpadas acenderem uma depois da outra ou permanecerem apagadas, quer dizer que a máquina está na seqüência oposta.

$\rightarrow$ Análise dos resultados.

Para a máquina em estudo, utilizou-se o método do seqüencímetro para a verificação da seqüência de fase.

Para um observador posicionado enfrente aos terminais da máquina, a visão das fases do enrolamento do estator é $A B C$. O valor especificado no projeto, ou seja, a seqüência de três letras é DCE (direita, centro, esquerda).

Assim, o ensaio de verificação da seqüência de fase foi validado, pois o seqüencímetro confirmou a seqüência de fase sendo $A B C$, conforme especificado em projeto.

\subsubsection{Ensaio de rejeição de carga ativa.}

Para um bom funcionamento de um gerador síncrono, é necessário que as suas estruturas estejam corretamente equilibradas. As conexões e encaixes entre as partes elétricas e mecânicas devem estar em perfeita harmonia, juntamente com os equipamentos de regulagem, como o Regulador de Velocidade (RV) e o Regulador de Tensão (RT).

O ensaio de rejeição de carga é realizado, principalmente, para garantir que as conexões e suportes da máquina não se desequilibrem com uma mudança brusca de carga, com a atuação do RV e RT. Pois na rejeição a máquina tende a disparar, e o RV, mais rápido, atua desexcitando a máquina até chegar ao ponto de tensão nominal à vazio. E também o RT, mais lento, atua fechando o distribuidor $e$ retornando a máquina para a velocidade nominal à vazio. 
$\rightarrow$ Objetivo do ensaio.

O ensaio de rejeição de carga objetiva, principalmente, equilibrar a velocidade de fechamento do distribuidor quando a máquina tende a disparar (sobrevelocidade) com a mudança repentina do valor da carga, dentro de valores admissíveis. Como verificações secundárias são avaliados os níveis de oscilação de pressão no eixo, mancais e conduto forçado; os ajustes finos do RV e RT; os níveis de sobretensão e a respectiva seletividade com o sistema de proteção além do desempenho do Sistema Digital de Supervisão e Controle (SDSC).

$\rightarrow$ Método do ensaio.

Primeiramente sincroniza-se a máquina ao sistema elétrico de potência. Uma vez conectada a unidade ao sistema com mínima carga, testa-se a estabilidade e resposta do $\mathrm{RV}$ e do $\mathrm{RT}$.

Existe uma dificuldade de se atingir as condições nominais de operação sem extrapolar os limites máximos dos parâmetros da unidade. Com isso, incrementa-se a carga até atingir os patamares de 25\%,50\%,75\% e 100\% da capacidade nominal de potência ativa do gerador ou outro valor determinado pelo fabricante da turbina e em comum acordo com o operador do sistema.

Em cada patamar, a rejeição é realizada com a abertura de disjuntores simulando uma perda abrupta de carga. Registram-se os parâmetros elétricos máximos e mínimos atingidos, como tensão e corrente de armadura, tensão e corrente de excitação e os valores das potências ativas e reativas.

Quanto às possíveis avarias causadas pelo aumento na aceleração durante o ensaio, o gerador é inspecionado para verificar sua integridade mecânica, se houve algum desprendimento de peças, rompimento de alguma vedação, entre outros fatores.

Para a realização do ensaio deve-se utilizar o circuito esquematizado a seguir. 


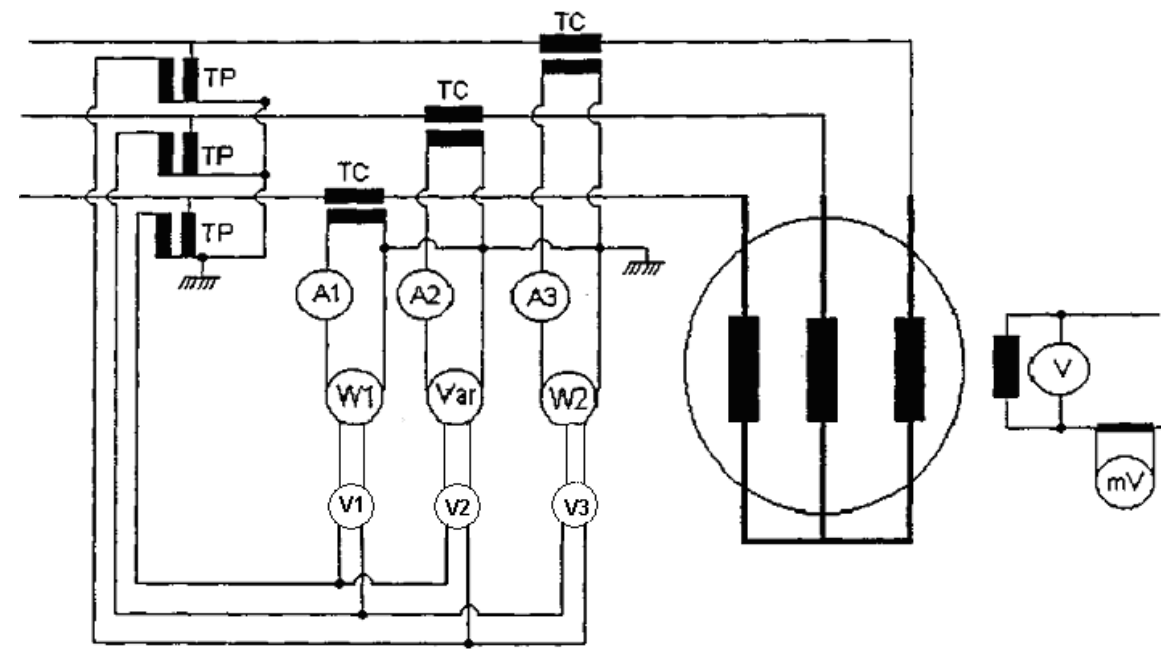

Figura 3.21: Esquemático de ligação do ensaio de rejeição de carga.

Legenda:

$\begin{array}{ll}\text { V1, V2 e V3 } & \text { Voltímetro de CA. } \\ \text { A1, A2 e A3 } & \text { Amperímetro de CA. } \\ \text { TC } & \text { Transformador de corrente } \\ \text { TP } & \text { Tranformador de potencial } \\ \text { W1,W2 e var } & \text { Wattímetro. } \\ \text { S } & \text { Shunt. } \\ \text { V } & \text { Voltímetro de CC. } \\ \text { mV } & \text { Milivoltímetro CC. }\end{array}$

Os resultados são considerados satisfatórios se os reguladores, RV e RT, atuarem dentro dos valores e tempos de resposta projetados, e se o gerador não apresentar nenhuma avaria. Quanto aos parâmetros elétricos medidos, estipulam-se níveis toleráveis de variação entre os valores máximos e mínimos.

$\rightarrow$ Análise dos resultados.

Os resultados obtidos para o ensaio de rejeição de carga são descritos na tabela 3.11, para os diferentes valores de carga. 
Tabela 3.11: Dados do ensaio de rejeição de carga.

\begin{tabular}{|l|c|c|c|c|c|c|c|c|}
\hline \multicolumn{1}{|c|}{ Carga } & \multicolumn{2}{|c|}{$25 \%$} & \multicolumn{2}{c|}{$50 \%$} & \multicolumn{2}{c|}{$75 \%$} & \multicolumn{2}{c|}{$100 \%$} \\
\hline \multicolumn{1}{|c|}{ Parâmetros } & Máximo & Mínimo & Máximo & Mínimo & Máximo & Mínimo & Máximo & Mínimo \\
\hline $\begin{array}{l}\text { Freqüência } \\
\text { [Hz] }\end{array}$ & 70,852 & 58,912 & 77,32 & 58,92 & 83,41 & 59,0 & 86,68 & 59,08 \\
\hline $\begin{array}{l}\text { Tensão } \\
\text { Estator [V] }\end{array}$ & 14324,1 & 14155,4 & 14438,1 & 13833 & 14360,3 & 13448,0 & 14714,1 & 13611,3 \\
\hline $\begin{array}{l}\text { Tensão } \\
\text { Rotor [V] }\end{array}$ & 97,77 & 63,65 & 102,75 & 41,78 & 108,27 & 23,98 & 133,09 & $-25,43$ \\
\hline $\begin{array}{l}\text { Corrente } \\
\text { Rotor [A] }\end{array}$ & 762,02 & 547,46 & 812,09 & 479,89 & 843,73 & 427,98 & 1012,54 & 420,74 \\
\hline $\begin{array}{l}\text { Corrente } \\
\text { Estator [A] }\end{array}$ & 774,69 & 9,45 & 1457,56 & 5,79 & 2187,13 & 5,78 & 2815,39 & 5,43 \\
\hline $\begin{array}{l}\text { Potência } \\
\text { Ativa [kW] }\end{array}$ & 19138,3 & 81,31 & 36129,5 & 65,35 & 53916,1 & 54,86 & 70241,4 & 53,30 \\
\hline $\begin{array}{l}\text { Potência } \\
\text { Aparente } \\
\text { [kVA] }\end{array}$ & 19153,9 & 232,08 & 36146,5 & 174,42 & 54145,5 & 134,91 & 70291,5 & 127,44 \\
\hline $\begin{array}{l}\text { Potência } \\
\text { Reativa } \\
\text { [kVar] }\end{array}$ & 2881,56 & $-1067,2$ & 398,83 & $-1269,9$ & 393,61 & $-5475,5$ & 2845,26 & 113,27 \\
\hline $\begin{array}{l}\text { Fator } \\
\text { Potência }\end{array}$ & 1,00 & 0,268 & 1,00 & 0,242 & 0,996 & 0,210 & 0,999 & 0,185 \\
\hline
\end{tabular}

Para uma análise quantitativa dos resultados obtidos no ensaio de rejeição de carga o ideal seria fazer uma comparação entre os valores máximos medidos e os valores nominais de operação dos parâmetros significativos para este tipo de teste. Como não foram coletados os valores antes da rejeição, considera-se satisfatório a análise feita a partir dos valores máximos e mínimos.

Os parâmetros significativos para este tipo de ensaio são a freqüência de operação e a tensão de armadura. A variação máxima tolerável entre os valores máximos e mínimos para estes parâmetros são estipulados de acordo com o tipo de acoplamento e montagem das estruturas que interligam o conjunto gerador-turbina.

Para a máquina em estudo tem-se: 
- Freqüência.

A variação máxima tolerável é de $60 \%$. Dos resultados obtidos para os diferentes patamares tem-se:

$\rightarrow$ Carga $25 \%$

$$
\Delta f=f_{\max }-f_{\min }=70,852-58,912=11,94 \Rightarrow \Delta f=20 \%
$$

$\rightarrow$ Carga $50 \%$

$$
\Delta f=f_{\text {max }}-f_{\text {min }}=77,32-58,92=18,4 \Rightarrow \Delta f=31 \%
$$

$\rightarrow$ Carga $75 \%$

$$
\Delta f=f_{\max }-f_{\min }=83,41-59,00=\Rightarrow \Delta f=41 \%
$$

$\rightarrow$ Carga $100 \%$

$$
\Delta f=f_{\max }-f_{\min }=86,68-59,08=\Rightarrow \Delta f=46 \%
$$

- Tensão de armadura.

A variação máxima tolerável é de $8 \%$. Dos resultados obtidos para os diferentes patamares tem-se:

$\rightarrow$ Carga 25\%.

$$
\Delta V=V_{\max }-V_{\min }=14324,1-14155,4=168,7 \Rightarrow \Delta V=1,2 \%
$$

$\rightarrow$ Carga $50 \%$.

$$
\Delta V=V_{\max }-V_{\min }=14438,1-13833=605,1 \Rightarrow \Delta V=4,4 \%
$$

$\rightarrow$ Carga $75 \%$.

$$
\Delta V=V_{\max }-V_{\min }=14360,3-13448,0=912,3 \Rightarrow \Delta V=6,8 \%
$$


$\rightarrow$ Carga $100 \%$.

$$
\Delta V=V_{\text {max }}-V_{\text {min }}=14714,1-13611,3=1102,8 \Rightarrow \Delta V=8 \%
$$

Portanto, com os resultados dos cálculos das variações dos parâmetros significativos para o ensaio de rejeição e sabendo que o RT e RV atuaram nos tempos de respostas projetados, a avaliação para mais um ensaio de comissionamento da máquina em estudo é considerada satisfatória dentro dos limites projetados.

\subsubsection{Curva de Fator de Potência Zero e determinação da corrente de excitação nominal.}

Concluído os ensaios à vazio e em curto-circuito, realiza-se o ensaio de obtenção da Curva de Fator de Potência Zero e a determinação da corrente nominal de excitação.

$\rightarrow$ Objetivo do ensaio.

O ensaio de obtenção da Curva de Fator de Potência Zero visa determinar a reatância de dispersão magnética pelo método do Triângulo de Potier, juntamente com a determinação da corrente nominal de excitação pelo método do Diagrama ASA.

$\rightarrow$ Método do ensaio.

No ensaio de Fator de Potência Zero o gerador é carregado com uma carga idealmente indutiva com baixo valor de fator de potência. Para isso, inicia-se o sincronismo com a rede elétrica operando em uma tensão um pouco acima da tensão nominal assegurando a saturação do circuito magnético. 
De acordo com [16], geralmente não é necessário obter a Curva de Fator de Potência Zero por completo. Dois pontos são suficientes, sendo que o primeiro é obtido perto da tensão nominal de armadura, fazendo com que a potência ativa de saída seja aproximadamente zero com o ajuste do RV. E o segundo é obtido com as características em curto-circuito para uma tensão terminal zero.

A determinação do Triângulo de Potier é descrita abaixo.

- Triângulo de Potier.

Determina-se graficamente o Triângulo de Potier seguindo o gráfico descrito na figura 3.22 abaixo.

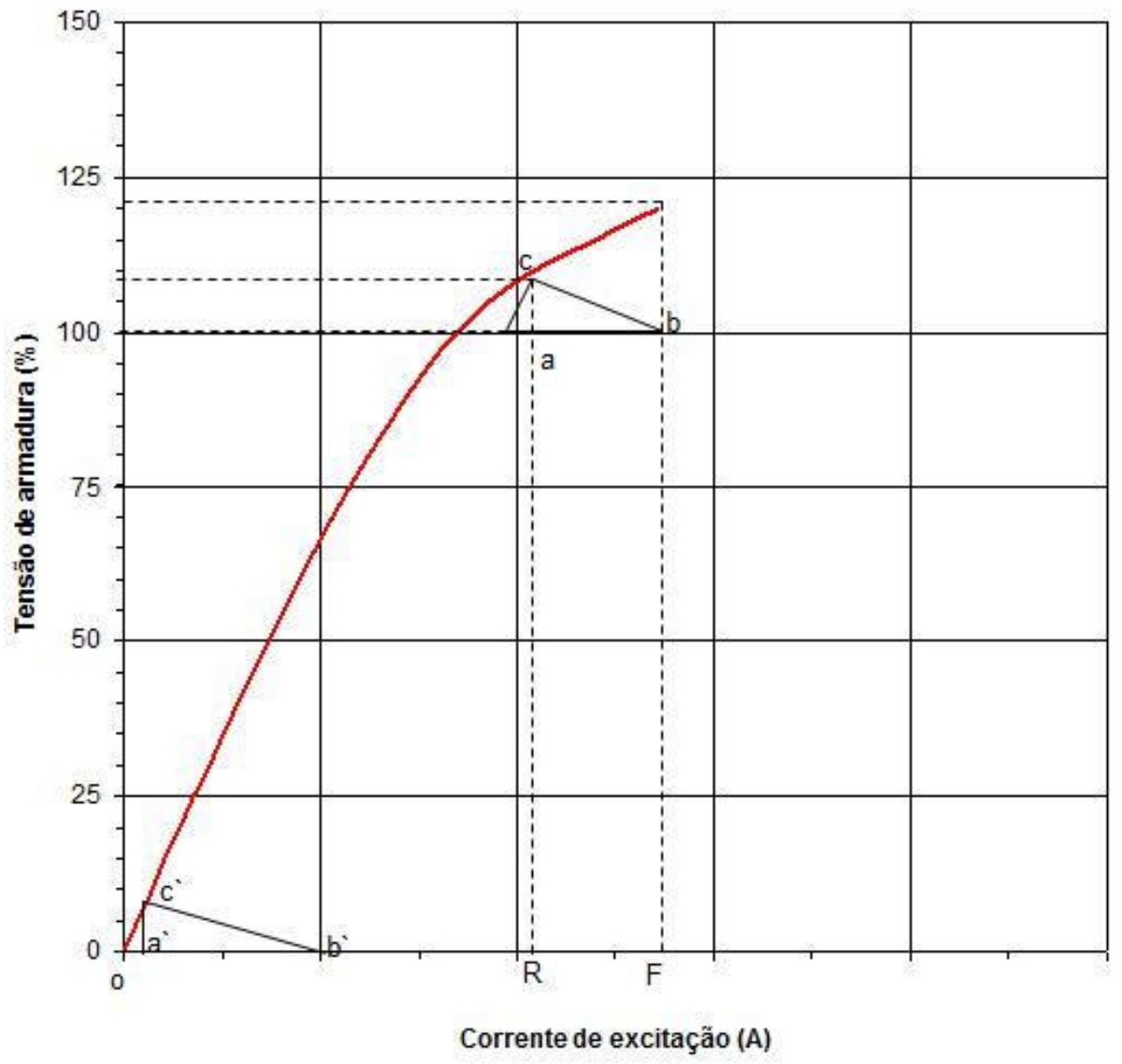

Figura 3.22: Determinação do Triângulo de Potier. 
Da figura 3.22 têm-se que o comprimento do seguimento OF é dado pela corrente de excitação necessária para gerar a tensão de excitação do modelo de circuito equivalente descrito pela figura 1.1. O seguimento RF é dado pela componente da corrente de excitação responsável por gerar a reação de armadura e o seguimento OR é dado pela componente da corrente de excitação responsável por produzir o fluxo de dispersão no entreferro.

O triângulo $a b c$ é conhecido como o Triângulo de Potier e sua altura $a c$ representa a queda de tensão pela Reatância de Potier $\left(X_{p}\right)$. Para uma dada corrente de armadura a base e a altura do triângulo é praticamente constante quando o efeito do fluxo de dispersão é considerado pequeno. Assim, consegue-se construir a Curva de Fator de Potência Zero pelo deslocamento do triângulo $a^{\prime} b^{\prime} c^{\prime}$ '(ponto com tensão terminal zero) até o triângulo $a b c$ (ponto de tensão nominal de armadura) ao longo da característica à vazio.

De acordo com [15], para uma máquina de pólos salientes tem-se que a reatância de Potier é 3 vezes o valor da reatância de dispersão.

Para a determinação da corrente nominal de excitação tem-se o seguinte método de cálculo.

- Diagrama ASA.

Para determinar a corrente de excitação nominal pelo método do Diagrama ASA, é necessário conhecer a característica à vazio, a característica em curtocircuito e a reatância de Potier.

A figura 3.23 descreve o método do Diagrama ASA. 


\section{Diagrama ASA}

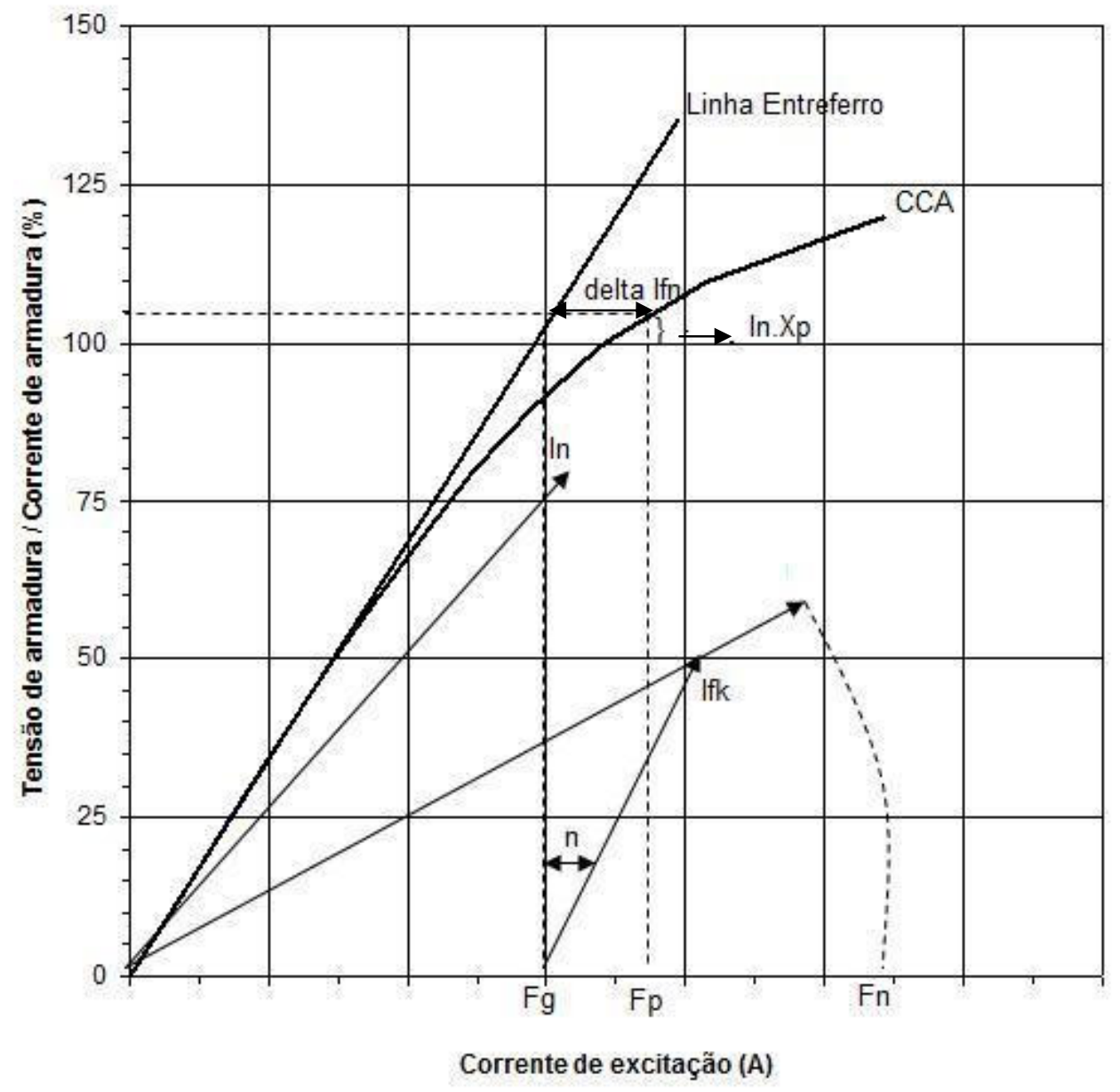

Figura 2.23: Diagrama ASA

Da figura 3.23 tem-se que o segmento $\mathrm{Fg}$ é o valor da corrente de excitação tirada da linha de entreferro para uma tensão nominal de excitação. O vetor $\overline{I f k}$ representa o valor da corrente de excitação obtida do ensaio em curto-circuito correspondente à corrente nominal de armadura e o ângulo $n$ é o ângulo de carga representado pelo fator de potência nominal de 0,95.

Pelo gráfico pode-se obter a corrente nominal de excitação pela seguinte equação: 


$$
I_{f n}=\Delta I_{f}+\sqrt{\left(I_{f g}+I_{f k} \sin \varphi_{n}\right)^{2}+\left(I_{f k} \cos \varphi_{n}\right)^{2}}
$$

onde

$\Delta I_{f}$ : Diferença entre a corrente de excitação da curva à vazio e da linha de entreferro.

$I_{f g}$ : Corrente de excitação tirada da linha de entreferro para uma tensão nominal de excitação.

$I_{f k}$ : Corrente de excitação para a corrente nominal de armadura tirada do ensaio em curto-circuito.

$\rightarrow$ Análise dos resultados.

Para a máquina em estudo, a tabela 3.12 descreve os resultados obtidos para o ensaio de fator de potência zero.

Tabela 3.12: Dados do ensaio de Fator de Potência Zero

\begin{tabular}{|c|c|c|}
\hline Tensão terminal (V) & Corrente de Excitação (A) & Fator de Potência \\
\hline 0 & 558,2 & 0,06876 \\
\hline 13843,9 & 846,00 & 0,10893 \\
\hline
\end{tabular}

O calculo da reatância de Potier é dada por:

$$
X_{p}=\frac{3450}{3104,3 x \sqrt{3}}=0,64 \Omega
$$

Sabendo que a impedância de base é $Z_{b}=2,56658 \Omega$ tem-se:

$$
X_{p}=\frac{0,64}{2,56658}=0,25 p u
$$




$$
\therefore X_{l}=\frac{0,25}{3}=0,08 p u
$$

Sabendo que a corrente de excitação determinada pelo ensaio em curtocircuito para uma corrente nominal de armadura é $I_{f k}=558,2 \mathrm{~A}$, que o valor da corrente de excitação determinada pela linha de entreferro é $I_{f g}=574,46$ A e que diferença entre a corrente de excitação da curva à vazio e da linha de entreferro é $\Delta I_{f}=16,26 A$, a corrente d excitação nominal pode ser obtida pela equação (3.10).

$$
\begin{gathered}
I_{f n}=16,26+\sqrt{(574,46+558,2 x 0,31)^{2}+(558,2 x 0,95)^{2}} \\
\therefore I_{f n}=932,75 A
\end{gathered}
$$

Sabendo que valor de projeto da corrente de excitação nominal é $I_{f_{\text {projeto }}}=1140,0 \mathrm{~A}$, e que o valor da resistência de dispersão é $X_{l \text { projeto }}=0,104 \mathrm{pu}$ pode-se calcular a diferença entre os valores de projeto e o valor calculado.

- $\Delta I_{f}=I_{f_{\text {projeto }}}-I_{f n}=1140,00-932,75=207,25 \Rightarrow \Delta I_{f}=18 \%$.

- $\Delta X_{l}=X_{\text {lprojeto }}-X_{l}=0,104-0,08=-0,02 \Rightarrow \Delta X_{l}=25 \%$

Baseando no critério de avaliação descrito em [6], do resultado encontrado acima, pode-se concluir que o cálculo da corrente de excitação nominal pelo método do Diagrama ASA foi considerado satisfatório, pois não ultrapassou a tolerância de $20 \%$ em relação ao valor de projeto. Já para a reatância de dispersão, o mesmo não pode ser concluído, pois o erro calculado ultrapassa a margem limite de $10 \%$ para esse parâmetro. Essa discrepância se deve, principalmente, na obtenção dos dados da curva de Fator de Potência Zero, em que no momento da medição os equipamentos não estavam devidamente calibrados. 


\section{EXEMPLO DE CÁLCULO DAS CARACTERÍSTICAS DO GERADOR}

Neste capítulo serão realizados os cálculos dos principais parâmetros do gerador síncrono em estudo utilizando os conceitos tratados em [16].

Inicia-se determinando a equação da linha de entreferro, como sendo:

$$
E_{f}=K_{a g} I_{f} \Rightarrow K_{a g}=\frac{E_{f}}{I_{f}}
$$

Escolhendo um ponto na parte linear da curva de saturação à vazio corrigida, tem-se:

$$
E_{f}=2735,3 \mathrm{~V} \rightarrow I_{f}=115,59 \mathrm{~A}
$$

Daí,

$$
K_{a g}=\frac{E_{f}}{I_{f}} \therefore \quad K_{a g}=\frac{2735,3}{115,59}=23,66 \mathrm{~V} / \mathrm{A} .
$$

Portanto a expressão matemática que descreve a parte linear da característica à vazio da máquina em estudo, considerando a correção da tensão residual do circuito magnético, é dada por:

$$
E_{f}=23,66 I_{f}
$$

Fazendo uma análise da curva de magnetização, pode-se obter uma expressão matemática para descrever o efeito físico da saturação. A expressão obtida tem a seguinte forma:

$$
I_{f}=\frac{E_{f}}{K_{a g}}+A_{x} e^{B_{x} E_{f}}
$$


O primeiro termo representa a parte linear da curva (linha de entreferro), e o segundo termo a parte exponencial que caracteriza a saturação magnética da máquina. Para encontrar os coeficientes desta expressão $\left(\begin{array}{lll}A_{x} & \text { e } & B_{x}\end{array}\right)$, devem-se utilizar os seguintes artifícios matemáticos.

Selecionam-se dois pontos que define melhor a análise.

Ponto a: $E_{f}=8107,7 \mathrm{~V} \rightarrow I_{f}=349,66 \mathrm{~A} \Rightarrow 6,98=A_{x} e^{B_{x} 8107,7}$

Ponto b: $E_{f}=16532,8 \mathrm{~V} \rightarrow I_{f}=1084,31 \mathrm{~A} \Rightarrow 385,54=A_{x} e^{B_{x} 16532,8}$

Característica à vazio

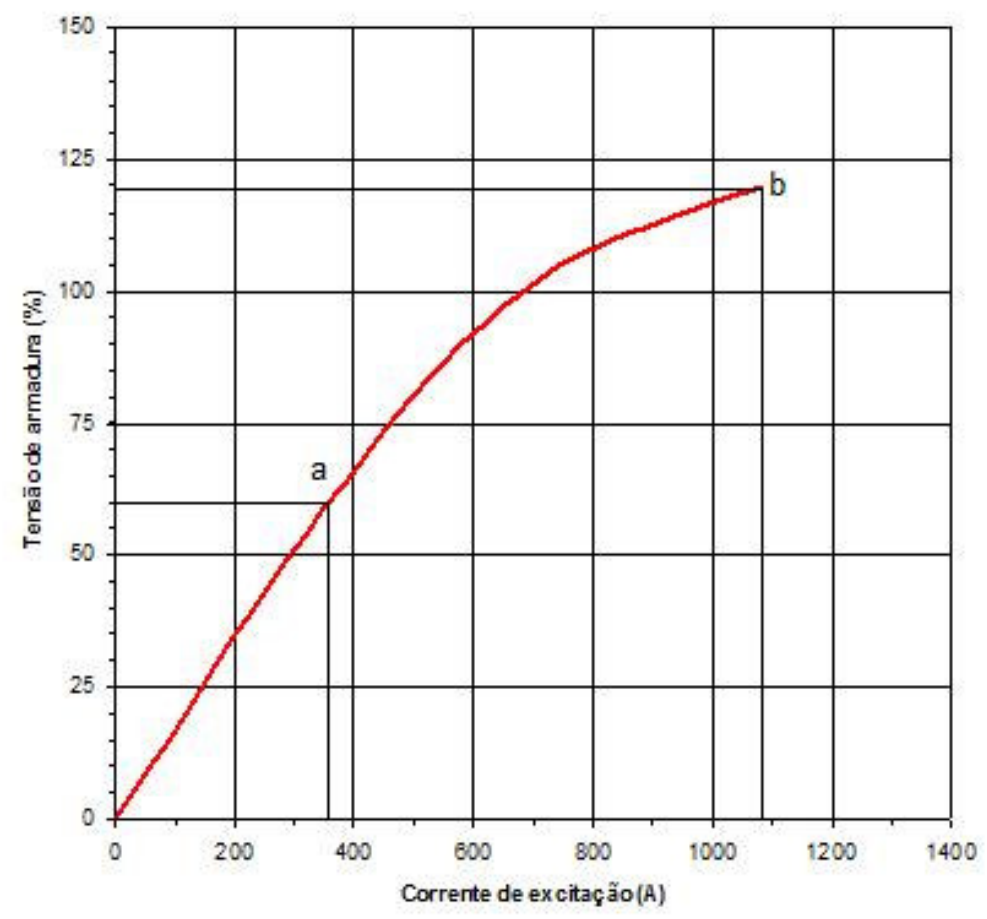

Figura 4.1: Exemplo - Característica à vazio.

Dividindo (4.4) por (4.3) tem-se:

$$
\frac{385,54}{6,98}=\frac{A_{x} e^{16532,8 B_{x}}}{A_{x} e^{8107,7 B_{x}}} \Rightarrow 55,23=e^{B_{x} 8425,1} \therefore B_{x}=0,000476 V^{-1} \text { e } A_{x}=0,00266
$$

Portanto, a fórmula matemática que descreve a curva de saturação à vazio da máquina em estudo é dada por: 


$$
I_{f}=\frac{E_{f}}{23,66}+0,00266 e^{0,000476 x E_{f}}
$$

O primeiro passo para se conhecer os parâmetros do gerador é determinar a localização do eixo em quadratura " $q$ ".

Tomando como referência a tensão nominal no estator, isto é, $\bar{V}_{\text {terminal }}=R_{a} I_{a}+V_{\text {nominal }}=7990,12 \angle 0^{\circ}$, e sabendo que $f p=0,95$ indutivo, localiza-se o eixo em quadratura da seguinte forma:

$$
j X_{q} \bar{I}_{a}+V_{\text {nominal }}=j(1,539)\left(3104,3 \angle-18,2^{\circ}\right)+\left(7990,12 \angle 0^{\circ}\right)=10512,37 \angle 25,57^{\circ}
$$

O eixo em quadratura " $q$ " está localizado em $25,57^{\circ}$ e conseqüentemente o eixo direto "d" localiza-se em $25,57^{\circ}+90^{\circ}=115,57^{\circ}$.

Logo,

$$
\begin{gathered}
E_{f}=(0,00731)(3104,3)+j(2,43)\left(2147,44 \angle-64,43^{\circ}\right)+j(1,539)\left(2241,68 \angle 25,57^{\circ}\right)+7990,12 \angle 0^{\circ} \\
\therefore \bar{E}_{f}=12446,30 \angle 25,56^{\circ} \mathrm{V}
\end{gathered}
$$

Este resultado confirma que o fasor $\bar{E}_{f}$ está localizado sobre o eixo em quadratura.

Utilizando (4.5), pode-se encontrar a corrente de excitação da seguinte forma:

$$
I_{f}=\frac{12446,3}{23,66}+0,00266 e^{0,000476 \times 12446,3} \Rightarrow I_{f}=527,04 \mathrm{~A}
$$

Com a corrente de excitação obtida, a tensão de excitação é facilmente calculada, sendo que primeiramente deve-se encontrar a resistência do enrolamento de campo, para uma temperatura de referência de $50^{\circ} \mathrm{C}$. Para isso, utiliza-se o ponto da curva de saturação à vazio que mais se aproxima do nominal.

$$
I_{f}=667,49 A \rightarrow V_{f}=83,02 \mathrm{~V} \Rightarrow R_{f}=\frac{83,02}{667,49}=124 \mathrm{~m} \Omega
$$


Logo,

$$
V_{f}=I_{f} R_{f}=(592,96)(0,124) \therefore V_{f}=73,52 \mathrm{~V}
$$

Calculando as potências e as perdas da máquina têm-se:

$$
\begin{aligned}
& \bar{S}_{3 \phi}=\bar{V}_{\text {nominal }} \bar{I}_{a}^{*}=74200 \angle 18,2^{\circ}=70487,92+j 23175,25 \\
& P_{\text {out }}=70487,92 \mathrm{~kW} \quad Q_{\text {out }}=23175,25 \mathrm{kvar}
\end{aligned}
$$

De acordo com [6], para o cálculo das perdas dos enrolamentos, utiliza-se o critério descrito na tabela 2.1. Os valores das demais perdas foram tirados dos valores nominais de projeto descritos no capítulo 2.

Para a máquina em estudo, utiliza-se a seguinte temperatura de referência: Estator: $115{ }^{\circ} \mathrm{C}$ e Rotor: $115{ }^{\circ} \mathrm{C}$, pois os dois enrolamentos pertencem a classe $\mathrm{F}$. Sendo assim, a correção do valor da resistência do enrolamento de campo e do enrolamento de armadura, tomando a temperatura de $115{ }^{\circ} \mathrm{C}$ e o valor nominal na temperatura de $50{ }^{\circ} \mathrm{C}$ é descrito a seguir.

$$
\begin{gathered}
R_{f 2}=\frac{\left(K+T_{2}\right)}{\left(K+T_{1}\right)} x R_{f 1} \quad \text { para } K=234,5 \Rightarrow R_{f 2}=\frac{(234,5+115)}{(234,5+50)} 0,124=164 \mathrm{~m} \Omega \\
R_{a 2}=\frac{\left(K+T_{2}\right)}{\left(K+T_{1}\right)} x R_{a 1} \quad \text { para } K=234,5 \Rightarrow R_{a 2}=\frac{(234,5+115)}{(234,5+50)} 0,00731=8,98 \mathrm{~m} \Omega
\end{gathered}
$$

Perda no enrolamento do estator:

$$
S W L=3 I_{a}^{2} R_{a}=3(3104,3)^{2}(0,00898)=259,61 \mathrm{~kW} .
$$

Perda no enrolamento do rotor.

$$
F W L=I_{f}^{2} R_{f}=(527,04)^{2}(0,164)=45,55 \mathrm{~kW} .
$$

Perdas rotacionais (considerando a perda total nos mancais):

$$
P_{R L}=312,00 \mathrm{~kW} .
$$


Perda por atrito e ventilação:

$$
P_{\text {atrito }}=90,00 \mathrm{~kW}
$$

Perdas externas (sistema de excitação e sistema de óleo):

$$
P_{\text {externa }}=25,00 \mathrm{~kW}
$$

Perdas no núcleo:

$$
P_{\text {núcleo }}=275,00 \mathrm{~kW}
$$

Perdas Totais:

$$
P_{T}=S W L+F W L+P_{R L}+P_{\text {externa }}+P_{\text {atrito }}+P_{\text {nucleo }}=1008,17 \mathrm{~kW} .
$$

Potência desenvolvida:

$$
P_{d e v}=3 V_{n o \min a l} I_{a} \cos \left(18,2^{\circ}\right)=70487,92 \mathrm{~kW} .
$$

Potência mecânica, considerando somente as perdas rotacionais:

$$
P_{m}=P_{d e v}+P_{R L}=70800,00 \mathrm{~kW} .
$$

Potência de entrada:

$$
P_{i n}=P_{m}+F W L=70887,41 k W .
$$

Calculando os torques desenvolvidos pela máquina, obtêm-se:

Torque:

$$
T_{d e v}=\frac{P_{d e v}}{\omega_{r m}}=\frac{70487,9}{17,13}=4114,88 \mathrm{Nm}
$$


Perdas rotacionais:

$$
T_{R L}=\frac{P_{R L}}{\omega_{r m}}=\frac{312}{17,13}=18,21 \mathrm{Nm} .
$$

Torque mecânico de entrada:

$$
T_{\text {in }}=T_{\text {dev }}+T_{R L}=4133,09 \mathrm{Nm} .
$$

Para o cálculo do rendimento do gerador, considera-se para a potência de entrada o somatório de todas as perdas mais a perda no enrolamento de campo.

Logo,

$$
\tilde{P}_{\text {in }}=P_{m}+F W L+P_{\text {externa }}+P_{\text {nucleo }}+P_{\text {atrito }}=71240,00 \mathrm{~kW}
$$

Portanto o rendimento da máquina é dado por:

$$
\eta=\frac{P_{\text {out }}}{\tilde{P}_{\text {in }}}=\frac{70487,92}{71240,00} \quad \therefore \quad \eta=98,9 \%
$$

Os resultados dos principais parâmetros calculados, seguindo a orientação e metodologia descrita em [16], sugere uma boa compreensão de como os valores nominais dos parâmetros influenciam na elaboração de um memorial descritivo para as características de uma máquina síncrona, para uma real situação de carga. 


\section{CONCLUSÃO}

Através de estudos, pesquisas, acompanhamento e visitas feitas na UHE Capim Branco II no município de Uberlândia no período de janeiro a março de 2007, percebeu-se que para a realização dos ensaios de comissionamento em uma unidade geradora, precisa-se de um grupo especializado e capacitado para executar com precisão e acurácia os testes efetuados na unidade antes de sua operação comercial.

O projeto de análise e cálculo dos principais parâmetros de um gerador síncrono foi desenvolvido de forma a compatibilizar os valores coletados em campo, utilizando para tanto, normas específicas que tratam dos cuidados necessários na execução e elaboração das Instruções de Testes de Campo (ITCs) pelos responsáveis da área.

Por meio de estudos na área de máquinas elétricas, pôde-se perceber, que não basta ter experiência se os conhecimentos dos valores agregados na teoria não forem aplicados no momento da execução dos ensaios e que para a elaboração de um relatório contendo os resultados e cálculos dos principais parâmetros é necessário um estudo prévio do comportamento de cada grupo gerador-turbina analisado.

Por fim, é importante salientar que através das diretrizes traçadas pode-se obter um trabalho contendo as informações relevantes para uma caracterização completa de uma máquina síncrona. 


\section{REFERÊNCIAS BIBLIOGRÁFICAS}

[1] IEC 60085 - "Electrical insulation - Thermal evaluation and designation". Genebra, 2007.

[2] VATECH HYDRO BRASIL. Manual de Comissionamento do Gerador - Un. 1 Usina Hidroelétrica de Capim Branco II, Barueri, 2006.

[3] IEEE Std 100, "The Authoritative Dictionary of IEEE Standards Terms". 7. ed. NY, 2000.

[4] IEEE Std c50.12-2005, "IEEE Standard for Salient-Pole $50 \mathrm{~Hz}$ and $60 \mathrm{~Hz}$ Synchronous Generators and Generator/Motors for Hydraulic Turbine Applications Rated 5 MVA and Above". NY, 2005.

[5] SEN, P. C. "Principles of Electric Machines and Power Electronics". New York, John Wiley and Sons, 1996.

[6] IEC 60034-4 - "Rotanting Electrical Machines - Part 4: Methods for determining synchronous machine quantities from tests". Genebra, 1985.

[7] IEEE Std 43-2000 (R2006), "IEEE Recommended Practice for Testing Insulation Resistance of Rotanting Machinery". NY, 2000.

[8] IEEE 4-1995, "IEEE Standard Techniques for High-Voltage Testing". NY, 1995.

[9] IEC 60034-1 - "Rotanting Electrical Machines - Part 1: Rating and performance". 11. ed. Genebra, 2004.

[10] IEEE Std 95-2002, "IEEE Recommended Practice for Testing Insulation of AC Electric Machinery (2300 V and Above) With High Direct Voltage". NY, 2002.

[11] MOSES, G. L., "AC and DC Voltage Endurance Studies on Mica Insulation for Electric Machinery", AIEE Transactions, 1951. 
[12] IEEE Std 118-1978, "IEEE Standard Test Code for Resistance Measurement". NY, 1978.

[13] IEEE Std 115-1995, "IEEE Guide: Test Procedure for Synchronous Machines Part 1: Acceptance and Performance Testing. Part 2: Test Procedures and Parameter Determination for Dynamic Analysis". NY, 1995.

[14] IEEE Std c57.13-1993 (R2003), "IEEE Standard Requirements for Instrument Transformers". NY, 1993.

[15] MATSCH, L. W., MORGAN, J. D. "Electromagnetic and Electromechanical Machines", Harper and Row, NY, 1986.

[16] GROSS, Charles A. "Electric Machines". New York, CRC Press, 2007.

[17] IEEE Std 1095-1989, "IEEE Guide for Installation of Vertical Generators and Generator/Motors for Hidroelectric Applications”. NY, 1989. 


\section{APÊNDICE}

Todas as fotos descritas neste anexo foram fornecidas pela equipe de comissionamento da UHE Capim Branco II.

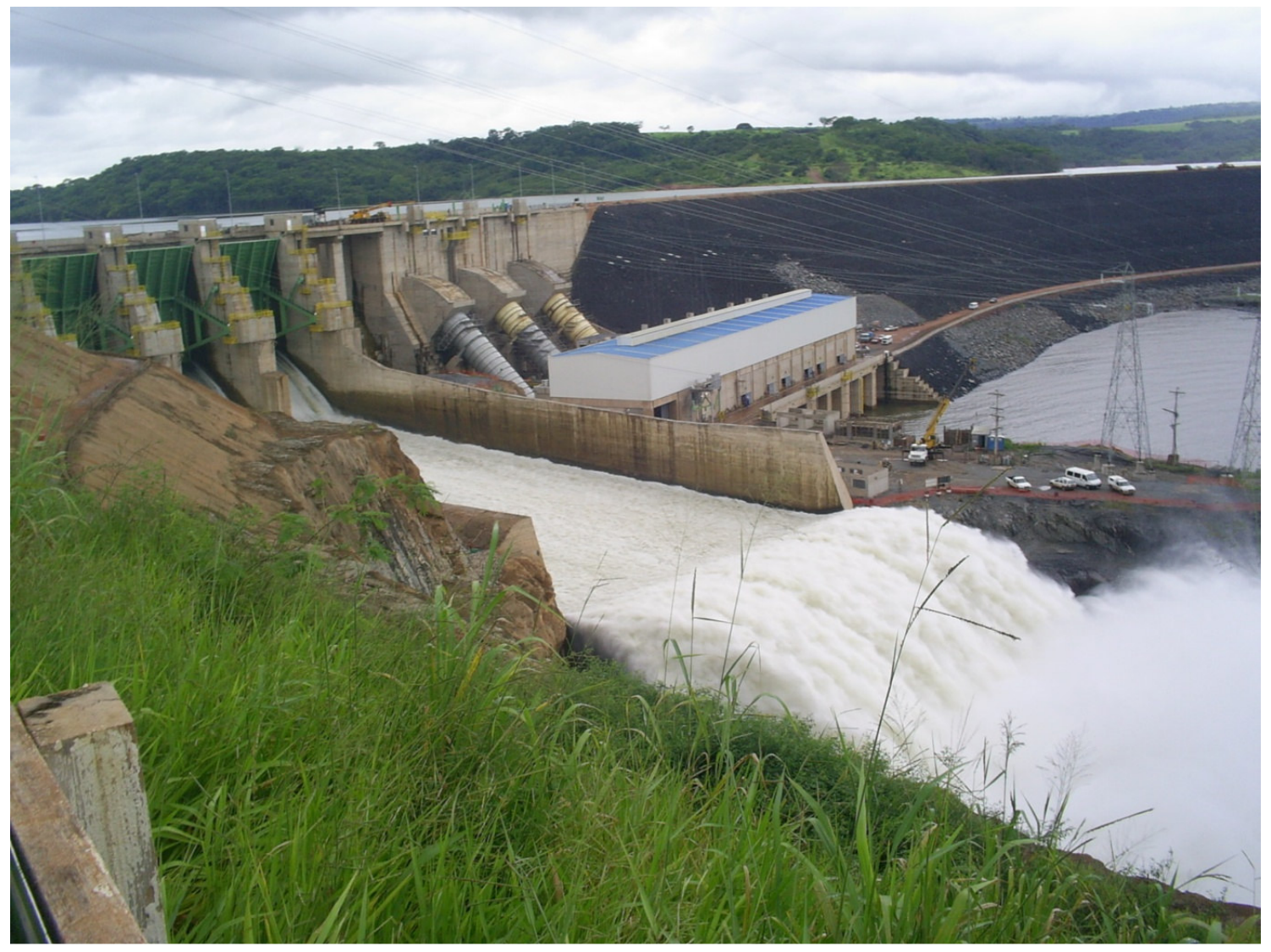

Figura A1: Vista do Vertedouro e da Casa de Força da UHE Capim Branco II, durante a fase de comissionamento da Unidade Geradora 1. 


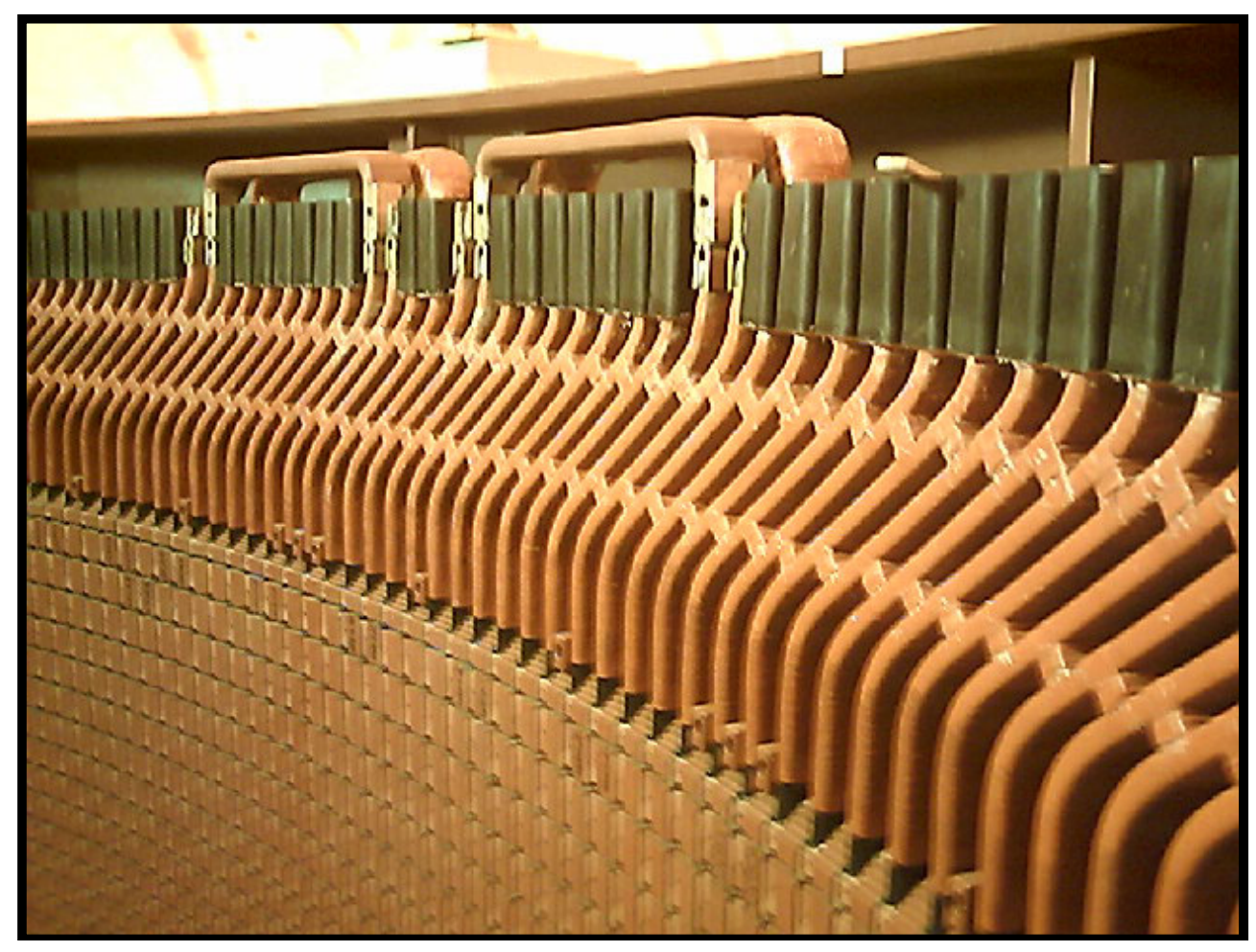

Figura A2: Estrutura do núcleo magnético do estator.

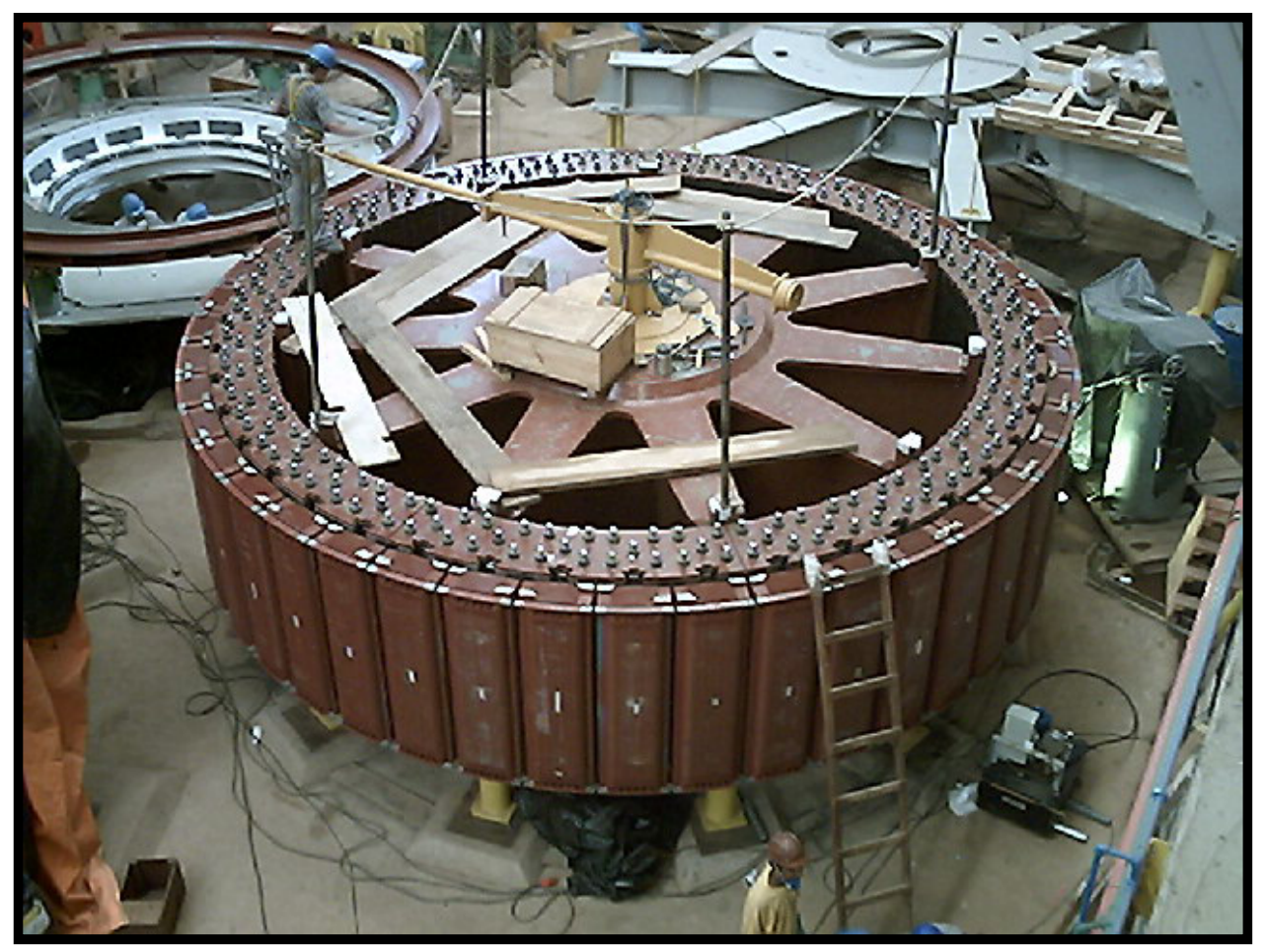

Figura A3: Estrutura do rotor. 


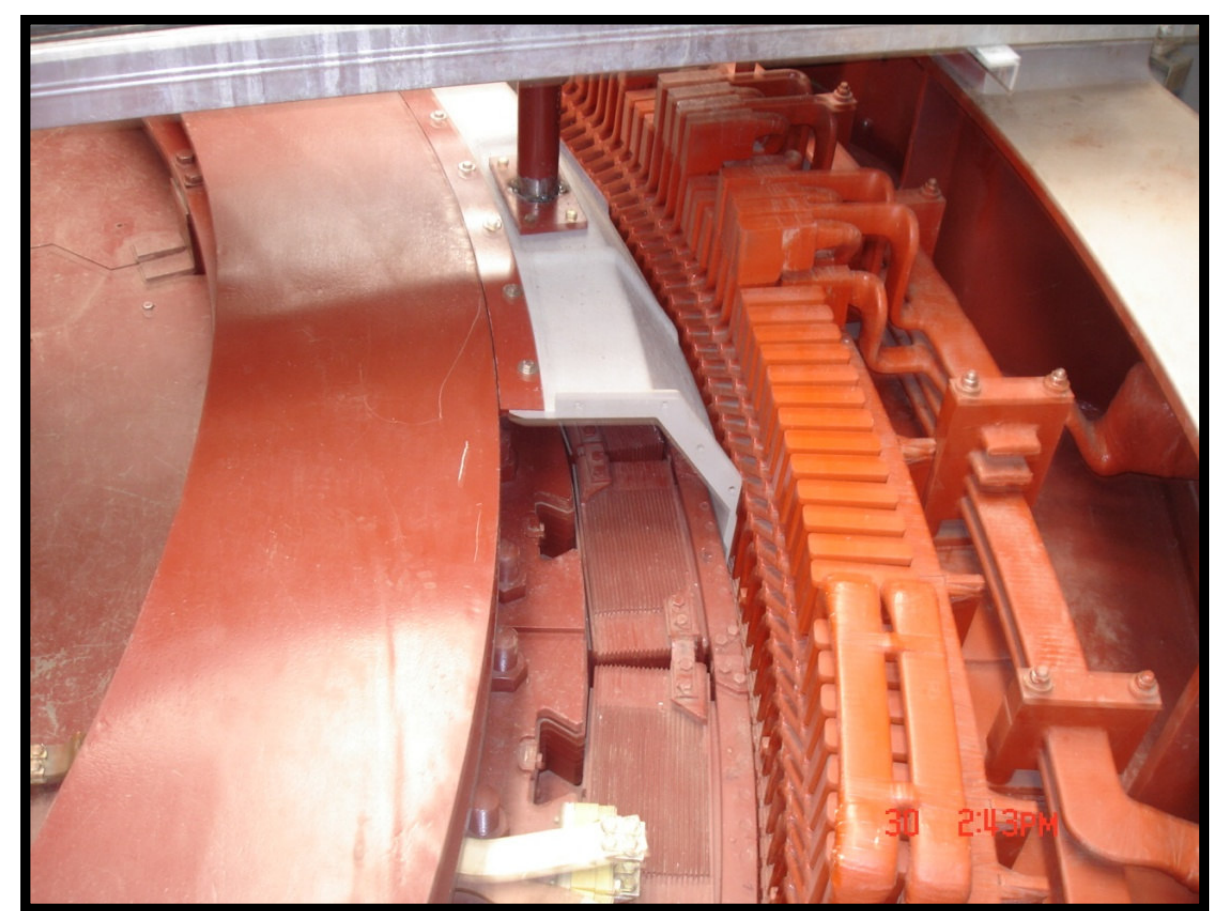

Figura A4: Vista do entreferro da máquina.

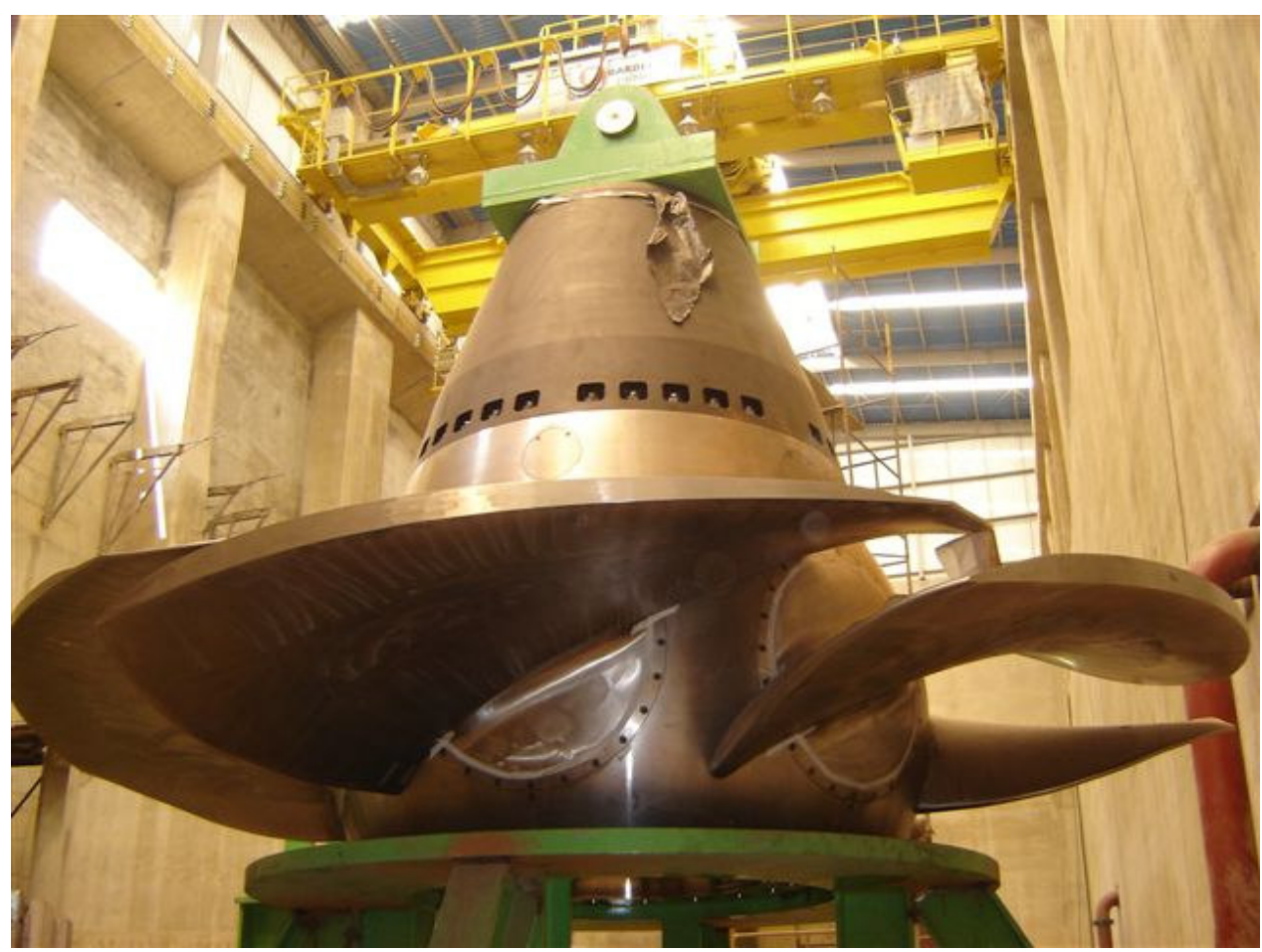

Figura A5: Turbina Kaplan 


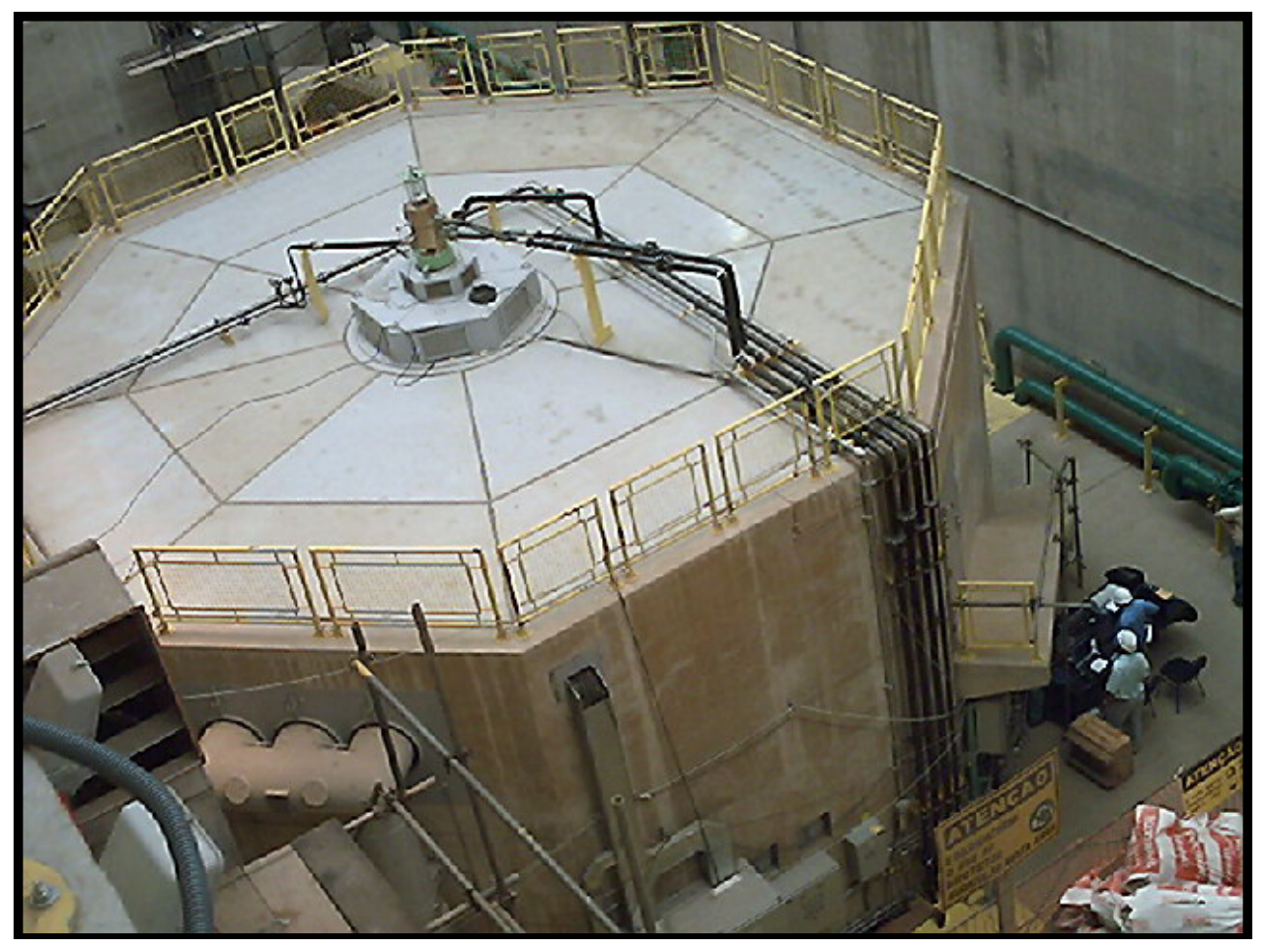

Figura A6: Vista panorâmica da máquina em fase final de comissionamento. 